\title{
Axial load behaviour of steel tube columns in-filled with various high-performance concretes
}

\author{
By \\ Katie Chu \\ Bachelor of Engineering in Civil Engineering, \\ Ryerson University, Toronto, Ontario, 2014
}

\author{
M.A.Sc. Thesis \\ Presented to Ryerson University \\ In Partial Fulfillment of the Requirements for the \\ Masters of Applied Science in the Program of Civil Engineering
}

Toronto, Ontario, Canada, 2014

(C) Katie Chu 2014 


\section{AUTHOR'S DECLARATION FOR ELECTRONIC SUBMISSION OF A THESIS}

I hereby declare that I am the sole author of this thesis. This is a true copy of the thesis, including any required final revisions, as accepted by my examiners.

I authorize Ryerson University to lend this thesis to other institutions or individuals for the purpose of scholarly research

I further authorize Ryerson University to reproduce this thesis by photocopying or by other means, in total or in part, at the request of other institutions or individuals for the purpose of scholarly research.

I understand that my thesis may be made electronically available to the public. 


\title{
Axial load behaviour of steel tube columns in-filled with various high performance concretes
}

\author{
Katie Chu, Masters of Applied Science, 2014 \\ Department of Civil Engineering \\ Ryerson University
}

\begin{abstract}
This research concentrates on the axial load behaviour of circular, square and rectangular concrete filled steel tube (CFST) columns incorporating high-performance selfconsolidating concretes such as ultra-high strength concrete (UHSC), engineered cementitious composite (ECC), lightweight concrete (LWC), and crumb rubber concrete (CRC). Seventy-four CFST specimens with varying slenderness, shape, concrete type and presence of internal bar reinforcements are tested experimentally under axial compression loading. The effect of these variables on axial load-deformation response, strain characteristics, failure modes, concrete confinement and axial strength are evaluated through experimental results. Performance of existing analytical/code based models for axial strength and concrete confined strength is evaluated. Concretes without coarse aggregates including UHSC proved less effective at enhancing axial strength of filled tube columns through confinement. In contrast, confinement in filled steel tube columns was found most effective with the use of concretes with coarse aggregates such as LWC and CRC.
\end{abstract}




\section{ACKNOWLEDGMENTS}

I am grateful to my supervising professor Dr. Khandaker M. Anwar Hossain for his excellent guidance during the completion of this research. Without him, this research would have not been accomplished. Not only did he train and teach me personally, he has given me countless opportunities to learn and gain experience. This thesis would not have been completed without the time and effort he put in proof-reading and corrections.

I would like to thank Mr. Nidal Jaalouk, Mr. Min Yao, Mr. Mohammad Aldardari, Mr. Alan Machin, and Mr. Dan Peneff for assisting me in specimen fabrication, casting, and testing in the Structures and Concrete Labs. I would also like to acknowledge the contribution of Research Assistant, Mr. Tony Cicchetti, in specimen fabrication and casting. Their assistance and expert advice were essential for successful completion of experimental tests.

I would like to acknowledge the financial support from the National Science and Engineering Research Council (NSERC) of Canada.

I am thankful to Dr. Abdurahman Lotfy of Lafarge Canada Inc. for providing lightweight slag aggregates. Thanks are also extended to him for his time and help in casting concrete and preparing test specimens.

In addition, I would like to thank Bekaert Corporation for providing the steel fibers and Grace Construction Products for providing concrete admixtures.

I extend my special thanks to examining committee members: Dr. Khaled Sennah and Dr. Abdurahman Lotfy.

Finally, my parents and family are thanked for their care, support and encouragement throughout my life. 


\section{TABLE OF CONTENTS}

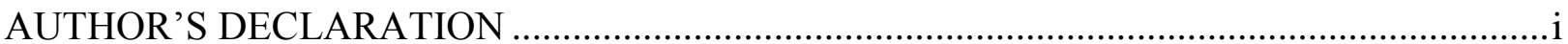

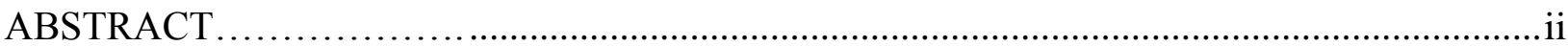

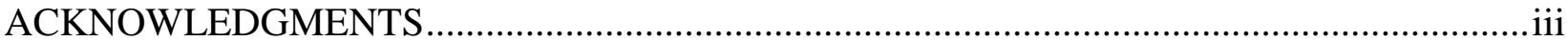

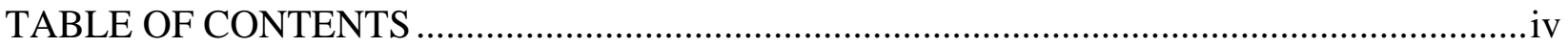

LIST OF SYMBOLS AND ABBREVIATIONS .......................................................................

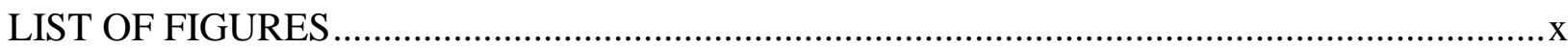

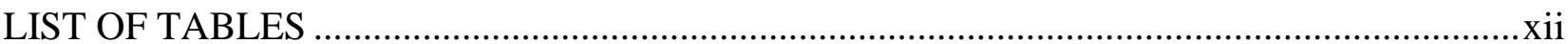

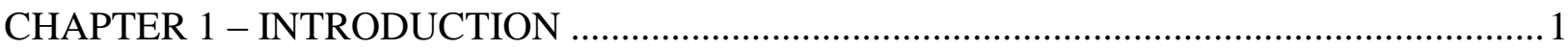

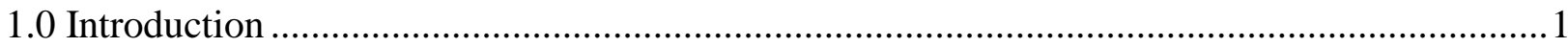

1.1 Research significance ....................................................................................................

1.2 Research scope

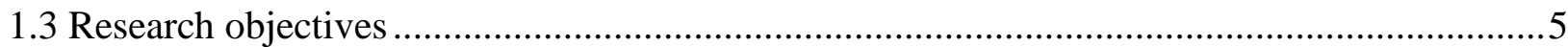

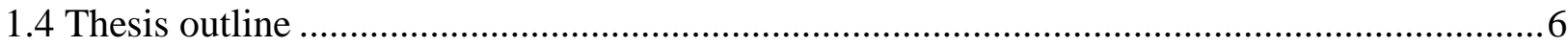

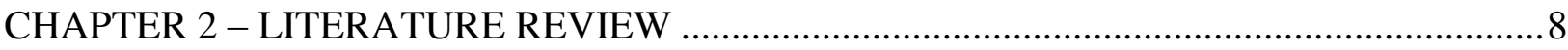

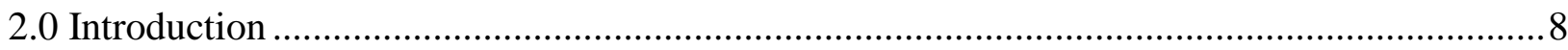

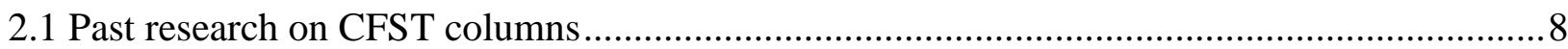

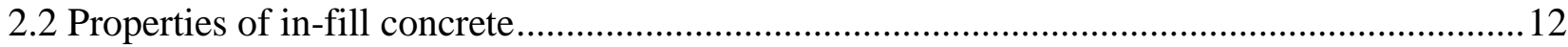

2.2.1 Ultra-high strength concrete ………….......................................................................13

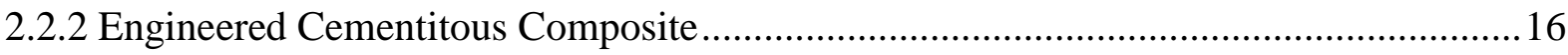

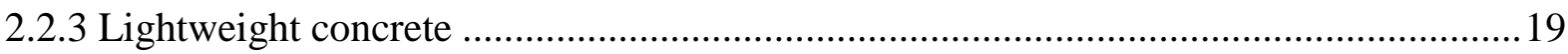

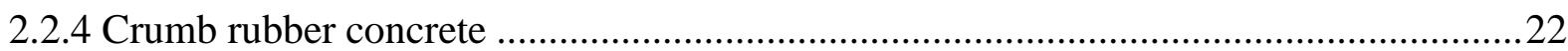

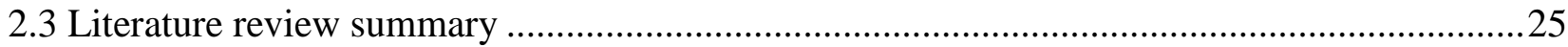

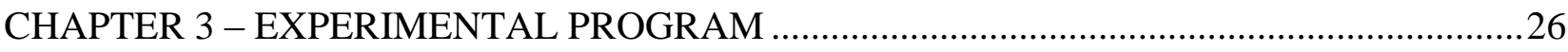




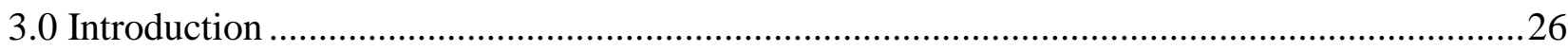

3.1 Geometric dimensions of specimens and reinforcement details ............................................26

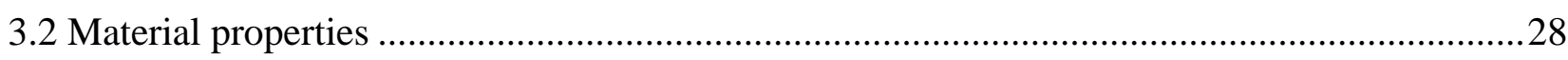

3.3 Casting of CFST specimens ............................................................................................

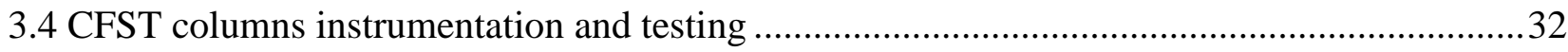

CHAPTER 4 -ANALYTICAL MODELS FOR AXIAL STRENGTH OF CFST

COLUMNS AND CONCRETE CONFINEMENT ......................................................................34

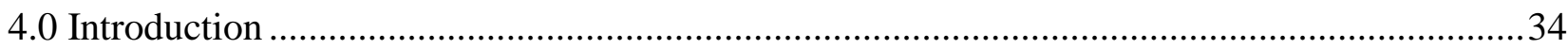

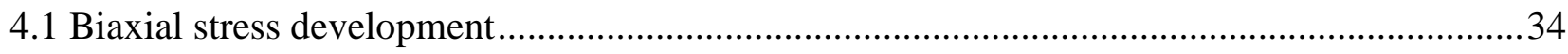

4.2 Quantification of lateral stresses and concrete confinement ...................................................36

4.3 Existing analytical models for confined concrete strength .......................................................38

4.4 Existing strength models for CFST columns ………….....................................................

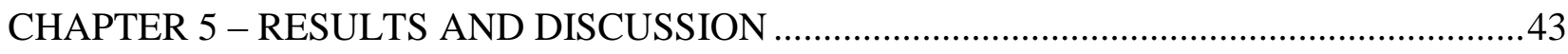

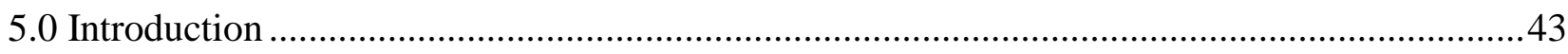

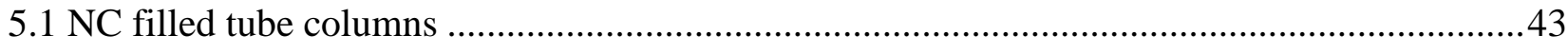

5.1.1 Axial load-displacement response and failure modes.....................................................43

5.1.2 Analysis of stress-strain behaviour in NC CFST columns ……………………............47

5.1.3 Identification of best model for NC CFST column strength prediction ..........................49

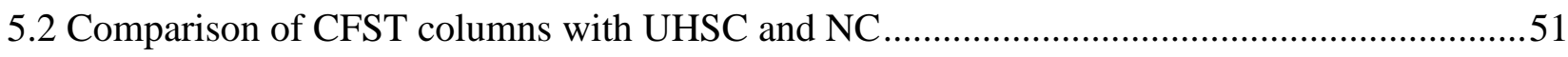

5.2.1 Axial load-displacement response and failure modes.....................................................51

5.2.2 Analysis of stress-strain behaviour ……………........................................................54

5.2.3 Identification of best model for UHSC CFST column strength prediction .....................60

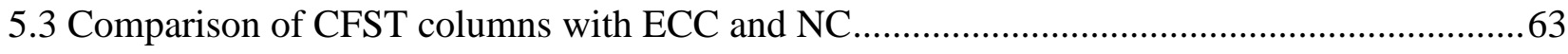

5.3.1 Axial load-displacement response and failure modes.....................................................63

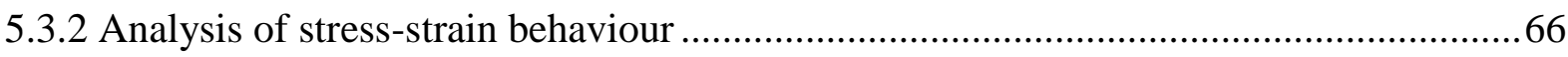

5.3.3 Identification of best model for ECC CFST column strength prediction ........................71 


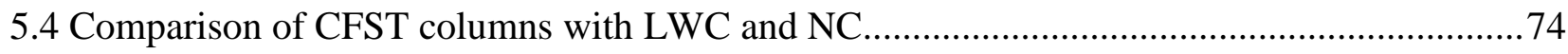

5.4.1 Axial load-displacement response and failure modes....................................................74

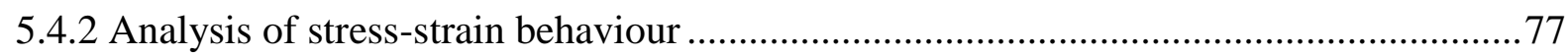

5.4.3 Identification of the best model for LWC CFST columns strength prediction................82

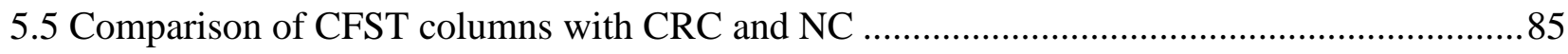

5.5.1 Axial load-displacement response and failure modes.................................................... 85

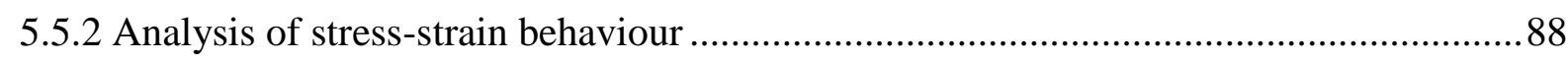

5.5.3 Identification of best model for CRC CFST column strength prediction ........................92

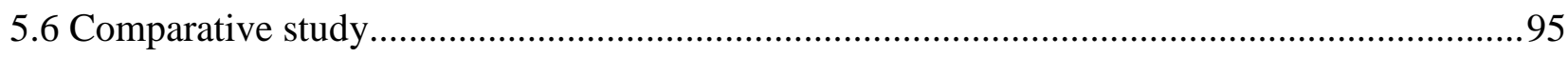

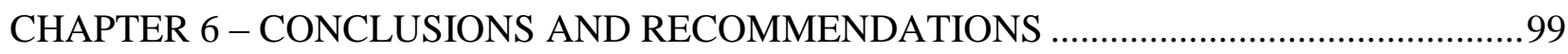

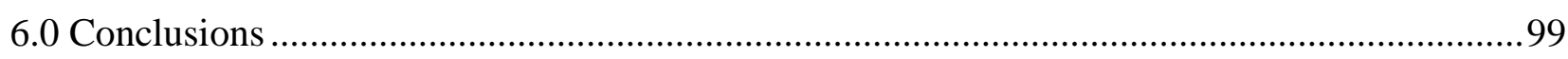

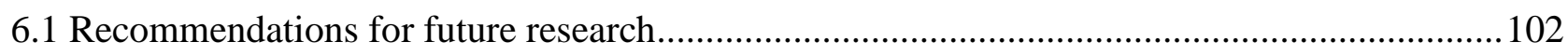

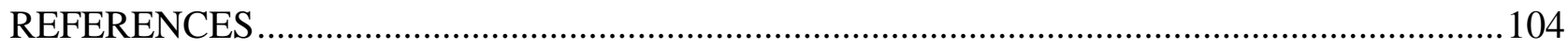




\section{LIST OF SYMBOLS AND ABBREVIATIONS}

$\mathrm{A}_{\mathrm{c}} \quad$ area of the concrete confined by steel tube

$\mathrm{A}_{\mathrm{cc}}$

$\mathrm{A}_{\mathrm{cch}}$

$\mathrm{A}_{\mathrm{s}}$

$\mathrm{A}_{\mathrm{sr}}$

b

$\mathrm{b} / \mathrm{t}$

$\mathrm{C}_{2}$

$\mathrm{C}_{\mathrm{rc}}$

cI

cII

D

$\mathrm{D} / \mathrm{t}$

$\mathrm{D}_{\mathrm{c}}$

d

$\mathrm{d}_{\mathrm{c}}$

$\mathrm{E}_{\mathrm{c}}$

$\mathrm{E}_{\mathrm{s}}$

$\mathrm{f}_{2}$

$\mathrm{f}_{2 \mathrm{~h}}$

$\mathrm{f}_{2 \max }$

$f_{c}$

$f_{c c}$

$\mathrm{f}_{\mathrm{c}}$

$\mathrm{f}^{\prime} \mathrm{cc}$ area of concrete only

area of concrete confined by hoop reinforcements

steel tube area

longitudinal reinforcement area

sectional breadth, larger dimension in rectangular sections

breadth-to-thickness ratio

shape factor

CFST axial design strength

circular CFST column without bar reinforcements

circular CFST column with bar reinforcements

outer steel tube diameter

diameter-to-thickness ratio

diameter of concrete confined by hoop reinforcements

sectional depth, smaller dimension in rectangular sections

concrete diameter

modulus of elasticity of the concrete

modulus of elasticity of the steel tube

steel tube lateral pressure

hoop reinforcement lateral pressure

maximum lateral pressure

axial stress in the concrete core

experimental confined concrete strength

compressive cylinder strength of concrete

calculated tube confined concrete strength 


\begin{tabular}{|c|c|}
\hline $\mathrm{f}_{\mathrm{cch}}^{\prime}$ & calculated hoop confined concrete strength \\
\hline $\mathrm{f}_{\text {cct }}^{\prime}$ & calculated total confined concrete strength \\
\hline$f_{p}$ & modified unconfined concrete strength \\
\hline$f_{y}$ & yield strength of the steel tube \\
\hline $\mathrm{f}_{\mathrm{yr}}$ & yield strength of longitudinal bar reinforcements \\
\hline $\mathrm{f}_{\mathrm{ys}}$ & von-Mises yield stress \\
\hline $\mathrm{g} 1$ & gauge for measuring transverse strain \\
\hline $\mathrm{g} 2$ & gauge for measuring axial strain \\
\hline $\mathrm{L}$ & CFST column height \\
\hline $\mathrm{L} / \mathrm{D}$ & length-to-diameter ratio \\
\hline $\mathrm{L} / \mathrm{d}$ & length-to-depth ratio \\
\hline $\mathrm{N}_{\mathrm{pl}, \mathrm{Rd}}$ & CFST axial design strength \\
\hline $\mathrm{N}_{\mathrm{u}}$ & theoretical axial strength of CFST column \\
\hline $\mathrm{P}_{\mathrm{r} 1}$ & theoretical axial strength of CFST column \\
\hline$P$ & nominal load applied on CFST column \\
\hline $\mathrm{P}_{\mathrm{c}}$ & axial load taken by concrete core \\
\hline $\mathrm{P}_{\mathrm{e}}$ & elastic critical load \\
\hline$P_{n}$ & CFST axial design strength \\
\hline $\mathrm{P}_{\mathrm{o}}$ & available compressive strength \\
\hline $\mathrm{P}_{\mathrm{p}}$ & calculated axial strength of CFST column \\
\hline $\mathrm{P}_{\mathrm{s}}$ & axial load taken by steel tube \\
\hline $\mathrm{P}_{\mathrm{u}}$ & experimental axial strength of CFST column \\
\hline $\mathrm{P}_{\mathrm{ys}}$ & axial load at biaxial yield stress \\
\hline $\mathrm{r}$ & rectangular CFST column \\
\hline $\mathrm{s}$ & hoop reinforcement longitudinal spacing \\
\hline s2 & square CFST column with $51 \mathrm{~mm}$ sectional dimension \\
\hline s4 & square CFST column with $102 \mathrm{~mm}$ sectional dimension \\
\hline $\mathrm{t}$ & steel tube thickness \\
\hline
\end{tabular}


$\alpha$

$\alpha_{1}$

$\beta$

$\varepsilon_{\mathrm{u}}$

$\varepsilon_{y s}$

$\theta$

$\lambda$

$\eta_{\mathrm{a}}, \eta_{\mathrm{b}}$

$\rho$

$\sigma_{\mathrm{a}}, \sigma_{\mathrm{sz}}$

$\sigma_{\mathrm{h}}, \sigma_{\mathrm{sh}}$

$\tau, \tau$

$\phi_{\mathrm{c}}$

$\phi_{\mathrm{s}}$

CFST

CRC, R

ECC, E

FA/C

HPFRCC

HSS

LWC, L

LWSCC, L

MTS

$\mathrm{NC}, \mathrm{N}$

SCC

UHSC, U

VPC transverse stress concentration factor

ratio of average stress in rectangular compression block to the specified concrete strength

axial stress concentration factor

axial strain at CFST ultimate axial load

axial strain at biaxial yield stress

strength enhancement factor

non-dimensional slenderness parameter

modification factors for confinement

slenderness ratio

steel tube axial stress

steel tube hoop stress

modification factors for confinement

concrete material safety factor

steel material safety factor

concrete-filled steel tube

crumb rubber concrete

engineered cementitious composite

fly ash-to-Portland cement ratio

high-performance fibre-reinforced composites

hollow structural section

lightweight concrete

lightweight self-consolidating concrete

material testing system

normal concrete

self-consolidating concrete

ultra-high strength concrete

volcanic pumice concrete 


\section{LIST OF FIGURES}

Figure 1.1: Concrete-filled steel tube columns ........................................................................ 1

Figure 3.1: Details of cII columns showing reinforcements (dimensions in $\mathrm{mm}$ ) .........................28

Figure 3.2: Sample sectional view of concrete control cylinders ................................................29

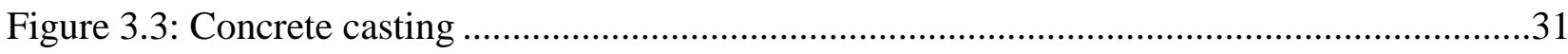

Figure 3.4: Experimental set-up and instrumentation of columns .................................................32

Figure 4.1: Development of biaxial stresses .............................................................................

Figure 4.2: Confinement effect in thin-walled composite column (Hossain, 2003b).......................36

Figure 4.3: Typical composite column response ………………................................................

Figure 5.1: Classification of CFST column failure modes ..........................................................4

Figure 5.2: Failure modes of NC-filled CFST columns ...............................................................46

Figure 5.3: Load-displacement responses of NC CFST columns ...................................................

Figure 5.4: Load-displacement responses of UHSC and NC CFST columns ................................52

Figure 5.5: Failure modes of UHSC-filled CFST columns …………………………….............53

Figure 5.6: Strain development in steel tube of columns filled with UHSC and NC .....................55

Figure 5.7: Performance of model for prediction of UHSC-filled CFST column strength .............62

Figure 5.8: Load-displacement responses of ECC and NC CFST columns ...................................64

Figure 5.9: Failure modes of ECC-filled CFST columns .................................................................65

Figure 5.10: Strain development in steel tube of columns filled with ECC and NC ......................66

Figure 5.11: Performance of model for prediction of ECC-filled CFST column strength ...............73

Figure 5.12: Load-displacement responses of LWC and NC CFST columns ................................74

Figure 5.13: Failure modes of LWC-filled CFST columns ..............................................................76

Figure 5.14: Strain development in steel tube of columns filled with LWC and NC.....................77 
Figure 5.15: Performance of model for prediction of LWC-filled CFST column strength ............84

Figure 5.16: Load-displacement responses of CRC and NC CFST columns .............................86

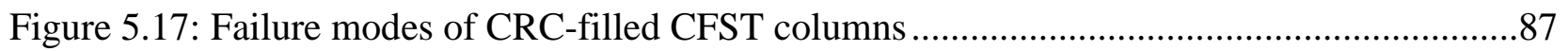

Figure 5.18: Strain development in steel tube of columns filled with CRC and NC...................88

Figure 5.19: Performance of model for prediction of CRC and NC filled CFST column strength.94

Figure 5.20: Axial load displacement of steel tubes in-filled with different concretes ................95

Figure 5.21: Steel strain for tube columns in-filled with different concretes .............................96 


\section{LIST OF TABLES}

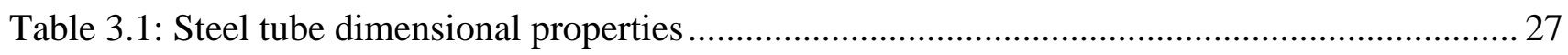

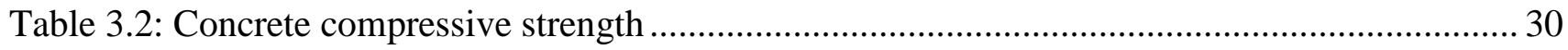

Table 3.3: Steel tube material properties ……………….................................................................. 31

Table 5.1: NC CFST column capacity and concrete strength increase..............................................4

Table 5.2: Biaxial stress factors in NC CFST columns ....................................................................

Table 5.3: Validation of models for confined concrete strength: cI NC-filled columns ......................48

Table 5.4: Validation of models for confined concrete strength: cII NC-filled columns .....................49

Table 5.5: Comparative study of NC-filled CFST strength prediction by analytical models...............49

Table 5.6: NC-filled CFST column strength predictions from model and design codes......................50

Table 5.7: UHSC and NC CFST column capacity and concrete strength increase .............................54

Table 5.8: Observed steel yield in UHSC and NC CFST columns .................................................56

Table 5.9: Biaxial stress factors in UHSC CFST columns ............................................................57

Table 5.10: Quantified concrete confined strength and lateral pressure in UHSC and NC CFST

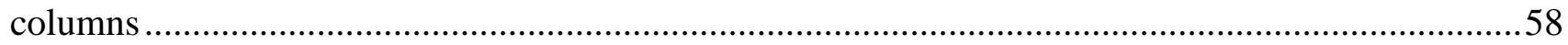

Table 5.11: Validation of models for confined concrete strength in UHSC-filled CFST columns.....59

Table 5.12: Comparative study of UHSC-filled CFST column strength prediction by analytical

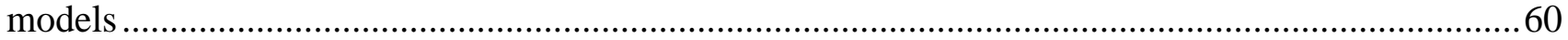

Table 5.13: UHSC-filled CFST column strength predictions from model and design codes ..............61

Table 5.14: ECC and NC CFST column capacity and concrete strength increase ...............................65

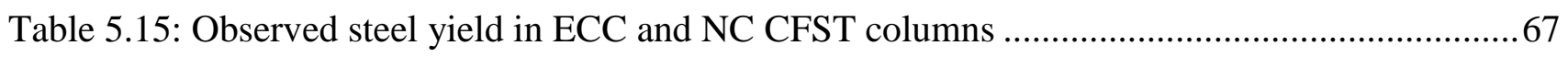

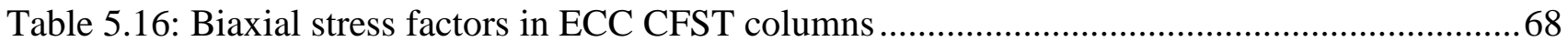

Table 5.17: Quantified concrete confined strength and lateral pressure in ECC and NC CFST columns

Table 5.18: Validation of models for confined concrete strength in ECC-filled CFST columns.........70

Table 5.19: Comparative study of ECC-filled CFST column strength prediction by analytical models 
Table 5.20: ECC-filled CFST column strength predictions from model and design codes .72

Table 5.21: LWC and NC CFST column capacity and concrete strength increase ..........................76

Table 5.22: Observed steel yield in LWC and NC CFST columns ............................................78

Table 5.23: Biaxial stress factors in LWC CFST columns ........................................................... 79

Table 5.24: Quantified concrete confined strength and lateral pressure in LWC and NC CFST columns.....

Table 5.25 Validation of models for confined concrete strength in LWC-filled CFST columns..... .81

Table 5.26 Comparative study of LWC-filled CFST column strength prediction by analytical models

Table 5.27: LWC-filled CFST column strength predictions from model and design codes .84

Table 5.28: CRC and NC CFST column capacity and concrete strength increase. .87

Table 5.29: Observed steel yield in CRC and NC CFST columns .....

Table 5.30: Biaxial stress factors in CRC CFST columns

Table 5.31: Quantified concrete confined strength and lateral pressure in CRC and NC CFST columns

Table 5.32: Validation of models for confined concrete strength in CRC and NC filled CFST columns

Table 5.33: Comparative study of CRC and NC CFST column strength prediction by analytical models

Table 5.34: CRC and NC CFST column strength predictions from model and design codes .94

Table 5.35: Comparison of CFST axial strength with respect to NC-filled column capacity .97

Table 5.36: Quantified concrete confined strength of CFST columns .98 


\section{Chapter One}

\section{INTRODUCTION}

\subsection{Introduction}

Concrete-filled steel tubes (CFST) are composite columns made of structural hollow sections. The steel tube encases a concrete core, as shown in Figure 1.1. Length, tube thickness, diameter, breadth, and depth of CFST columns are denoted by L, t, D, b, and d, respectively. Benefits of such columns begin at the construction stage, as CFST are relatively simple to fabricate, and removable formwork becomes unnecessary. During its service life, the steel tube protects concrete from adverse environmental agents. Alternatively, concrete improves fire resistance of the column by acting as a heat sink (Pires et al., 2012; Moliner et al., 2013).

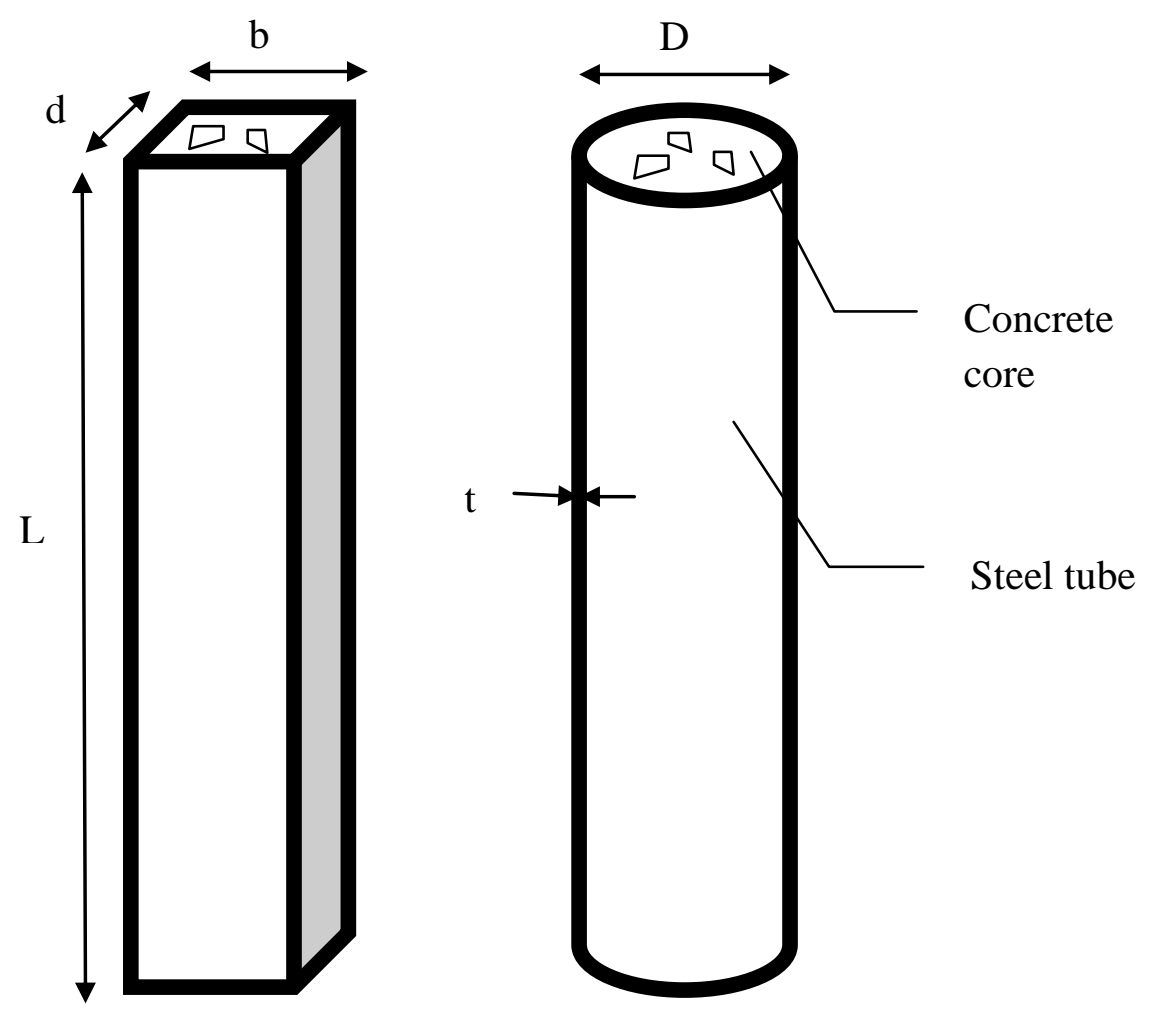

Figure 1.1 Concrete-filled steel tube columns 
Previous researchers analyzed the behaviour of circular CFST columns under axial compression and eccentric loading (Gardner \& Jacobson, 1967; Shakir-Khalil \& Zeghiche, 1989; Hossain, 2003a). At initial stages of loading, concrete and steel tube have little interaction due to differences in Poisson's ratio of the two materials (de Oliveira et al., 2009; Bukovská \& Karmazínová, 2012). As axial load increases, concrete softens and begins to dilate. Concrete forms a radial lateral pressure on the steel tube. The steel tube protects concrete from spalling by confinement. On the other hand, the concrete core prevents inward buckling of steel. Thus strength and ductility are improved in CFST composite elements, allowing for smaller column dimensions and applications in seismic regions (Uy, 2008).

Concrete in-fill plays a significant role in the structural behaviour of filled tube columns. Recent advancement in technology has developed high performance concretes. High performance concretes have properties superior to those of NC, such as improved strength, ductility, or selfconsolidating characteristics. Use of high performance concretes such as ultra-high strength concrete (UHSC), Engineered Cementitious Composite (ECC), lightweight concrete (LWC), and crumb rubber concrete (CRC), can add to the strength and ductility of filled tube composite columns. Previous research studied filled tube columns with normal concrete (NC) and selfconsolidating concrete (SCC) (Lachemi et al., 2006a,b), but very little work has been done on new high-performance concretes. Therefore, urgent research is needed to understand the structural behaviour of columns in-filled with high-performance concretes under axial compression.

Self-consolidating steel fibre-reinforced UHSC having no coarse aggregate maintains flowability during placement and reaches high compressive resistance (Hossain et al., 2012). Stiffness typically increases with concrete compressive strength. However, due to the presence of steel 
fibres, UHSC can achieve improved ductility. Benefits of this type of UHSC are expected to improve performance of filled tube columns under axial compression.

Emerging ECC exhibits tensile ductility typically not found in NC. The strain hardening capacity of ECC is 300 to 500 times higher than NC (Weimann \& Li, 2003). Portland cement, fine aggregates, and supplementary cementitious materials (such as fly ash and slag) are usually used to form ECC. Through the use of polyvinyl alcohol fibres in the cementitious matrix, microcracking develops under load (Zhang \& Bing, 2008). Microcracking of ECC improves durability and mechanical properties by allowing for unique strain hardening characteristics (Özbay et al., 2013). Thus, ECC is expected to significantly improve ductility and confinement of filled steel tube columns.

The use of LWC can lead to the construction of filled tube columns with lower self-weight. That self-weight can reduce the total load on the structure, and will be very good for seismic applications. Applications of LWC have also been developed in recent times from various aggregates (Hossain, 1998; Hossain, 1999). One form of lightweight self-consolidating concrete (LWSCC) is made from commercially manufactured pelletized slag aggregates. Slag aggregates are useful in geographic areas where natural forms of lightweight aggregates are not readily available. Applications of LWC and filled tube columns are often closely associated, for example, both have been used for constructing high-rise buildings. Thus, it is necessary to study the behaviour of the two components together in LWC/LWSCC-filled steel tube columns.

As crumb rubber has been found to complement asphalt binder properties in the past (Bahia \& Davies, 1994; Rodríguez-Alloza et al., 2014), it was used as sand replacement to produce rubberized concrete in recent studies (Mohammed et al., 2012). The use of crumb rubber is not 
only beneficial to the natural environment, it has also shown improved ductility and energy absorption in concrete (Liu et al., 2012). Although the use of CRC does not achieve extremely high strength, lower compressive resistance may lead to more effective confinement in filled steel tube columns.

It is worth noting that most newly developed high-performance concretes are self-consolidating. SCC can remove the need for compaction and provide ease of casting. As a result, specimens will have better quality of concrete because compaction is not needed. The use of SCC can also extend the available time for construction by minimizing noise, since no vibration is required for proper concrete placement.

Although a lot of research has been done on filled steel tubes in the past, little literature is available on the use of these columns with various high-performance concretes such as UHSC, ECC, LWC, and CRC. The proposed research will concentrate on these aspects.

\subsection{Research significance}

Novel high-performance concretes will continue to develop from on-going research to improve material strength, ductility, lightness, and ecological soundness. There is need for research on filled steel tube columns using this new generation of high-performance concretes, since most of the available literature is based on NC or SCC. Thus, this research is warranted and will study the axial load behaviour of CFST columns using UHSC, ECC, LWC, and CRC. Moreover, analytical models for concrete confined strength and code-based design recommendations for estimating axial compressive resistance of filled steel tube columns were all developed based on NC. Therefore urgent research is needed to study the behaviour of filled steel tube columns with modern high-performance concretes under axial loading. This is necessary to determine whether 
or not existing analytical and code-based models for concrete confinement and axial capacity of filled steel tube columns are applicable for newly developed high-performance concretes. Modifications to current filled steel tube axial strength models may be necessary to incorporate high-performance concretes. Therefore, the outcomes and recommendations from this research will be valuable for the construction industry in Canada and over the world.

\subsection{Research scope}

The scope of this research is to carryout experimental and theoretical investigations on structural behavior of circular, square, and rectangular filled steel tube columns incorporating high performance concretes (UHSC, ECC, LWC, and CRC) that have been developed at Ryerson University over the last few years. Experimental results are used to evaluate the performance of existing concrete confinement and filled steel tube axial strength models. Furthermore, the performance of design codes including CSA (2009), AISC (2005), Eurocode (2004) for axial strength of CFST columns are studied for compatibility with different types of concrete core materials.

\subsection{Research objectives}

The main objectives of this research are to:

- Study the characteristics of steel tube columns in-filled with different concretes under axial compression loading through experimental and theoretical investigations. Explore the effects of concrete in-fill, slenderness, type of cross-section (circular, square, rectangular) and presence of longitudinal reinforcement on failure modes, stress-strain characteristics, axialload displacement response, concrete confined strength, and axial capacity of steel tube columns. 
- Compare axial behaviour of UHSC, ECC, LWC, and CRC steel tube columns with that of NC. Compare the degree of strength enhancement and confinement between columns with different types of concrete in-fill. Identify which concrete maximizes the effects of confinement, and is most efficient for enhancing strength of CFST columns.

- Determine biaxial stress factors for different concrete types, column shapes, and slenderness, which are used in calculating theoretical concrete confined strength and axial strength of filled steel tubes.

- Evaluate the performance of existing analytical models and design codes for estimating concrete confined strength and axial capacity of filled steel tubes with various dimensional and concrete material properties - as most existing analytical models and design codes were derived based circular non-reinforced columns with NC.

\subsection{Thesis outline}

This thesis consists of six chapters which are outlined as follows:

Chapter 1 presents a brief introduction on CFST columns. Recently developed concrete materials are also introduced, followed by research significance and objectives of this study.

Chapter 2 presents a comprehensive literature review on research advances in CFST columns to date. Literature on progression in development of UHSC, ECC, LWC, and CRC are also reviewed.

Chapter 3 details geometric dimensions of column specimens. Properties of materials used and the CFST column fabrication process are described. Experimental instrumentation and procedures are provided. 
Chapter 4 describes the development of existing models for estimating confined strength of concrete and axial capacity of CFST columns. Existing models are evaluated against experimental results in the following chapter. Both analytical and code-based equations are included.

Chapter 5 reports experimental axial load-displacement, failure modes, axial capacities and stress-strain characteristics for tested CFST columns. Experimental results from steel tubes infilled with each type of concrete were compared with respect to NC filled columns. Experimental concrete confinement and column ultimate axial strengths were compared with analytical and code-based models. Furthermore, strength enhancement and confinement of different highperformance concretes were compared.

Chapter 6 Main conclusions of this study are presented based on experimental and analytical results, along with recommendations for future research. 


\section{Chapter Two}

\section{LITERATURE REVIEW}

\subsection{Introduction}

This chapter presents literature review on CFST columns, and how previous researchers have understood their behaviour under axial compression. The development and characteristics of modern high-performance concretes are presented. How these concretes have been studied in composite CFST columns is also discussed.

\subsection{Past research on CFST columns}

CFST columns have been applicable for a variety of structural applications. For example, CFST columns have been used for resistance to seismic activities (Lee et al., 2009) and in tall buildings such as the Commerzbank in Frankfurt, Germany (Uy, 1998). In practical application, holes have been provided at strategic locations in steel tubes allowing for concrete to be cast in segments. The use of collars is a popular CFST beam-column connection. Bridges have also been built using concrete filled steel composites (Zhong et al., 2008). These applications are reasonable, since filled steel tube columns allow for smaller column dimensions and lower costs, as the less expensive concrete component takes majority of axial loads (O’Shea \& Bridge, 2000; Dundu, 2012). Furthermore, CFST columns show improved ductility and energy absorption capacity (Chitawadagi et al., 2010). The steel tube is capable of taking the role of both longitudinal and hoop bar reinforcements. This allows filled steel tube columns to surpass structural performance of bare hollow sections or normal reinforced concrete columns (Han, 2002). Concrete confinement by steel also has an effect on improving shrinkage and creep as well (Nakai et al., 1991; Terrey et al., 1994; Ichinose et al., 2001; Yang et al., 2008). 
Several researchers have studied behaviour of CFST columns with circular, square, rectangular sectional shapes in the past forty years (Gardner \& Jacobson, 1967; Schneider, 1998; Roeder, 1999; Sakino et al., 2004). Under axial compression, the steel tube was found to increase axial strength of CFST columns. This increase in column axial strength is due to concrete confinement, and limited extension of internal concrete cracking (Han et al., 2003; Fam et al., 2004). Effects of concrete confinement are typically not considered at initial stages of axial loading. This is because Poisson's ratios of the two materials differ so that steel has higher deformations compared with concrete (Johansson, 2002). Thus, concrete and steel lack interaction under small loads. When concrete begins to soften under greater load, the deformation properties change. The concrete dilates outward, applying lateral pressure on the steel tube. The steel tube is said to be mobilized at this point, as transverse hoop stresses develop to confine concrete. Therefore, the concrete falls under triaxial confinement, while the steel tube experiences biaxial stresses. This confinement effect causes the filled tube column to withstand load greater than the sum of individual steel and concrete axial strengths (Dundu, 2012). Concrete also delays inward steel buckling, which is typically characteristic of hollow structural sections (HSS). Local buckling does not occur if bond strength between concrete and steel is strong enough (Giakoumolis \& Lam, 2004)

CFST columns can be classified based on loading conditions. Type A columns refer to load applied across steel and concrete portions simultaneously. Type B columns refer to load applied on the concrete core only. The degree of confinement in Type B columns was more significant compared to that of Type A columns (Sakino et al., 2004). However, Type A loading conditions may arise in practical applications. Furthermore, design of CFST columns based on Type A loading may provide beneficial conservatism for safety considerations. 
A wide range of factors affect confinement and axial strength of CFST columns under axial compression. Concrete confinement has been found to be more effective for circular CFST with low slenderness ratio, resulting in higher axial strength in these columns (Vrcelj \& Uy, 2002; Zeghiche \& Chaoui, 2005; de Oliveira et al., 2009). Hossain (2003b) performed experimental investigations on thin-walled composite columns of varying slenderness to find that strength reduction increased dramatically due to increasing slenderness ratio (until slenderness of 24 was reached). Difference in slenderness resulted in varying failure modes of CFST columns. Concrete crushing and steel yielding occurred in shorter columns, and longer columns failed by global instability. Failure modes of NC filled columns given the slenderness ratio are common in the literature. Nonetheless, failure modes of filled steel tube columns are expected to be dependent on the strength, ductility, and material properties of concrete in-fill. Softer concretes may lead to greater axial stress on the steel tube, resulting in buckling failure. Conversely, stiffer concretes may result in shear failure. Therefore, resulting behaviour due to slenderness ratio should vary with concrete type.

Unlike circular hollow tubes, square and rectangular steel HSS surround the concrete core by a series of plane surfaces and angles. Some authors concluded that concrete confinement was nonexistent in square or rectangular CFST (Shams \& Saadeghvaziri, 1997). Plates forming the sides of square and rectangular HSS were described as ineffective in concrete confinement due to lack of rigidity. Only concrete near the centre and corners of square and rectangular CFST columns were effectively confined (de Oliveira et al., 2009). Thus, circular-shaped CFST columns were capable of achieving greater confined concrete strength. Numerous studies in the past have explored the effects of circular, square, and rectangular steel hollow sectional shapes on concrete filled tube column behaviour. However, different concrete in-fill materials may not interact with 
steel plate or arched surfaces at the interior of hollow structural sections in the same way as NC does. For example, a more ductile concrete may be capable of exhibiting better concrete confinement in square and rectangular sections compared with NC.

Furthermore, concrete confinement also increases as diameter-to-thickness ratio decreases (Giakoumelis \& Lam, 2004; Gupta et al., 2007). In addition, CFST columns were found to exhibit more local buckling and crushing of concrete for higher diameter-to-thickness ratio.

Axial capacity of CFST columns increases with steel and concrete material strength, as expected (Zeghiche \& Chaoui, 2005; de Oliveira et al., 2009). Although it was determined that axial strength of CFST columns increased linearly with steel yield strength (Sakino et al., 2004), this is not necessarily the case with concrete compressive strength. Whether or not the relationship between axial capacity of CFST columns and concrete compressive strength follows linearity is yet to be confirmed.

Due to requirements from certain code provisions which state that bar reinforcements are mandatory in concrete columns, a new challenge emerged in quantifying axial capacity of CFST columns in-filled with bar-reinforced concrete. Hoop reinforcements also provide additional concrete confinement and axial capacity of CFST column increases due to contributions from longitudinal bars (Lachemi et al., 2006a). However, few studies have been completed on CFST columns with bar reinforcements, especially using different types of concrete in-fill.

Tube and hoop reinforcement confinement in filled tube columns have been analyzed and quantified by researchers in the past based studies on NC. However, concrete behaviour under compression was also found to relate to Poisson's ratio and elastic modulus. Moreover, the 
relationship between elastic modulus and compressive strength is not necessarily the same for $\mathrm{NC}$ compared with concrete reinforced with various types of fibres.

No research has been done on several newly developed high performance concretes. Therefore, although a vast amount of literature is available on filled steel tube columns to determine the effects of dimensional and material properties, the emergence of different types of concrete has sparked new areas of study.

\subsection{Properties of in-fill concrete}

A significant number of experimental tests on axial strength of CFST columns were previously done with NC in-fill. Existing analytical models and code-based equations from past research have also been shown to perform well in estimating the axial strength of steel tube columns infilled with NC. Bond strength between concrete and steel was found to be significantly affected by the type of in-fill after testing thirty-six square and circular tube columns (Hunaiti, 1996).

Besides NC, SCC as in-fill for steel tube columns is common in literature (Han \& Yao, 2004; Han et al., 2005; Lachemi et al., 2006a,b). SCC provides for ease of construction when fabricating filled steel tube columns, since no additional compaction is necessary to achieve proper placement. Authors who studied SCC-filled steel tube columns concluded that behaviour was similar to NC. However, these results do not imply that tube column axial behaviour will be the same for all types of concrete in-fill.

Investigations on high-strength concrete (Toshiaki et al., 2004) concluded that not only does concrete compressive resistance have an effect on column axial capacity, in-fill material also changes deformation characteristics and behaviour. Deformation capacity was reduced with the use of high-strength concrete in normal-strength steel tubes, but is expected to improve by 
increasing steel strength or tube thickness. Furthermore, publications on the effects of compaction on filled tube column ultimate strength show that even the same core materials within the steel tube can yield different results based on homogeneity of concrete (Han \& Yang, 2001; Han \& Yao, 2003; Han \& Yao, 2004). However, limited experimentation has been done comparing the effects of different in-fill material on steel tube columns, especially for recently developed high-performance concretes.

\subsubsection{Ultra-high strength concrete}

Experimentation was done in the past on UHSC CFST under axial compression (Yu et al., 2008).

Prior to Yu et al. (2008), the performance of SCC filled CFST columns was analyzed for compressive strengths ranging from 50 to $90 \mathrm{MPa}$ (Han \& Yao, 2004; Han et al., 2005; Lachemi et al., 2006b). To further extend the range of SCC compressive strengths tested in CFST, Yu et al. (2008) performed experiments on circular and square thin-walled columns in-filled with concrete of up to $121 \mathrm{MPa}$ cube compressive strength. In addition to water, cement, sand, slag, and high-range water-reducing admixture, the mix design included coarse aggregates. The resulting slump flow was $600 \mathrm{~mm}$. Thin-walled sections were fabricated by cutting and tack welding steel sheets in the desired configurations. Column slenderness ranged from 12 to 120 , tube thickness was constant at $1.6 \mathrm{~mm}$, and load eccentricity ratios differed from 0.0 to 0.6 . As load was applied at intervals across both concrete and steel (rather than continuous loading), columns are classified as Type A. Square columns filled with high-strength concrete failed in a similar manner as those tested with normal-strength concrete by other researchers (Schneider, 1998; Han et al., 2001). However, circular columns filled with high-strength concrete failed in shear. In addition, the post-peak behaviour of load-displacement responses was found to be steeper in square columns compared with circular CFST columns. Thus, circular columns 
showed more effective concrete confinement, even with high-strength concrete as in-fill. Yu et al. (2008) concluded that CFST columns in-filled with self-consolidating high-strength concrete under axial compression showed lower ductility compared to those with NC.

However, ductile behaviour of CFST columns is expected to improve with the presence of steel fibre-reinforcement (Khaloo et al., 2014). Steel fibres are anticipated to improve brittle behaviour in NC by creating a bridge between cracks to hold materials together rather than allowing portions to spall off under load. Researchers in the past had studied mechanical properties and durability of self-consolidating steel fibre-reinforced UHSC, and SCC incorporating various materials such as fly ash and slag (El-Dieb, 2009; El-Dieb \& Reda, 2012; Fava et al., 2003; Cattaneo et al., 2012). Khaloo et al. (2014) presented experimental results on standard 150 x $300 \mathrm{~mm}$ cylinders and $100 \times 140$ x $1200 \mathrm{~mm}$ beam specimens made of SCC with steel fibre volume fractions ranging from 0.5 to 2 percent. Two concrete mix designs were used with compressive strength from 40 to $60 \mathrm{MPa}$. In addition to steel fibres, concrete materials included cement, silica fume (included in the $60 \mathrm{MPa}$ concrete but not in the $40 \mathrm{MPa}$ concrete), water, fine aggregates, coarse aggregates, filler, and admixtures. Besides rheological properties, mechanical characteristics were evaluated to determine effects of steel fibre content on concrete performance. Slump flow diameter of concrete decreased with the increased presence of steel fibre reinforcements, but less so for those with higher compressive strength due in part to inclusion of silica fume content. Although slump flow diameter of $60 \mathrm{MPa}$ concrete decreased from $800 \mathrm{~mm}$ to about $720 \mathrm{~mm}$ with the increase in steel fibre content, the concrete can still be considered workable, capable of self-consolidation, and is acceptable based on EFNARC (2005) standards. The increased fibre content to $2 \%$ also decreased concrete compressive strength by up to $7.5 \%$. However, splitting tensile strength increased up to $6.02 \mathrm{MPa}$, while flexural strength 
increased to 7.44 MPa. These results indicate how the increased steel fibre content in higher strength concrete with silica fume can improve its ductile characteristics while maintaining workability.

Based on available literature, few experimental investigations have been done on selfconsolidating fibre-reinforced UHSC filled tube columns. UHSC is important for expanding the potential of tall buildings, however concrete usually exhibits increasingly brittle properties with increased compressive strength. Steel fibre-reinforcement provides a viable alternative for mitigating brittle properties of concrete while desired compressive strength is achieved. Thus, it is practical to find out the behaviour of steel fibre-reinforced UHSC in various applications. The effect of removing coarse aggregates on mechanical properties of UHSC is also a subject of interest. Yet these topics are not widely available in literature. Besides general concrete response under different loading conditions, composite action between UHSC and steel in filled tube columns is useful in many ways and worthy of in depth analysis. For example, concrete-steel bonding may differ due to the presence of steel fibres. In addition, steel fibres may allow UHSC to share more similarities with the steel tube in CFST columns, allowing for better interaction and higher degree of composite action. Few publications have studied steel fibre-reinforced UHSC in composite structural elements.

Moreover, concrete confinement is expected to improve in more ductile materials. However, high concrete compressive strength has shown to have negative effects on concrete confinement in CFST columns. Thus, steel fibres may increase ductile behaviour of UHSC CFST columns. In contrast, fibre bridging may hinder dilation of concrete from mobilizing the steel tube to initiate strength enhancement in CFST columns. Further research is needed to better understand confinement of steel fibre-reinforced UHSC without aggregates. No documentation on this 
material without the incorporation of coarse aggregates have been applied to CFST columns. Novel self-consolidating steel fibre-reinforced UHSC containing no coarse aggregate had been developed at Ryerson University. Its effect on CFST column behaviour is yet to be explored, since the presence of steel fibres and lack of coarse aggregates are expected to have an impact on CFST column behaviour. The confinement of steel fibre-reinforced UHSC without aggregate will be investigated in this thesis.

\subsubsection{Engineered Cementitious Composite}

ECC was meant to provide a solution to brittle properties typically found in NC, and to achieve a material exhibiting tensile ductility (Nawy, 2008). A number of options were attempted, including the use of continuous aligned fibres allowing for exceedingly high degree of ductility (Aveston et al., 1971; Krenchel \& Stang, 1989), and discontinuous fibres (Allen, 1971; Lankard, 1986; Naaman, 1992). Eventually these materials capable of strain hardening behaviour were classified as high-performance fibre-reinforced composites (HPFRCC). To expand applicability, cost-effectiveness, and constructability, a branch of HPFRCC was developed called ECC. ECC typically has moderate tensile strength from $2 \mathrm{MPa}$ to $6 \mathrm{MPa}$ (Fischer et al., 2003; Li, 1993)

Large propagating cracks generally develop in $\mathrm{NC}$ during its service life, exposing the interior to adverse environments, and leading to a number of durability issues. The presence of polyvinyl alcohol fibres (used most often in ECC) allow for multiple microcracks to form in ECC under service loads. This behaviour of ECC causes strain-hardening characteristics to develop (Özbay et al., 2013; Ranade et al., 2014), magnifying ductility and flexural strength (Li, 2011). Strain hardening refers to the ability of ECC to increase load capacity even after the first crack appears, and is a characteristic typically found in ductile metals such as steel. These properties are 
achieved while still limiting the volume of fibres to $2 \%$ or less in ECC. As a result, ECC has low water absorption, which protects the material from reinforcement corrosion (Şahmaran and Li, 2009; Miyazato and Hiraishi, 2005). Furthermore, Yun and Rokugo (2012) found that ECC retains $97 \%$ of the original dynamic modulus after 300 cycles of freezing and thawing. Thus, ECC exhibits impressive durability compared with NC. As ECC is a relatively new material, research is still on-going regarding its behaviour under various scenarios of loading and environmental agents.

Şahmaran et al. (2009) explored mechanical properties of ECC with variables such as aggregate type, aggregate size, and fly ash/Portland cement (FA/C) ratios. Their research progressed the indepth understanding of effects of various materials on ECC mechanical properties. Different aggregates types included microsilica sand (with lowest maximum aggregate size), dolomitic limestone crushed sand (with intermediate maximum aggregate size), and gravel sand (with highest maximum aggregate size). Each of the three aggregate types was mixed with varying FA/C ratios from 1.2 to 4.2 percent by mass. Compressive test results indicated that increasing fly ash content had negative effects on concrete compressive strength. On the other hand, compressive strength of ECC increased when using microsilica sand as aggregate compared with crushed sand and gravel sand. It was noted that surface texture and aggregate size tested in the study did not have an effect on ECC compressive strength as it does in NC. When testing uniaxial tensile performance, it was also found that increasing FA/C ratios lessened the tensile strength of ECC in withstanding the first crack. In turn, fly ash content increased tensile strain capacity (Wang \& Li, 2007). Furthermore, crushed sand (which had greater surface roughness) showed greater toughness under tension, indicating that tensile ductility is affected by aggregate surface texture. Şahmaran et al. (2009) also found that aggregate size did not contribute to 
improving matrix toughness, potentially due to the presence of fly ash. Fly ash increase also had the effect of reducing crack width in ECC, where aggregate size was not found to have any influence. Under flexure, microcracks developed at midspan, and increased in number along from that point outward on the tension face. ECC with FA/C of 1.2 reached up to $12.75 \mathrm{MPa}$ in flexural strength, and decreased with increased fly ash content. However, larger aggregate size had the opposite effect on ductility, and is attributed to poorer distribution of PVA fibres. Although, little literature is available on ECC under confinement, the findings of Şahmaran et al. (2009) have improved the understanding of ECC mechanical properties.

Literature shows that since the development of ECC as a structural material, its mechanical and durability properties have been research extensively. Research on ECC in composite structures will further determine its potential and extend its structural applications. ECC under composite action presents a broad field of study yet to be understood. Few researchers have investigated the behaviour of ECC in concrete-steel composite structural elements.

NC has been capable of interacting with steel in composite structures, however it is often limited by brittle behaviour. Brittle behaviour of concrete and the difference in properties between the two materials can often cause concrete to easily debond from steel. When ECC was developed, the capability of strain-hardening was emphasized. ECC has been known to exhibit strainhardening behaviour similar to that of steel. Thus, ECC is expected to have a positive effect on steel-concrete interaction. Composite action is expected to improve when ECC is used for in-fill in steel-concrete composite structures. This research will provide a better understanding of the benefits and limits of ECC in composite construction. In particular, this research focuses on the unexplored area of ECC under confinement. In CFST columns, ECC falls under triaxial stress. Experimentations will provide insight on whether or not strain-hardening behaviour of ECC will 
allow it to better interact with and transfer load to steel. ECC's ductile behaviour is expected to improve ductility of CFST columns. On the contrary, fibres in ECC may prevent dilation, decrease strength enhancements, and have negative effects on concrete confinement.

Compressive strength of over $60 \mathrm{MPa}$ has been achieved in ECC in the past, which is comparable with that of $\mathrm{NC}$ (Lepech and $\mathrm{Li}$, 2007). This novel material is expected to enhance confinement and ductile characteristics in CFST columns in this study. ECC with $2.2 \%$ FA/C and microsilica sand is used as in-fill in CFST columns in the current research in order to incorporate both compressive strength and tensile ductility, and begin exploring the potential of ECC under confinement.

\subsubsection{Lightweight concrete}

Several forms of LWC are currently available for different structural applications. Foamed concrete and volcanic pumice aggregate LWC have been chosen in the past as in-fill material in CFST column tests (Hunaiti et al., 2002; Hossain, 2003a). Hunaiti (2002) tested square, rectangular, and circular CFST columns in-filled with foamed concrete and lightweight aggregate concrete, $\mathrm{NC}$, or no in-fill at all. Specimens were classified as short columns with a length of $400 \mathrm{~mm}$, and were placed under axial compression under Type A loading conditions. Hunaiti (2002) found that foamed concrete had higher axial capacity contribution compared with lightweight aggregate concrete, potentially due to better homogeneity of foamed concrete. Moreover, foamed concrete confinement was greater than that of lightweight aggregate concrete, although they shared similar concrete compressive strength. Thus, foamed concrete experienced greater strength enhancement due to confinement compared with lightweight aggregate concrete

tube columns, by reaching up to double the unconfined cube compressive strength. Although the 
unconfined compressive strength of $\mathrm{NC}$ was about six times greater than that of foamed concrete, CFST columns in-filled with foamed concrete achieved up to $80 \%$ strength of those infilled with NC. Lightweight aggregate concrete filled columns achieved up to $70 \%$ that of CFST columns in-filled with NC. Hunaiti (2002) also recorded the significant effect of diameter/breadth-to-thickness ratio on local buckling of steel, and that CFST columns retain a certain degree of deformation capacity even after buckling (this is typically not the case for bare steel sections). Hunaiti (2002) mentioned that diameter/breadth-to-thickness ratio has significant effect on triaxial stresses developed in confined concrete as well. NC provided better resistance to steel local buckling compared with LWC. Strain experienced by steel tubes in-filled with lightweight aggregate concrete was also greater than in $\mathrm{NC}$, indicating better composite action between concrete and steel. As a result, lightweight aggregate concrete CFST had greater ductility compared with bare steel tube columns. The work from Hunaiti (2002) provided a basis for the behaviour of LWC under confinement in CFST columns. However, other available types of concrete are yet to be explored.

Fifty-two square and rectangular hollow sections in-filled with volcanic pumice concrete (VPC) and NC were tested by Hossain (2003b) to determine axial load behaviour. VPC is a form of LWC with density of $1800 \mathrm{~kg} / \mathrm{m}^{3}$, made from locally available volcanic pumice waste aggregates. During casting, concrete was manually placed into steel tubes and compacted using a poker vibrator. Hollow structural sections were fabricated by welding steel sheets or obtained commercially. Sectional dimensions, tube thickness, and slenderness of thin-walled composite columns varied to observe effects of dimensional properties. Columns were loaded axially, and eccentricity was avoided. A difference was observed between commercially available hollow sections, and those fabricated at the site of testing. Under axial compression, debonding between 
concrete and steel was observed at earlier stages of loading for steel sections constructed by hand, compared with those purchased commercially. NC had higher unconfined compressive strength than the VPC, and during testing, VPC-filled columns deformed more significantly than NC filled columns. Strain was also measured axially and transversely at mid-height and at the top of composite columns. For shorter columns, it was found that strain values were greater at the top than at mid-height. The opposite was true for more slender columns where global buckling causes high stress at mid-height. In addition, VPC-filled columns resulted in higher strain values compared with NC-filled columns, particularly at the top of the column. Load displacement curves also indicated that VPC-filled columns undergo greater deformations, attributed to VPC's lower modulus of elasticity compared with NC. Code-based and analytical models for estimating axial capacity of NC CFST columns were found to be capable of predicting strength of VPC filled tubes as well.

Results from these investigations concluded that LWC allowed for greater deformations to occur in CFST columns. In addition, LWC-filled tube columns were found capable of achieving axial capacity comparable to CFST columns in-filled with NC. However, the use of VPC in construction is limited to regions where pumice aggregates are readily available (Hossain, 2004). The innovation of commercially manufactured pelletized slag aggregates allow for LWC concrete to be fabricated in regions where volcanic pumice is not locally available. Since slag aggregate LWC has not been tested as in-fill for CFST columns, the behaviour of these columns are studied experimentally herein. Particularly, the behaviour of this concrete under confinement is studied in this thesis. It is expected that self-consolidating characteristics of this type of LWC will improve homogeneity and structural integrity of CFST columns. 


\subsubsection{Crumb rubber concrete}

Rubber tires are a common waste product which has been incorporated for application in civil engineering in hope to lessen the negative environmental effects of disposal. Applications of rubber tires in engineering include use in asphalt paving mixtures, concrete, lightweight fillers, and transportation system barriers (Shu \& Huang, 2013). For incorporation in pavement and structural materials, rubber tires are crushed into smaller particles of specified sizes, also known as crumb rubber. Incorporation of crumb rubber proved to be successful in improving asphalt binder viscosity (Heitzman, 1992; Abdelrahman \& Carpenter, 1999; Airey et al., 2002). Despite material enhancements provided by crumb rubber in asphalt pavements, the use of crumb rubber in concrete has been more difficult to accomplish (Huang et al., 2004). Including crumb rubber in a concrete mix design typically involves replacement of coarse or fine aggregates. However, crumb rubber's water-resistant material properties make it less compatible for bonding with cement paste in concrete (Huang et al., 2004; Topcu, 1995). Researchers have also found that rubber particles tend to hinder proper cement hydration (Chou et al., 2007). Recent studies have suggested a chemical modification of rubber particle surfaces in order to improve the interaction with cement (Huang et al., 2013; Juang et al., 2011; Dong et al., 2013). Another option was to reduce crumb rubber particles to sizes similar to Portland cement (Shu \& Huang, 2013). However, these options may not be economical. In addition, due to high compressibility, rubber particles may act similar to pores in the concrete to significantly reduce compressive strength (Huang et al., 2013). Tensile tests also showed unfavorable results with the incorporation of crumb rubber (Eldin \& Senouci, 1993; Khatib \& Bayomy, 1999). On the other hand, rubber concrete displayed enhanced concrete ductility (Li et al., 2004). 
In efforts to develop its optimal use in concrete, $\mathrm{Li}$ et al. (2004) investigated crumb rubber in the form of 25.4 x 25.4 x $5 \mathrm{~mm}$ chips with surface treatments and fibres. Rubber particle treatments included either chemical or physical means, by placing rubber in $\mathrm{NaOH}$ solution or drilling holes into the centre of chips. Rubber fibres were $5 \mathrm{~mm}$ thick with varying length from $25.4 \mathrm{~mm}$ to $76.2 \mathrm{~mm}$. In addition, one batch of concrete with rubber fibres also contained polypropylene fibres to observe the effect of hybridization. Thus, ten different batches of concrete were prepared, where various forms of rubber replaced coarse aggregates. During casting, Li et al. (2004) found no significant effects of rubber on concrete workability. Cylinders of $152.4 \mathrm{~mm}$ diameter and $304.8 \mathrm{~mm}$ height were used to determine compressive modulus, compressive strength, and Poisson's ratio, and split tensile strength of each concrete. Load displacement curves under split tensile testing differed between rubber concrete and NC. The area under the graph was much greater due to large displacement in rubberized concrete compared with NC, showing significantly higher energy absorption. Rubber concrete showed greater toughness compared with NC. On the other hand, strength and stiffness of concrete with rubber inclusions was lower. This was explained by stress concentrations developing at locations of the softer rubber material causing the interfacial zone to be weak, and loss in concrete-rubber bond. The resulting effect was a decrease in strength and modulus of elasticity in rubber concrete. Li et al. (2004) suggested that in order to improve compressive strength of rubberized concrete, the interfacial zone and bond between rubber and concrete matrix must be improved. Chemical surface treatment using $\mathrm{NaOH}$ solution did not show to provide a solution to the problem of weak material bonding. Nonetheless, they did find fibrous rubber more effective in transferring load compared with rubber chips, and could become a viable option for improving concrete 
properties. Furthermore, shorter fibres and hybridization with polypropylene fibres were more effective in improving concrete strength.

Moreover, other researchers found that impact resistance and energy absorption improved with the presence of crumb rubber (Eldin et al., 1993). Rubber also allows for lighter weight as it replaces heavier aggregate particles. An optimal amount of crumb rubber is also capable in improve freeze-thaw resistance (Benazzouk \& Queneudec, 2002).

Few experimental investigations have been done on rubber concrete in composite structures. However, rubber concrete is potentially beneficial in concrete-steel composites. Strength of rubber concrete can be enhanced by steel components. Furthermore, rubber concrete may show improved ductility and interaction with steel.

CFST columns typically enhance strength due to effects of confinement. Rubber concrete under confinement is yet to be understood, since no literature has been found on this topic. It is possible that rubber particles will cause stress concentrations in concrete rather than transferring stresses lateral to the steel tube under confinement. On the other hand, rubber concrete has the potential to soften more easily under load, and may result in more effective concrete dilation and mobilization of the steel tube. As described by Hunaiti (2002), it does not take very high concrete compressive strength to achieve significant strength enhancement under confinement. Thus, lower strength of rubber concrete may be advantageous when applied to CFST columns. The steel tube has potential to enhance rubber concrete compressive strength. In return, ductility and toughness of rubber concrete may enhance column behaviour. Up until now, the behaviour of CRC in CFST columns has not been documented in literature to the knowledge of the author. 
Thus, this research sets out to determine the effect of CRC on CFST column confinement and ductility.

\subsection{Literature review summary}

Experimental work has been done mostly on NC or SCC CFST columns, and equations/models have been derived for finding axial capacity and concrete confined strength. On the other hand, little research has been done on new concretes, especially UHSC, ECC, LWC, and CRC. Design equations are available from various codes. But those design equations/models for concrete

confinement and axial strength may not be applicable to new concretes. Due to lack of information on the effect of newly developed concretes on confinement of composite structural members, this study is performed on CFST columns with various concretes. The current research will study these aspects through conducting comprehensive experimental and analytical investigations with the goal of performance evaluation of code-based design equations. This proposed research will lead to the development of new or modified equations that will be helpful for engineers and designers. 


\section{Chapter Three}

\section{EXPERIMENTAL PROGRAM}

\subsection{Introduction}

An extensive experimental research has been planned to study the axial compressive behaviour of circular, square, and rectangular CFST columns with or without bar reinforcements. Five sets of columns were in-filled with five different types of concrete, including UHSC, ECC, LWC, $\mathrm{CRC}$, and NC. Length-to-diameter ratio also differed among columns of the same shape. Load displacement response and stress-strain characteristics under axial concentric loading were documented and studied. This chapter will describe the geometric dimensions of specimens, properties of the materials, and experimental program.

\subsection{Geometric dimensions of specimens and reinforcement details}

Seventeen steel hollow structural sections (HSS) sizes shown in Table 3.1 were used to encase concrete as CFST columns. Circular columns are differentiated based on the presence or absence of bar reinforcements, designated by 'cII' and 'cI' respectively. Two sizes of square columns are designated as 's4' (for $102 \mathrm{~mm}$ dimension) and 's2' (for $51 \mathrm{~mm}$ dimension). Rectangular sections are designated by ' $r$ '. The numerical value at the end of each tube designation represents the column slenderness (length-to-diameter or length-to-depth ratio). Four sets of the seventeen tubes listed in Table 3.1 and one set of six tubes (indicated by asterisks in Table 3.1) were used to prepare CFST column specimens. Each set was in-filled with a different type of concrete, namely NC, UHSC, ECC, LWC, and CRC. Representative steel tube sizes were selected for CRC in-fill. 
The tube thickness, outer tube diameter, sectional breadth, and sectional depth $(\mathrm{t}, \mathrm{D}, \mathrm{b}$, and d respectively) of specimens are presented in Table 3.1 .

Table 3.1: Steel tube dimensional properties

\begin{tabular}{cccccc}
\hline $\begin{array}{c}\text { Steel tube } \\
\text { designation }\end{array}$ & $\begin{array}{c}\text { Thickness, } \\
\text { mm }\end{array}$ & $\begin{array}{c}\text { Diameter, } \\
\text { mm }\end{array}$ & $\begin{array}{c}\text { breadth, } \\
\text { mm }\end{array}$ & $\begin{array}{c}\text { depth, } \\
\text { mm }\end{array}$ & $\begin{array}{c}\text { Breadth/diameter- } \\
\text { to-thickness ratio }\end{array}$ \\
\hline cI-3* & 4.8 & 114 & - & - & 24 \\
cI-4 & 4.8 & 114 & - & - & 24 \\
cI-9* & 4.8 & 114 & - & - & 24 \\
cII-3 & 4.8 & 114 & - & - & 24 \\
cII-4 & 4.8 & 114 & - & - & 24 \\
cII-9 & 4.8 & 114 & - & - & 24 \\
r-6* & 3.2 & - & 102 & 51 & 32 \\
r-12 & 3.2 & - & 102 & 51 & 32 \\
r-20* & 3.2 & - & 102 & 51 & 32 \\
s4-3 & 3.2 & - & 102 & 102 & 32 \\
s4-6 & 3.2 & - & 102 & 102 & 32 \\
s4-10 & 3.2 & - & 102 & 102 & 32 \\
s2-6* & 1.6 & - & 51 & 51 & 32 \\
s2-9 & 1.6 & - & 51 & 51 & 32 \\
s2-12 & 1.6 & - & 51 & 51 & 32 \\
s2-16* & 1.6 & - & 51 & 51 & 32 \\
s2-20 & 1.6 & - & 51 & 51 & 32 \\
\hline & $*$ Only these sizes were in-filled with CRC. & \\
\hline
\end{tabular}

Details of reinforcement arrangements in circular (cII) CFST columns are shown in Figure 3.1. Columns with L/D (length-to-diameter) ratio of 9 were $1000 \mathrm{~mm}$ in length, those with L/D ratio of 4 were $500 \mathrm{~mm}$ in length, and those with L/D ratio of 3 were $300 \mathrm{~mm}$ in length. Four longitudinal bars were placed in each cII column with the ends bent at 90 degrees, and were enclosed by hoop reinforcements according to the spacing shown in Figure 3.1. 


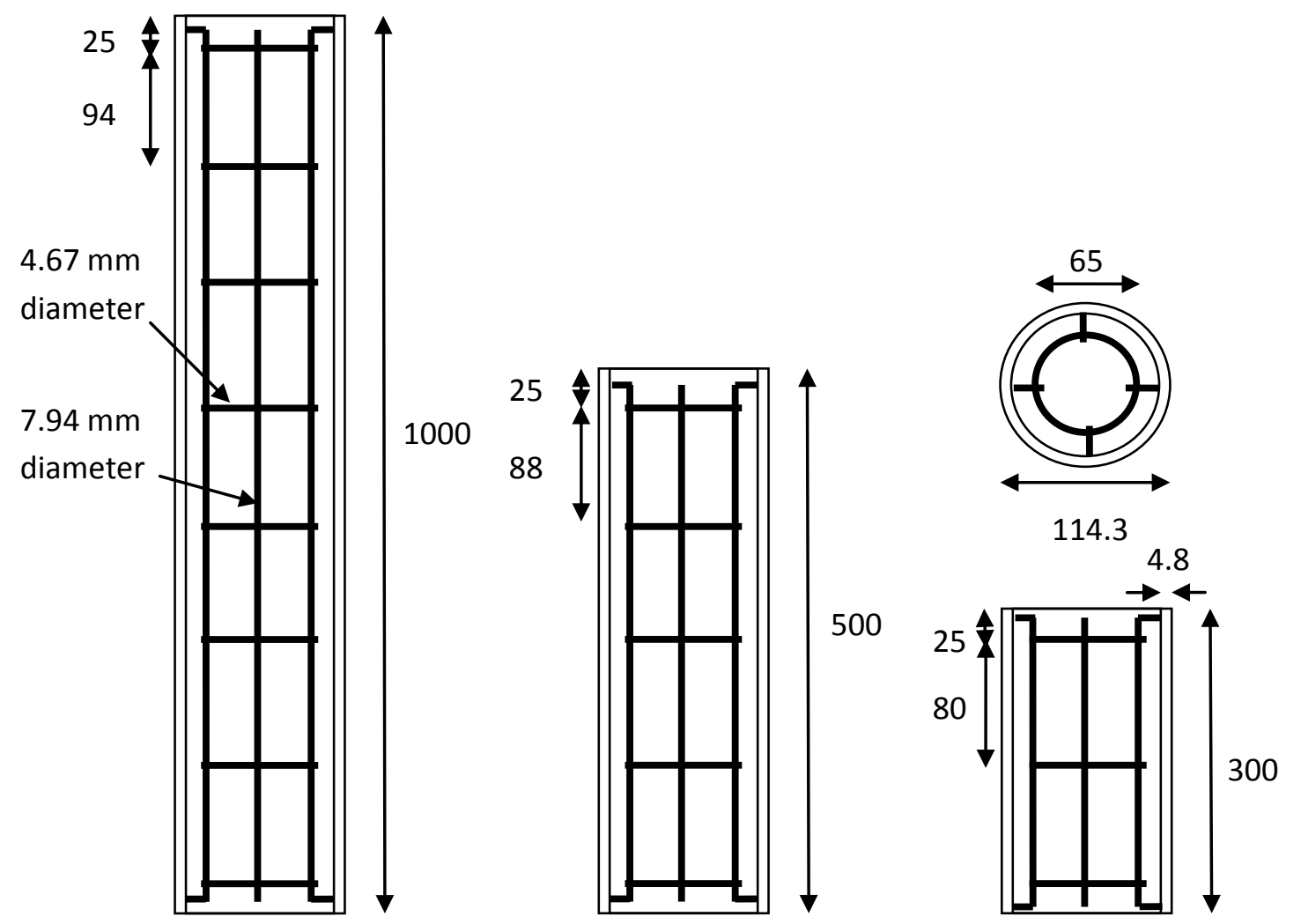

Figure 3.1: Details of cII columns showing reinforcements (dimensions in mm)

\subsection{Material properties}

Five concretes were used as in-fill for steel tube columns. Each of the concretes was made with different materials according to commercially available mix proportions, or mix designs developed by the research team at Ryerson University.

$\mathrm{NC}$ was made with commercially available pre-packaged dry contents, to which $2.4 \mathrm{~L}$ of water was added during mixing for every $30 \mathrm{~kg}$ bag (a sample of NC is shown in Figure 3.2a). Dry contents included nominal aggregate size of $10 \mathrm{~mm}$, Portland cement, silica fume, and airentraining admixture. After mixing in a $40 \mathrm{~L}$ capacity rotating drum mixer, concrete was placed into steel tubes (dimension are listed in Table 3.1) on a vibrating table for compaction. 
UHSC components included Type 10 cement, silica sand, undensified silica fume, high-range water reducing admixture (ADVAcast 575), and $13 \mathrm{~mm}$-long straight steel fibres with diameter of $0.2 \mathrm{~mm}$ (a sample of UHSC is shown in Figure 3.2b). UHSC was mixed in a $75 \mathrm{~L}$ capacity pan mixer, where water and superplasticizer were added to dry materials (excluding steel fibres). Steel fibres were then scattered onto the paste during mixing for even distribution. UHSC was poured directly into steel tubes with no addition compaction methods necessary, as the concrete was designed to consolidate under its own weight.
a) $\mathrm{NC}$
b) UHSC
c) ECC

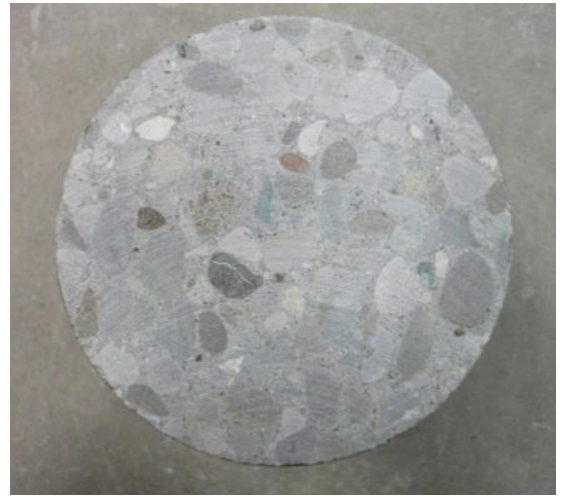

d) LWC

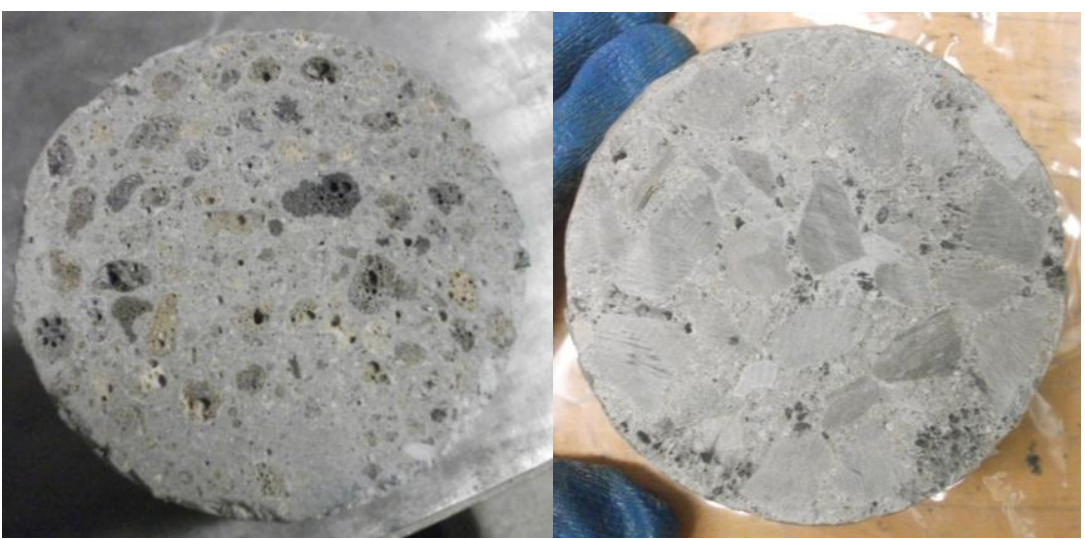

Figure 3.2: Sample sectional view of concrete control cylinders

ECC used in this research included Portland cement with $2.2 \%$ class F fly ash replacement for improving flowability and strain capacity (Wang \& Li, 2007), silica sand, polyvinyl fibres, and 
high-range water-reducing admixture (a sample of ECC is shown in Figure 3.2c). After cementitious materials and silica sand were placed in a shear mixer, water with superplasticizer were added. When thick paste formed, fibres were introduced into the mix slowly to ensure even distribution. ECC was then poured directly into steel tubes without further compaction, as it was designed to self-consolidate.

Commercially available coarse and fine pelletized slag aggregate were used for fabricating LWSCC (a sample of LWSCC is shown in Figure 3.2d). In addition to slag aggregates, Type 10 cement, class F flyash, densified silica fume, and high-range water-reducing admixture (Glenium 7102), and water were mixed to obtain LWSCC. After contents were mixed evenly in a rotating drum mixer, LWC was poured directly into steel tubes without further compaction.

CRC self-consolidating characteristics were achieved by incorporating Portland cement, slag, 19 mm maximum size coarse aggregate, and natural sand (a sample of CRC is shown in Figure 3.2e). CRC was then developed by replacing $20 \%$ sand by volume with crushed tire crumb rubber of 600 micron size. High-range water-reducing admixture (ADVAcast 575) and water were added to dry materials in a rotating drum mixer to produce CRC.

Compressive strength $\left(\mathrm{f}^{\prime}{ }_{\mathrm{c}}\right)$ for each concrete type has been tabulated in Table 3.2 based on $200 \mathrm{x}$ $100 \mathrm{~mm}$ standard control cylinders. Control specimens were casted at the same time as CFST columns, and at the age of testing they were crushed.

Table 3.2: Concrete properties

\begin{tabular}{cccccc}
\hline & NC & UHSC & ECC & LWC & CRC \\
\hline $\begin{array}{c}\text { Cylinder compressive strength (MPa) at } \\
\text { the age of testing }\end{array}$ & 66 & 127 & 50 & 36 & 46 \\
$\begin{array}{c}\text { Age at testing (days) } \\
\text { Water to cementitious material ratio }\end{array}$ & 273 & 246 & 236 & 232 & 98 \\
NA & 0.22 & 0.27 & 0.35 & 0.32 \\
\hline
\end{tabular}


Table 3.3 also lists the steel tube yield strength $\left(f_{y}\right)$, and steel Young's elastic modulus ( $\left.E_{s}\right)$ for each shape as derived from at least three coupon specimens. Coupon tension tests were also used to determine longitudinal and hoop reinforcement yield strength of $635 \mathrm{MPa}$ and $662 \mathrm{MPa}$, respectively.

Table 3.3: Steel tube material properties

\begin{tabular}{ccc}
\hline Steel tube designation & $\begin{array}{c}\text { Steel yield strength, } \\
\text { MPa }\end{array}$ & $\begin{array}{c}\text { Steel modulus of elasticity, } \\
\text { GPa }\end{array}$ \\
\hline Circular & 333 & 176 \\
Rectangular & 372 & 236 \\
Square (102 mm dimension) & 351 & 205 \\
Square (51 mm dimension) & 365 & 206 \\
\hline
\end{tabular}

\subsection{Casting of CFST specimens}

Casting has been done in vertically upright position as shown in Figure 3.3. Concrete has been cast from the top of the specimen.

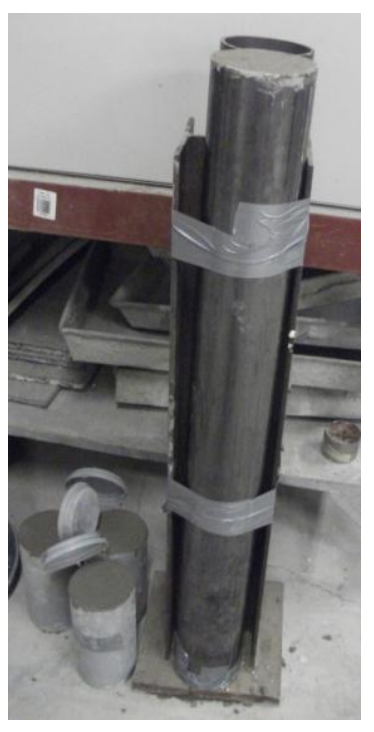

Figure 3.3: Concrete casting 
After concrete mixing, it was poured into the steel tubes. Since all high-performance concretes studied herein were SCC, there was no additional compaction needed as it was self flowing. But for NC a vibratory table was used to provide proper consolidation. During casting concrete control specimens in the form of $100 \times 200$ cylinders were also made, so that the strength of concrete would be known. After casting, specimens were covered for 24 hours to prevent moisture loss, and then air cured until testing. Control specimens were cast and cured in the same way as the specimens.

\subsection{CFST column instrumentation and testing}

Before testing, columns were ground flat to ensure load was applied evenly across steel and concrete components. In order to measure axial and transverse strain of CFST columns, gauges were attached in the horizontal (g1) and vertical (g2) orientations shown in Figure 3.4.
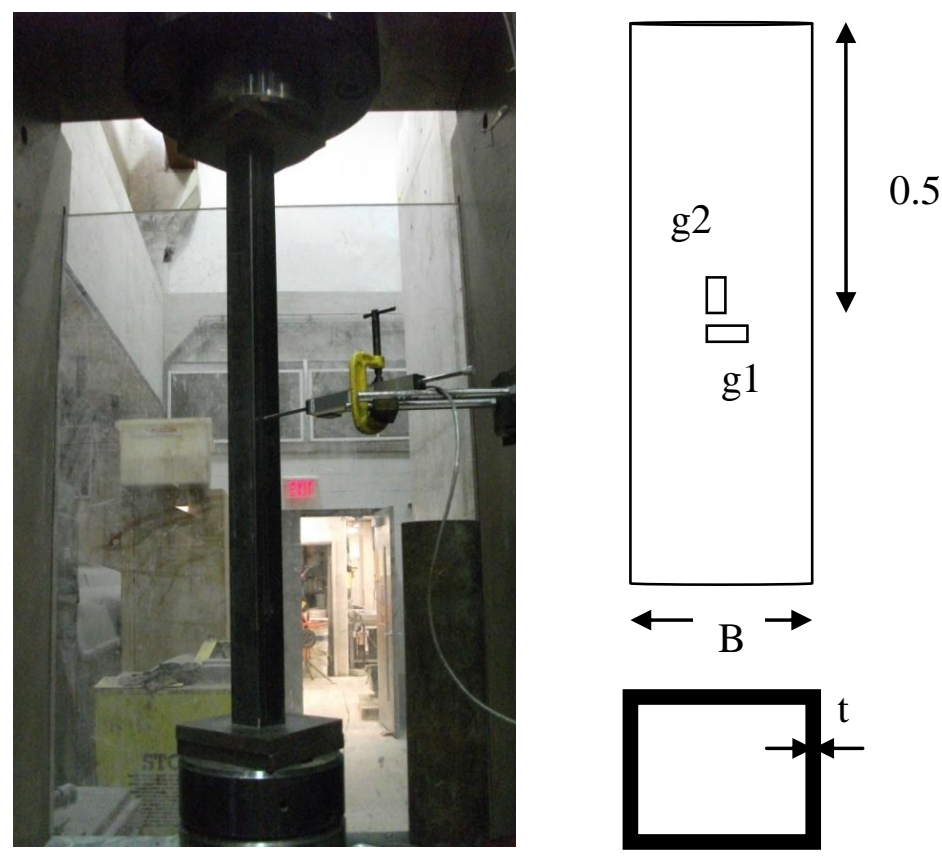

Figure 3.4: Experimental set-up and instrumentation of columns 
CFST columns were placed in a $4600 \mathrm{kN}$ capacity Material Testing System (MTS) under concentric axial loading at a rate of $0.2 \mathrm{MPa} / \mathrm{s}$ (see Figure 3.4 for experimental setup). During loading history, axial load-displacement response and strain data were recorded by a data acquisition system. During testing, failure modes and overall behaviour of CFST columns were monitored. 


\section{Chapter Four}

\section{ANALYTICAL MODELS FOR AXIAL STRENGTH OF CFST COLUMNS AND CONCRETE CONFINEMENT}

\subsection{Introduction}

This chapter presents analytical models for axial strength of CFST columns and concrete confinement based on the work of previous authors and current research. Analytical equations are based on the biaxial model, which is used to describe stress in the steel tube of filled columns. Besides explaining analytical models for concrete confinement and axial strength, available code provisions are also presented. These models will be used to compare theoretical concrete confined strength and axial capacity of filled steel tube columns, which will be presented in the next chapter.

\subsection{Biaxial stress development}

CFST columns under axial concentric loading exhibit triaxial compression in the concrete core. At later stages of loading, concrete begins to soften and dilate, expanding radially, and applying lateral pressure on the steel tube (de Oliveira et al., 2009). Load applied in the axial direction and lateral pressure from the concrete core put the steel tube under biaxial stresses. The von-Mises failure criterion given in Eq. 4.1 was considered applicable for modelling steel yielding under axial and hoop stresses ( $\sigma_{\mathrm{a}}$ and $\sigma_{\mathrm{h}}$, respectively) (Hossain 2003b; McAteer et al., 2004; Lachemi et al., 2006b):

$f_{y s}^{2}=\sigma_{a}^{2}+\sigma_{h}^{2}-\sigma_{a} \sigma_{h}$

where $\sigma_{\mathrm{a}}$ and $\sigma_{\mathrm{h}}$ are determined from experimental strain, and are defined by Eqs. 4.2 and 4.3. 
$\sigma_{a}=\beta f_{y s}$

$\sigma_{h}=\alpha f_{y s}$

The von-Mises yield stress, $f_{\mathrm{ys}}$, is the steel tube yield strength corresponding to each column. Each $\mathrm{f}_{\mathrm{ys}}$ value corresponds to a different failure envelope. The failure envelope for circular CFST columns with steel tube yield strength of $333 \mathrm{MPa}$ (tested in the current research) is shown Figure 4.1. Biaxial stress factors, $\alpha$ and $\beta$, are found by determining the point of intersection between experimental stresses and the von-Mises failure envelope. Example of how experimental stresses intersect with the von-Mises failure envelope is shown in Figure 4.1 based on current research on NC filled tubes with bar reinforcements (namely columns NcII-3 and NcII-9). $\alpha$ and $\beta$ can be used to calculate theoretical strength of CFST columns, and vary with column slenderness and material properties.

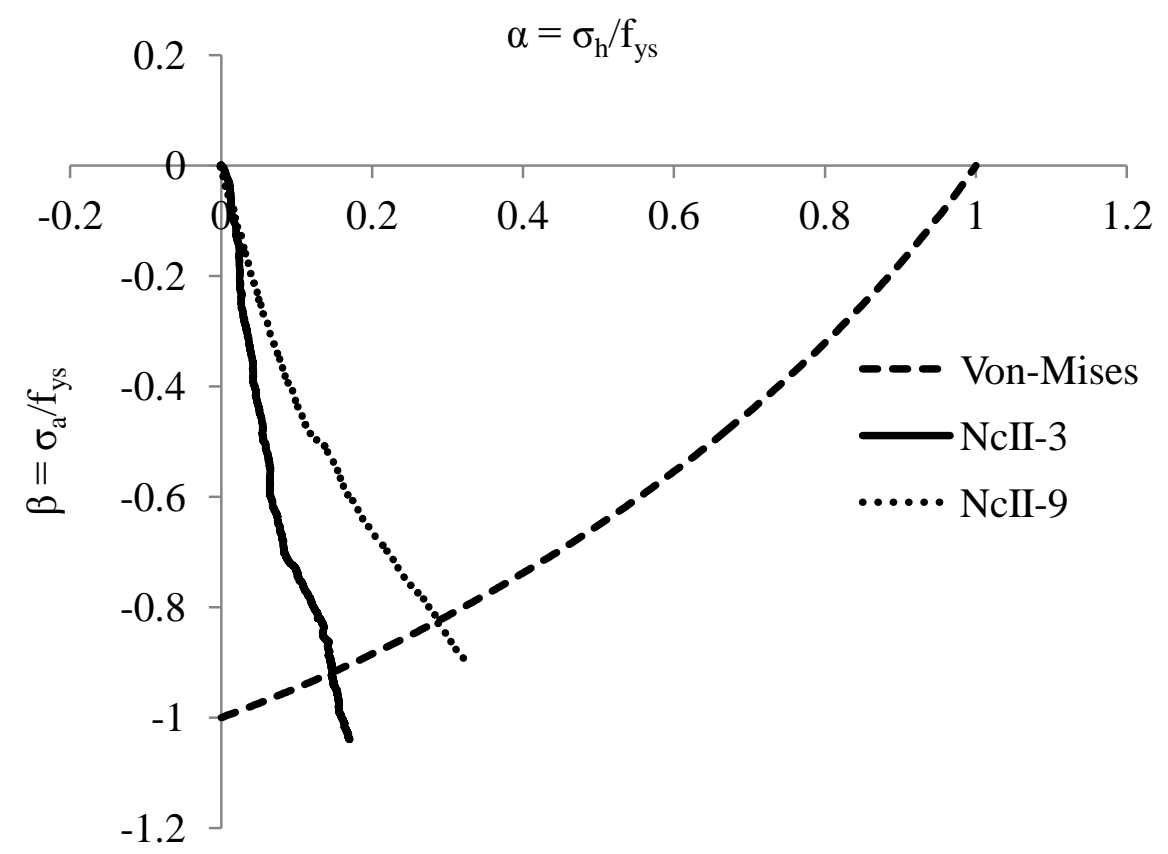

Figure 4.1: Development of biaxial stresses 


\subsection{Quantification of lateral stresses and concrete confinement}

Besides axial stresses applied to the concrete core, lateral pressures also develop from the presence of steel tube $\left(f_{2}\right)$ as shown in Figure 4.2, where $\sigma_{\mathrm{sz}}$ is the axial stress and $\sigma_{\mathrm{sh}}$ is the hoop stress. Lateral pressure from hoop reinforcements $\left(f_{2 h}\right)$ also develops in a similar manner.
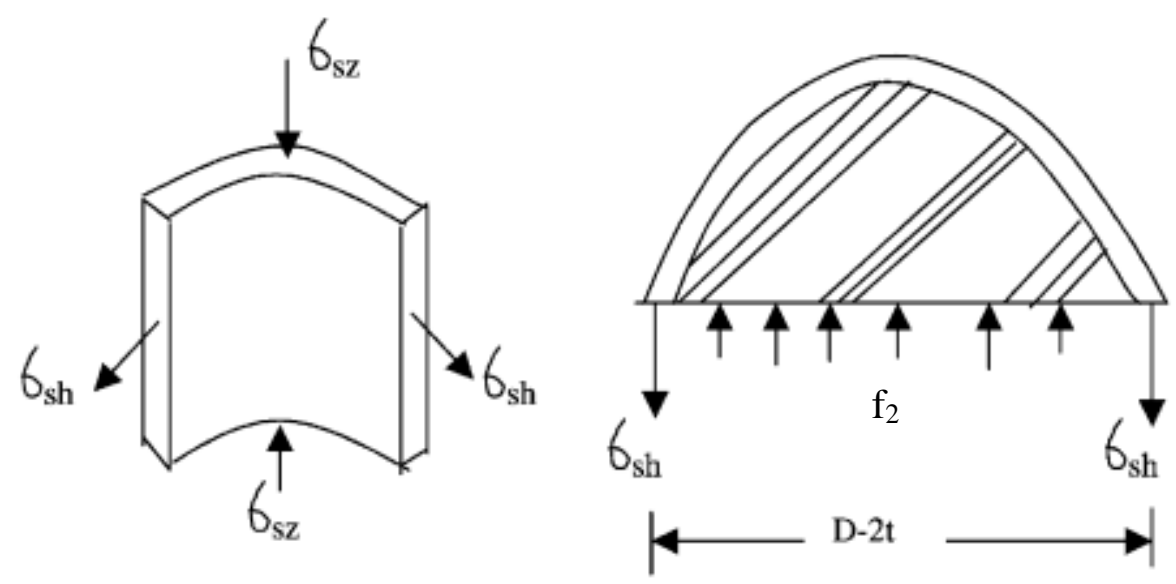

Figure 4.2: Confinement effect in thin-walled composite column (Hossain, 2003b)

Lateral pressure from the steel tube can be calculated from Eq. 4.4 (Hossain 2003b):

$f_{2}=\frac{2 t}{D-2 t} \sigma_{h}$

where $t$ is the tube thickness, $\mathrm{D}$ is the outer tube diameter, and $\sigma_{\mathrm{h}}$ is transverse stress. Eq. 4.5 estimates lateral pressure from the tube with the assumption that peak lateral pressure occurs at biaxial steel yielding:

$f_{2}=\frac{2 t}{D-2 t} \alpha f_{y s}$

Therefore, the biaxial stress factor, $\alpha$, and yield strength of steel, $f_{\mathrm{ys}}$, are incorporated from Eq. 4.3. Lateral pressure from hoop reinforcements is calculated by Eq. 4.6: 
$f_{2 h}=\frac{2 A_{s r} f_{y r}}{D_{c} s}$

where $A_{s r}$ is the longitudinal reinforcement area, $f_{y r}$ is the longitudinal bar strength, $D_{c}$ is the diameter of concrete confined by hoops, and s is hoop spacing. Taking the sum of equations 4.5 and 4.6, the maximum lateral pressure $\left(f_{2 \max }\right)$ in CFST columns can be calculated by Eq. 4.7 (Lachemi et al., 2006a):

$f_{2 \max }=\frac{2 t}{D-2 t} \alpha f_{y s}+\frac{2 A_{s r} f_{y r}}{D_{c} s}$

Besides lateral pressures, stress-strain graphs as shown in Figure 4.3 describe the development of concrete axial stresses in CFST columns, where specimens NcI-9 and NcII-9 are taken as examples for illustration.

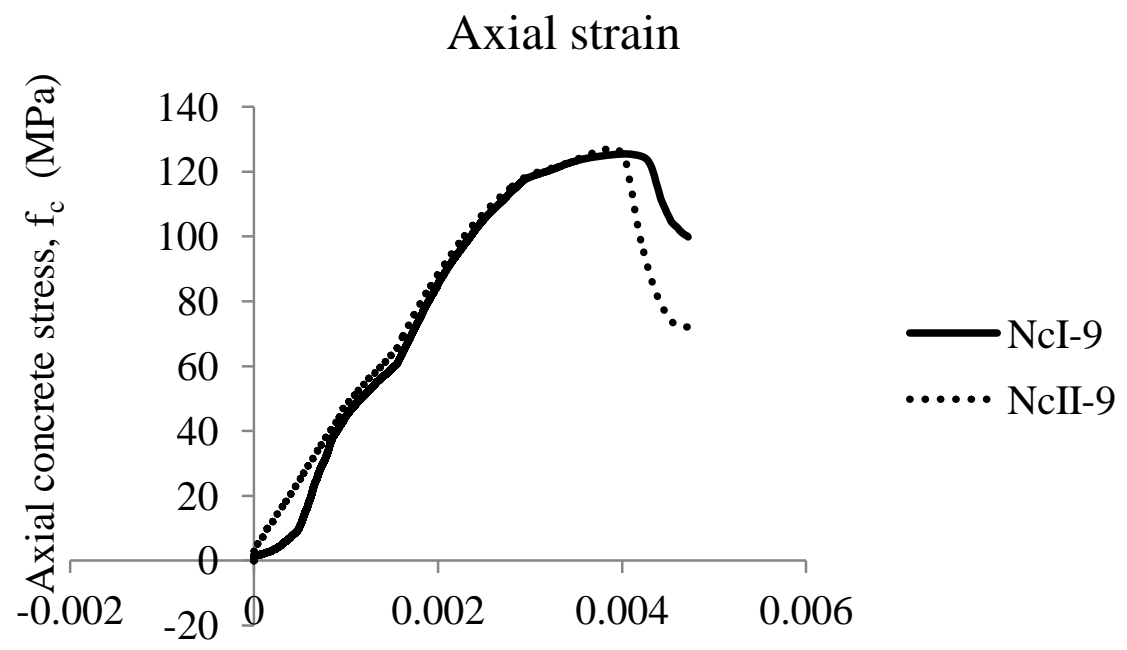

Figure 4.3: Typical composite column response

Axial load was applied across the entire CFST cross-sectional area during testing, and is denoted by $\mathrm{P}$. This load is shared between steel $\left(\mathrm{P}_{\mathrm{s}}\right)$ and concrete $\left(\mathrm{P}_{\mathrm{c}}\right)$ material components, as described by Eq. 4.8 . 
$P=P_{c}+P_{S}$

Concrete axial stress is determined by Eq. 4.9, where $\mathrm{P}_{\mathrm{s}}$ can be found from experimental axial stress $\left(\sigma_{\mathrm{a}}\right)$ and steel sectional area $\left(\mathrm{A}_{\mathrm{s}}\right)$ in Eq. 4.10.

$f_{c}=\frac{P_{c}}{A_{c}}=\frac{P-P_{S}}{A_{c}}$

$P_{s}=A_{s} \sigma_{a}$

For each CFST columns, a stress-strain diagram can be drawn, as shown in Figure 4.3. Figure 4.3 illustrates how the presence of bar reinforcements in specimen NcII-9 allows for slightly higher axial stress to be taken by the concrete core compared with NcI-9. Steel yielding always occurred before ultimate CFST column capacity for columns tested herein. Thus it is expected that concrete confined strength, $f_{c c}$, is determined as the value of $f_{c}$ at ultimate axial load of the column. In this way, experimental concrete confined strength for each CFST column can be determined.

\subsection{Existing analytical models for confined concrete strength}

Early studies on concrete confinement under triaxial hydraulic pressure by Richart et al. (1928) provided a basis for researchers studying confined concrete strength. Mander et al. (1988) later developed an equation for modeling strength of concrete confined by bar reinforcements, however, uniaxial yielding is assumed resulting in potentially over-predicted strength. O'Shea and Bridge (2000) modified the Mander et al. (1988) equation based on experimental results on concrete-filled tube columns. Lachemi et al. (2006b) proposed three models for estimating confined strength of concrete $\left(\mathrm{f}_{\mathrm{cc}}\right.$ ) based on the work of Richart et al. (1928), Mander et al. 
(1988), and O'Shea and Bridge (2000) presented in Eqs. 4.11, 4.12, and 4.13. Subscripts R, M, and $\mathrm{O}$ denote authors of research from which equations were based on.

$f^{\prime}{ }_{c c(R)}=f^{\prime}{ }_{c}+8.2 \frac{t \alpha f_{y s}}{D-2 t}$

${f^{\prime}}^{\prime}{ }_{c c(M)}=f^{\prime}{ }_{c}\left(2.254 \sqrt{1+15.88 \frac{t \alpha f_{y s}}{f^{\prime}{ }_{c}(D-2 t)}}-4 \frac{t \alpha f_{y s}}{{f^{\prime}{ }_{c}(D-2 t)}(D-254)}-1.254\right)$

${f^{\prime}}^{\prime}{ }_{c(O)}=f^{\prime}{ }_{c}\left(2.172 \sqrt{1+14.92 \frac{t \alpha f_{y s}}{{f^{\prime}}_{c}(D-2 t)}}-4 \frac{t \alpha f_{y s}}{{f^{\prime}{ }_{c}(D-2 t)}^{(D-2 t}}-1.228\right)$

Hossain (2003b) developed Eq. 4.14 for determining concrete tube confined strength by incorporating a modified unconfined concrete strength $\left(f_{p}\right)$ given in Eq. 4.15:

$f^{\prime}{ }_{c c(H)}=f_{p}+4.1 \frac{2 t}{D-2 t} \alpha f_{y s}$

$f_{p}=1.61\left(d_{c}\right)^{-0.1} f^{\prime}{ }_{c}$

where $\mathrm{f}^{\prime}{ }_{\mathrm{c}}$ is the concrete cylinder compressive strength, $\mathrm{t}$ is the steel tube thickness, $\alpha$ is the transverse biaxial stress factor, $\mathrm{f}_{\mathrm{ys}}$ is the steel tube yield strength, $\mathrm{D}$ is the outer tube diameter, and $\mathrm{d}_{\mathrm{c}}$ is the concrete section diameter.

In addition to tube confinement, Lachemi et al. (2006b) proposed models (Eqs. 4.16, 4.17, and 4.18) for hoop reinforcement confined concrete strength ( $\left.f^{\prime}{ }_{c c h}\right)$ based on the works of Richart et al. (1928), Mander et al. (1988), and O'Shea and Bridge (2000), denoted by subscripts R, M and O, respectively:

$f_{c c h(R)}^{\prime}=8.2 \frac{A_{s r} f_{y r}}{D_{c} s}$ 


$$
\begin{aligned}
& f^{\prime}{ }_{c c h(M)}=f^{\prime}{ }_{c}\left(2.254 \sqrt{1+15.88 \frac{A_{s r} f_{y r}}{f^{{ }^{\prime} D_{c} s}}}-4 \frac{A_{s r} f_{y r}}{f^{\prime}{ }_{c} D_{c} s}-0.254\right) \\
& f^{\prime}{ }_{c c h(O)}=f^{\prime}{ }_{c}\left(2.172 \sqrt{1+14.92 \frac{A_{s r} f_{y r}}{f^{\prime} D_{c} s}}-4 \frac{A_{s r} f_{y r}}{f^{\prime}{ }_{c} D_{c} s}-0.228\right)
\end{aligned}
$$

where $A_{s r}$ is the longitudinal reinforcement area, $f_{y r}$ is the longitudinal reinforcement bar strength, $\mathrm{D}_{\mathrm{c}}$ is the hoop confined concrete diameter and $\mathrm{s}$ is the hoop spacing.

To obtain total confined strength for CFST columns with bar reinforcements at the interior, Eq. 4.19 combines the effect of tube and hoop confinement. Models for tube confined concrete strength (Eqs. 4.11 to 4.14) and corresponding models for hoop confinement (Eqs. 4.16 to 4.18 ) are used to obtain three models for total confinement $\left(\mathrm{f}^{\prime}{ }_{\text {cct }}\right)$ denoted by subscripts $\mathrm{R}, \mathrm{M}$, and $\mathrm{O}$, respectively (Eqs. 4.20, 4.21 and 4.22, respectively):

$$
\begin{aligned}
& f^{\prime}{ }_{c c t}=f^{\prime}{ }_{c c}\left(\frac{A_{c c}}{A_{c}}\right)+f^{\prime}{ }_{c c h}\left(\frac{A_{c c h}}{A_{c}}\right) \\
& f^{\prime}{ }_{c c t(R)}=\frac{A_{c c}}{A_{c}}\left[f^{\prime}{ }_{c}+8.2 \frac{t \alpha f_{y s}}{D-2 t}\right]+8.2 \frac{A_{s r} f_{y r}}{D_{c} s} \frac{A_{c c h}}{A_{c}} \\
& f^{\prime}{ }_{c c t(M)}=\frac{A_{c c} f_{c}^{\prime}}{A_{c}}\left(2.254 \sqrt{1+15.88 \frac{t \alpha f_{y s}}{f^{\prime}{ }_{c}(D-2 t)}}-4 \frac{t \alpha f_{y s}}{f^{\prime}{ }_{c}(D-2 t)}-1.254\right) \\
& +\frac{A_{c c h} f_{c}^{\prime}}{A_{c}}\left(2.254 \sqrt{1+15.88 \frac{A_{s r} f_{y r}}{f_{c}^{\prime} D_{c} s}}-4 \frac{A_{s r} f_{y r}}{f^{\prime}{ }_{c} D_{c} s}-0.254\right) \\
& f^{\prime}{ }_{c c t(O)}=\frac{A_{c c} f^{\prime}{ }_{c}}{A_{c}}\left(2.172 \sqrt{1+14.92 \frac{t \alpha f_{y s}}{f^{\prime}{ }_{c}(D-2 t)}}-4 \frac{t \alpha f_{y s}}{f^{\prime}{ }_{c}(D-2 t)}-1.228\right) \\
& +\frac{A_{c c h} f_{c}^{\prime}}{A_{c}}\left(2.172 \sqrt{1+14.92 \frac{A_{s r} f_{y r}}{f_{c}^{\prime} D_{c} s}}-4 \frac{A_{s r} f_{y r}}{f_{c}^{\prime} D_{c} s}-0.228\right)
\end{aligned}
$$


where $A_{c}$ is the area of concrete confined by steel, $A_{c c}$ is the area of concrete only, and $A_{c c h}$ is the area confined by hoop reinforcements.

\subsection{Existing strength models for CFST columns}

Several code recommendations are available for design of CFST columns, including CSA (2009), AISC (2005), and Eurocode (2004) described as follows. The CAN/CSA S16-09 (2009) equation for calculating compressive resistance of CFST columns $\left(\mathrm{C}_{\mathrm{rc}}\right)$ is shown in Eq. 4.23:

$C_{r c}=\left(\tau \varphi_{s} A_{s} f_{y}+\tau^{\prime} \alpha_{1} \varphi_{c} A_{c} f_{c}^{\prime}\right)\left(1+\lambda^{2 n}\right)^{-1 / n}$

where factors $\tau=\frac{1}{\sqrt{1+\rho+\rho^{2}}}$ and $\tau^{\prime}=1+\left(\frac{25 \rho^{2} \tau}{\frac{D}{t}}\right)\left(\frac{f_{y}}{0.85 f^{\prime}{ }_{c}}\right)$, where $\rho=0.02\left(25-\frac{L}{D}\right)$ and $\alpha_{1}=0.85-0.0015 f^{\prime}{ }_{c}$. Material safety factors, $\phi_{\mathrm{s}}$ and $\phi_{\mathrm{c}}$, assume a value of 1 for the purpose of comparison. Relative slenderness, $\lambda$, is calculated by determining elastic critical load and $\mathrm{C}_{\mathrm{rc}}$ when $\lambda=0$. The value of $\mathrm{n}$ is assumed to be 1.8 .

The AISC-LRFD (2005) code provisions for determining ultimate load of CFST columns $\left(\mathrm{P}_{\mathrm{n}}\right)$ is given in Eq. 4.24:

$P_{n}=\left\{\begin{array}{cc}P_{o}\left(0.658^{\frac{P_{o}}{P_{e}}}\right), & 0.44 P_{o} \leq P_{e} \\ 0.877 P_{e}, & 0.44 P_{o}>P_{e}\end{array}\right.$

where $P_{o}=A_{s} f_{y}+A_{s r} f_{y r}+C_{2} A_{c} f^{\prime}$, and $C_{2}$ factor is defined based on column cross-sectional shape. $\mathrm{P}_{\mathrm{e}}$ is the elastic critical load, for which calculations are similar to the equations provided in CSA (2009).

Eurocode (2004) provides Eq. 4.25 to determine the ultimate axial compressive strength of CFST columns $\left(\mathrm{N}_{\mathrm{pl}, \mathrm{Rd}}\right)$ : 
$N_{p l . R d}=\eta_{a} A_{s} f_{y}+\eta_{b} A_{c} f^{\prime}{ }_{c}+A_{s z} f_{y r}$

where $A_{s z}$ is the longitudinal steel reinforcement area, and $\eta_{\mathrm{a}}$ and $\eta_{\mathrm{b}}$ are the modification factors to account for effects of confinement.

Hossain (2003b) proposed a model for axial compressive strength of CFST columns $\left(\mathrm{N}_{\mathrm{u}}\right)$ without reinforcements, provided in Eq. 4.26:

$N_{u}=\beta A_{s} f_{y s}+A_{c} f^{\prime}{ }_{c c}$

where axial stress factor, $\beta$, is applied to strength of the steel tube. Confined concrete strength, $\mathrm{f}^{\prime}{ }_{\mathrm{cc}}$, is calculated by Eq. 4.14 .

Lachemi et al. (2006b) proposed Eq. 4.27 based on the Hossain (2003b) model with the addition of contributions from hoop and longitudinal reinforcements.

$P_{r 1}=\beta A_{s} f_{y s}+A_{c c} f^{\prime}{ }_{c c}+A_{c c h} f^{\prime}{ }_{c c h}+A_{r a} f_{y r}$

Tube confined concrete strength is obtained from Eqs. 4.11 to 4.13 , and corresponding hoop confinement equations are provided in Eqs. 4.16 to 4.18. Thus three models for axial strength of CFST columns, $\mathrm{P}_{\mathrm{r} 1}$, can be defined based on the works of Richart et al. (1928), Mander et al. (1988) and O'Shea and Bridge (2000) in Eqs. 4.28, 4.29, and 4.30, respectively.

$$
\begin{aligned}
& P_{r 1(R)}=\beta A_{s} f_{y s}+A_{c c} f_{c c(R)}^{\prime}+A_{c c h} f^{\prime}{ }_{c c h(R)}+A_{r a} f_{y r} \\
& P_{r 1(M)}=\beta A_{s} f_{y s}+A_{c c} f_{c c(M)}^{\prime}+A_{c c h} f^{\prime}{ }_{c c h(M)}+A_{r a} f_{y r} \\
& P_{r 1(O)}=\beta A_{s} f_{y s}+A_{c c} f^{\prime}{ }_{c c(O)}+A_{c c h} f^{\prime}{ }_{c c h(O)}+A_{r a} f_{y r}
\end{aligned}
$$




\section{Chapter Five}

\section{EXPERIEMNTAL RESULTS AND DISCUSSIONS}

\subsection{Introduction}

This chapter presents the behaviour of tested CFST columns under Type A axial compression loading where load was applied through both steel and concrete. Axial load-displacement response, stress-strain characteristics, confined strength, and axial capacity of CFST columns are described. First, results for NC filled columns are presented and discussed. Then, performance of CFST columns in-filled with each type of high-performance concrete is compared with respect to normal concrete (NC) CFST columns. Analytical and code-based models for concrete confined strength and axial capacity are used to verify their compatibility with different concrete in-fill materials.

\subsection{NC filled tube columns}

The load-displacement response and stress-strain characteristics of NC-filled tube columns under axial compression are reported here. Calculated values for confined concrete strength and axial capacity of CFST columns using analytical and code-based design equations are compared with experimental values.

\subsubsection{Axial load-displacement response and failure modes}

Five different types of failure modes were identified from experimental tests of CFST columns under axial compression, illustrated in Figure 5.1. Failure by radial expansion is shown in Figure 5.1a, where the concrete pushes outwards on the steel tube until it bulges into a barrel-like shape. If load continues, the column typically fails when the steel tube tears due to extensive pressure 
from the concrete core. Local buckling failure shown in Figure 5.1b often occurs at multiple locations along the column length. Figure 5.1c shows how a plastic hinge can form when several local buckles are concentrated at one location along the column length, causing the column to bend. Alternatively, shear failure can occur as shown in Figure 5.1d, where the concrete core has shifted along a slanted plane. Finally, global buckling is shown in Figure 5.1e, where the column bends at one location often near mid-height.

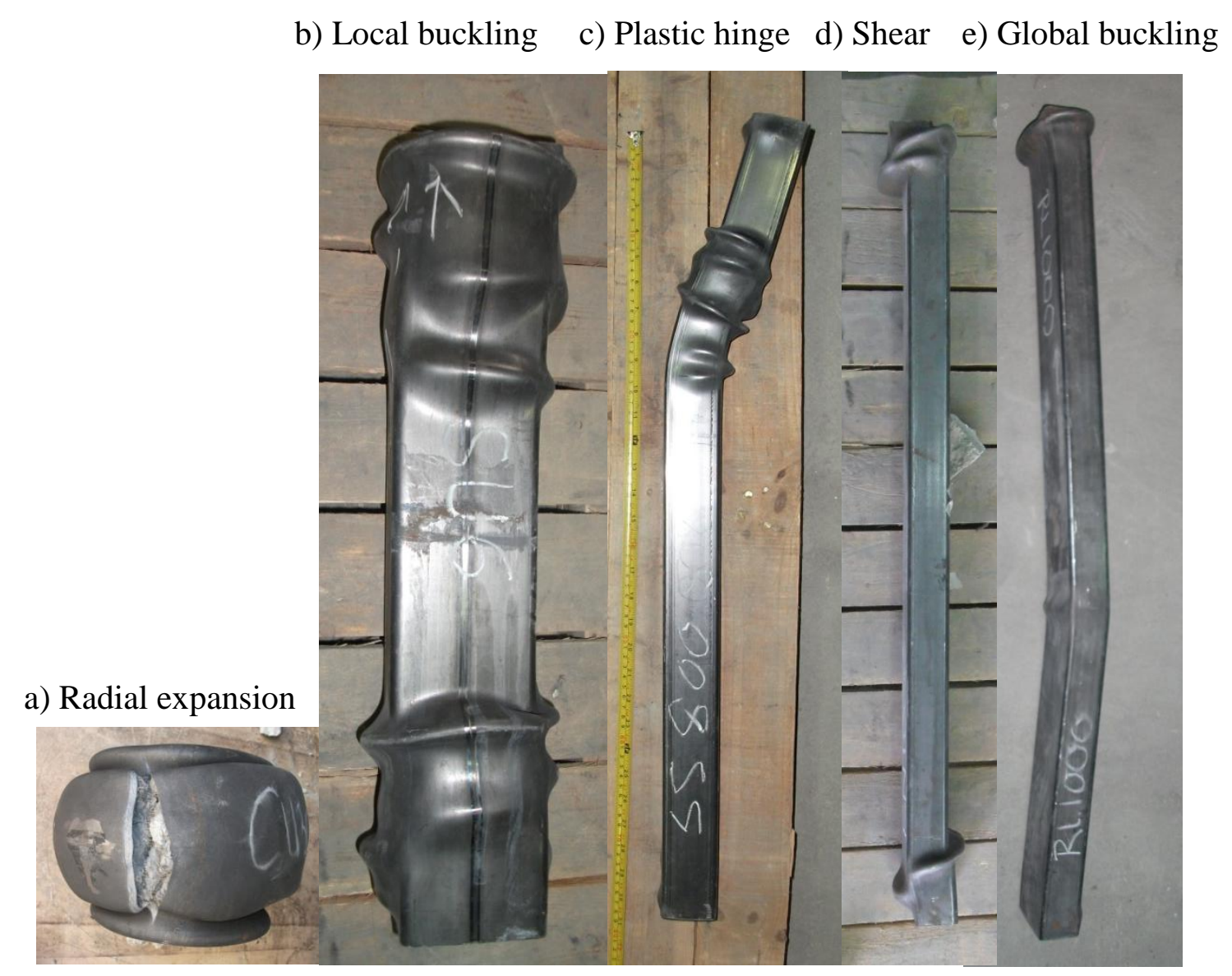

Figure 5.1: Classification of CFST column failure modes

Column designations (Table 5.1) used to identify each specimen are described as follows: The first letter in each column designation is defined by concrete in-fill (N: normal concrete, $\mathrm{U}$ : ultra- 
high strength concrete, E: engineered cementitious composite, L: lightweight concrete, and R: crumb rubber concrete), followed by column type or shape (cI: circular without bar reinforcements, cII: circular with bar reinforcements, s4: square with $102 \mathrm{~mm}$ dimension, s2: square with $51 \mathrm{~mm}$ dimension, and $\mathrm{r}$ : rectangular). The numerical value at the end of each column designation is the slenderness ratio. Slenderness is defined as length-to-diameter (L/D) ratio for circular columns, or length-to-depth $(\mathrm{L} / \mathrm{d})$ ratio for square and rectangular columns where depth $(\mathrm{d})$ is the smaller sectional dimension.

Table 5.1: NC CFST column capacity and concrete strength increase

\begin{tabular}{ccc}
\hline Column Designation & Axial strength, kN & Failure mode \\
\hline NcI-3 & 1410 & Radial expansion \\
NcI-4 & 1403 & Shear \\
NcI-9 & 1511 & Shear \\
NcII-3 & 1601 & Radial expansion \\
NcII-4 & 1584 & Shear \\
NcII-9 & 1592 & Shear \\
Nr-6 & 716 & Radial expansion \\
Nr-12 & 800 & Plastic hinge \\
Nr-20 & 639 & Shear \\
Ns4-3 & 1217 & Radial expansion \\
Ns4-6 & 1198 & Local buckling \\
Ns4-10 & 1204 & Local buckling \\
Ns2-6 & 266 & Shear \\
Ns2-9 & 296 & Shear \\
Ns2-12 & 318 & Global buckling \\
Ns2-16 & 296 & Shear \\
Ns2-20 & 309 & Shear \\
\hline
\end{tabular}

Table 5.1 lists experimental axial strength of NC-filled tube columns, and corresponding failure modes. Columns with slenderness ratio of 3 failed by radial expansion. For columns with slenderness ratio from 4 to 12 often failed due to shear or steel local buckling. CFST columns 
with slenderness ratio from 16 to 20 failed due to shear. Several NC filled columns after testing are shown Figure 5.2. Axial strength of NC-filled columns increases with cross-sectional area, and with the presence of bar reinforcements as expected.

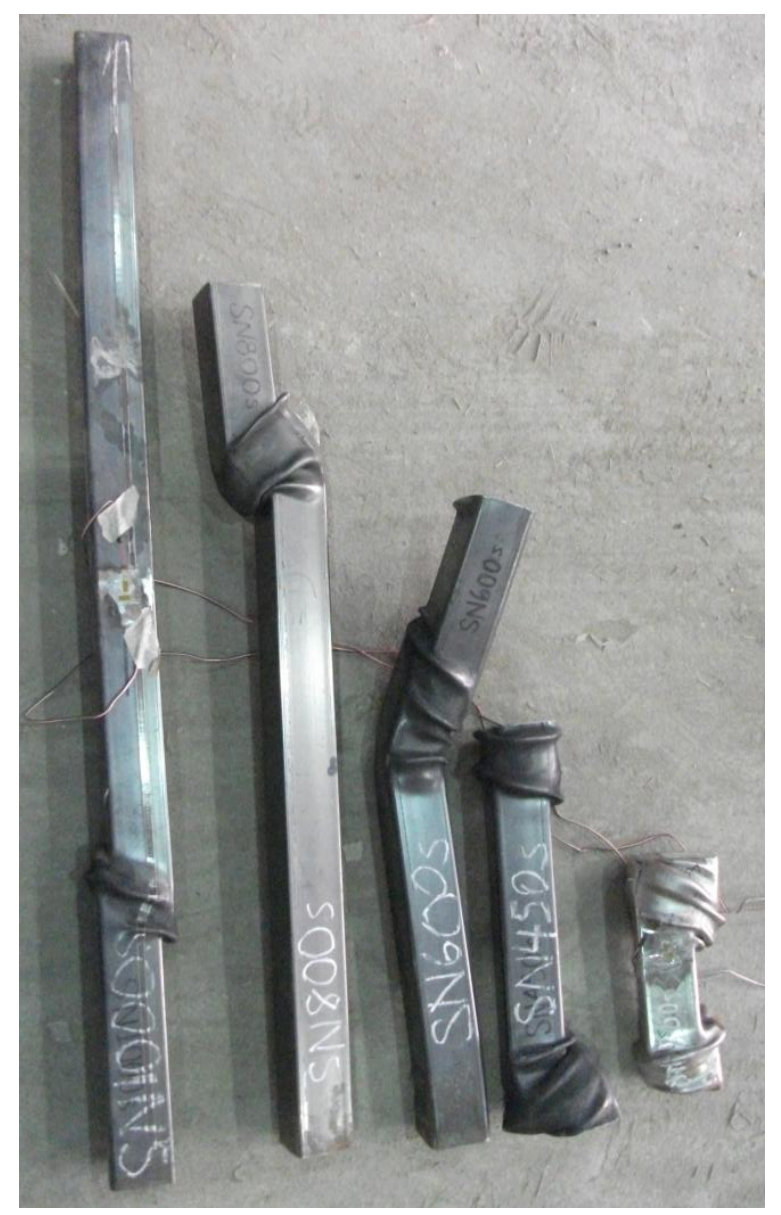

Ns2-20 Ns2-16 Ns2-12 Ns2-9 Ns2-6

Figure 5.2: Failure modes of NC-filled CFST columns

The effect of slenderness ratio on axial load-displacement response of circular, square, and rectangular CFST columns in-filled with NC are illustrated in Figure 5.3. Circular CFST columns shown in Figure 5.3a tend to show more ductile behaviour compared with square and rectangular ones in Figure 5.3b. This can be observed by a more flat plateau after first peak load is reached in circular CFST columns. This flat plateau after first peak load is further emphasized 
in NcII-3 and NcII-9 columns with longitudinal reinforcements. Thus, the presence of bar reinforcements has an effect of increasing CFST column ductility. Post-peak load tended to decrease at a faster rate for columns with higher slenderness ratio, since those columns typically failed due to global instability.

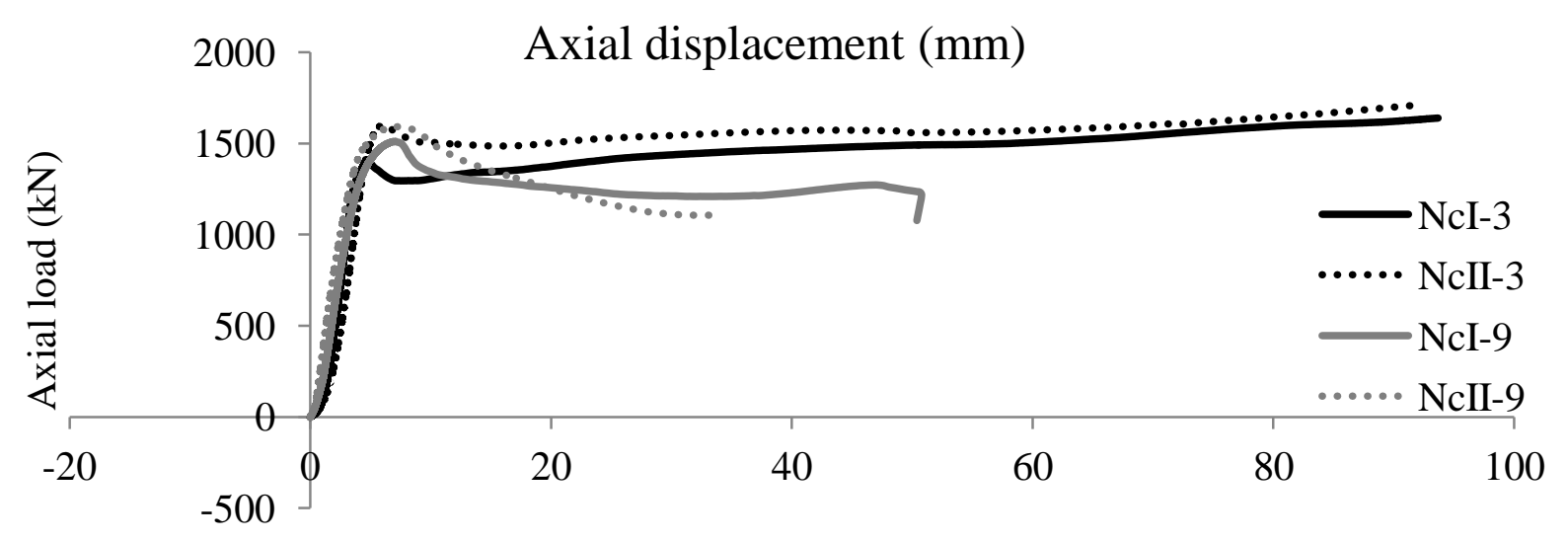

a) Axial load-displacement response for circular columns

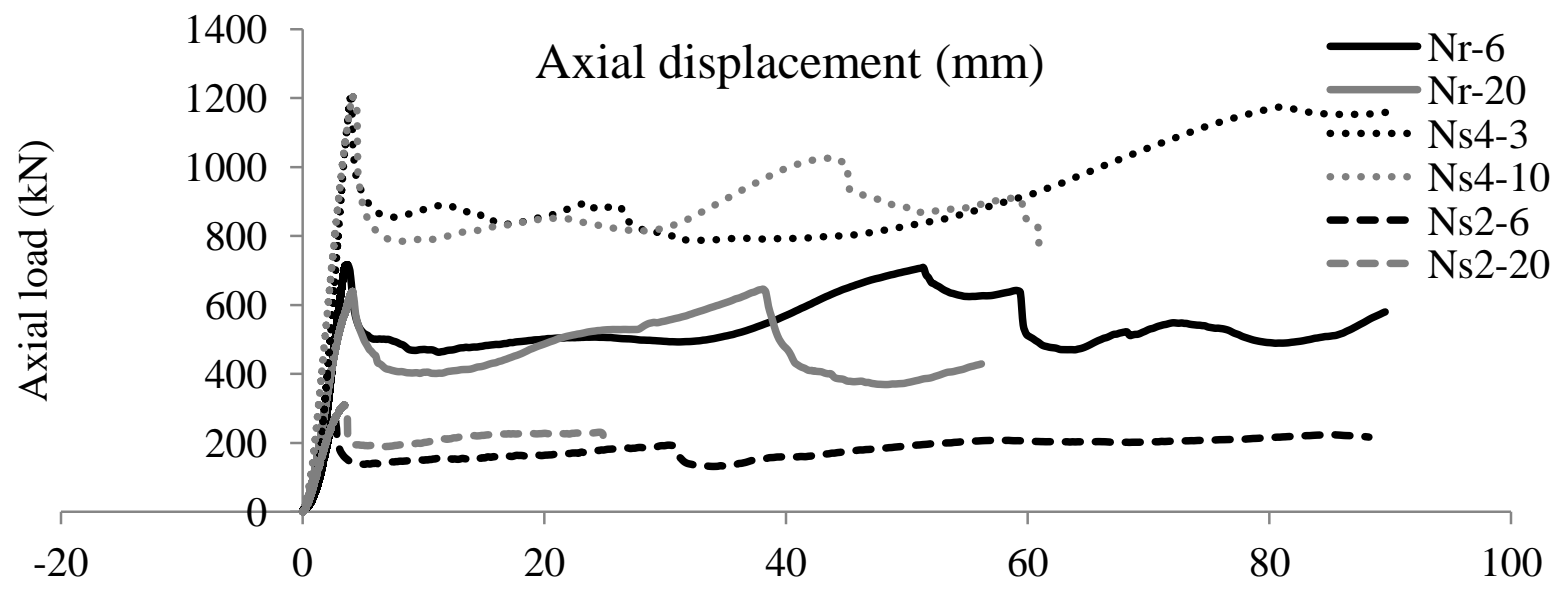

b) Axial load-displacement response for square and rectangular columns

Figure 5.3: Load-displacement responses of NC CFST columns

\subsubsection{Analysis of stress-strain behaviour in NC CFST columns}

Biaxial stress factors for NC-filled columns are shown in Table 5.2. Factors are used in analytical models to calculate confined strength and axial capacity of CFST columns. Biaxial 
stress factors vary with column type, shape, and slenderness, as well as with steel and concrete material properties. Since load is applied axially, $\beta$ is typically higher than $\alpha$.

Table 5.2: Biaxial stress factors in NC CFST columns

\begin{tabular}{ccccc}
\hline & Slenderness ratio & \multicolumn{3}{c}{ Stress concentration factors } \\
\hline Shape & L/D or L/d & $\alpha$ & $\beta$ \\
\hline cI & $3-9$ & $0.18-0.26$ & $0.88-0.82$ \\
cII & $3-9$ & $0.15-0.28$ & $0.90-0.81$ \\
r & $6-20$ & $0.11-0.05$ & $0.94-0.98$ \\
s4 & $3-10$ & $0.23-0.18$ & $0.87-0.90$ \\
s2 & $6-20$ & $0.20-0.17$ & $0.88-0.91$ \\
\hline
\end{tabular}

Table 5.3 applies confined strength models based on research from Richart et al. (1928), Mander et al. (1988), and O'Shea and Bridge (2000), and the model from Hossain (2003b) (Eqs. 4.11 through 4.14). Theoretical models are with experimental confinement for CFST columns infilled with NC.

Table 5.3: Validation of models for confined concrete strength: cI NC-filled columns

\begin{tabular}{|c|c|c|c|c|c|c|c|c|c|}
\hline \multirow{3}{*}{ Column } & \multicolumn{5}{|c|}{ Confined concrete strength $\left(\mathbf{f}^{\prime}{ }_{\mathrm{cc}}\right), \mathrm{MPa}$} & \multirow{2}{*}{\multicolumn{4}{|c|}{ Ratio Theoretical/Test }} \\
\hline & \multirow{2}{*}{ Test } & \multicolumn{4}{|c|}{ Theoretical models } & & & & \\
\hline & & $\begin{array}{l}\text { Eq. } \\
4.11\end{array}$ & $\begin{array}{l}\text { Eq. } \\
4.12\end{array}$ & $\begin{array}{l}\text { Eq. } \\
4.13\end{array}$ & $\begin{array}{l}\text { Eq. } \\
4.14\end{array}$ & $\begin{array}{l}\text { Eq. } \\
4.11\end{array}$ & $\begin{array}{l}\text { Eq. } \\
4.12\end{array}$ & $\begin{array}{l}\text { Eq. } \\
4.13\end{array}$ & $\begin{array}{l}\text { Eq. } \\
4.14\end{array}$ \\
\hline NeI-3 & 108 & 89 & 98 & 90 & 89 & 0.82 & 0.91 & 0.84 & 0.82 \\
\hline NeI-9 & 126 & 96 & 107 & 98 & 97 & 0.77 & 0.85 & 0.78 & 0.77 \\
\hline $\mathrm{Nr}-6$ & 92 & 79 & 86 & 80 & 82 & 0.86 & 0.93 & 0.87 & 0.88 \\
\hline $\mathrm{Nr}-20$ & 71 & 72 & 75 & 70 & 74 & 1.00 & 1.05 & 0.99 & 1.04 \\
\hline Ns4-3 & 92 & 85 & 93 & 86 & 85 & 0.92 & 1.01 & 0.94 & 0.92 \\
\hline Ns4-10 & 89 & 81 & 89 & 82 & 81 & 0.91 & 0.99 & 0.92 & 0.91 \\
\hline Ns2-6 & 73 & 83 & 92 & 85 & 88 & 1.14 & 1.25 & 1.16 & 1.21 \\
\hline Ns2-20 & 91 & 80 & 88 & 81 & 85 & 0.88 & 0.96 & 0.90 & 0.94 \\
\hline
\end{tabular}


In addition, Table 5.4 shows total confinement calculated from Eqs. 4.20, 4.21, and 4.22 in NCfilled CFST columns with bar reinforcements. Analytical models generally perform well for estimating confinement in NC-filled CFST columns.

Table 5.4: Validation of models for confined concrete strength: cII NC-filled columns

\begin{tabular}{|c|c|c|c|c|c|c|c|}
\hline \multirow[t]{3}{*}{ Column } & \multicolumn{4}{|c|}{ Confined concrete strength $\left(\mathbf{f}^{\prime}{ }_{\text {cct }}\right), \mathrm{MPa}$} & \multicolumn{3}{|c|}{ Ratio Theoretical/Test } \\
\hline & \multirow[t]{2}{*}{ Test } & \multicolumn{3}{|c|}{ Theoretical models } & & & \\
\hline & & Eq. 4.20 & Eq. 4.21 & Eq. 4.22 & Eq. 4.20 & Eq. 4.21 & Eq. 4.22 \\
\hline NcII-3 & 128 & 87 & 135 & 126 & 0.68 & 1.05 & 0.98 \\
\hline NcII-9 & 127 & 104 & 155 & 144 & 0.82 & 1.22 & 1.13 \\
\hline
\end{tabular}

\subsubsection{Identification of best model for NC CFST column strength prediction}

Tables 5.5 and 5.6 compare experimental and theoretical axial strength of CFST columns.

Table 5.5: Comparative study of NC-filled CFST strength prediction by analytical models

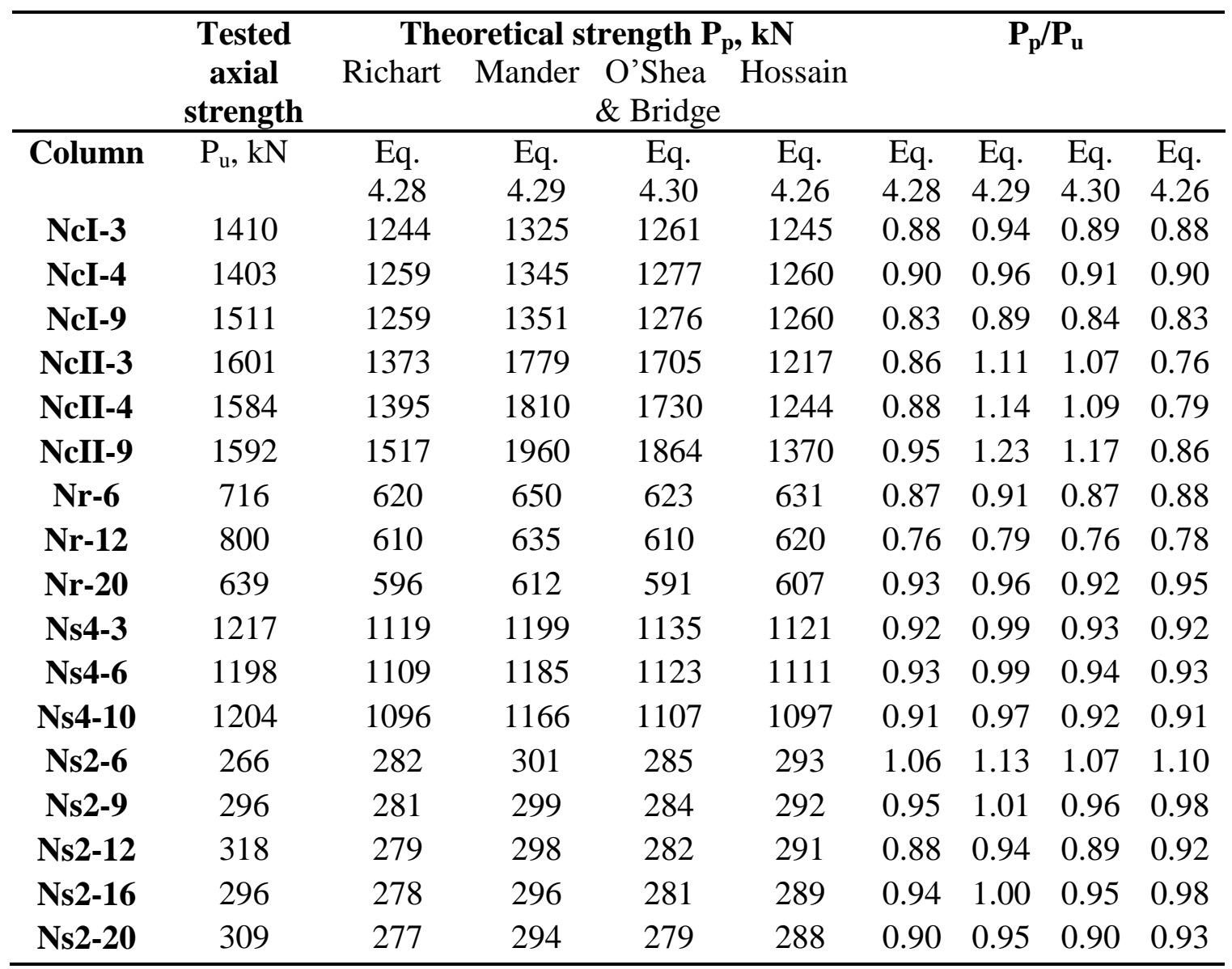


Table 5.5 shows calculated axial strength of NC-filled CFST columns using Eqs. 4.28, 4.29, and 4.30, and Eq. 4.26 from Hossain (2003b). The Richart et al.-based model (Eq. 4.28) proposed by Lachemi et al. (2006b) was considered more conservative, and was compared with code-based design equations in Table 5.6.

Table 5.6: NC-filled CFST column strength predictions from model and design codes

\begin{tabular}{cccccccccc}
\hline & $\begin{array}{c}\text { Tested } \\
\text { axial } \\
\text { strength }\end{array}$ & $\begin{array}{c}\text { Lachemi } \\
\text { Lachetical axial strength } \mathbf{P}_{\mathbf{p}}, \mathbf{k N} \\
\text { CSA }\end{array}$ & $\begin{array}{c}\text { AISC } \\
\text { Eurocode }\end{array}$ & & & $\mathbf{P}_{\mathbf{p}} / \mathbf{P}_{\mathbf{u}}$ & \\
Column & $\mathbf{P}_{\mathbf{u}}$, kN & Eq. 4.28 & Eq. 4.23 & Eq. 4.24 & Eq. 4.25 & Eq. & Eq. & Eq. & Eq. \\
& & & & & & 4.28 & 4.23 & 4.24 & 4.25 \\
NcI-3 & 1410 & 1244 & 1317 & 1076 & 1438 & 0.88 & 0.93 & 0.76 & 1.02 \\
NcI-4 & 1403 & 1259 & 1260 & 1063 & 1326 & 0.90 & 0.90 & 0.76 & 0.94 \\
NcI-9 & 1511 & 1259 & 1073 & 976 & 1193 & 0.83 & 0.71 & 0.65 & 0.79 \\
NcII-3 & 1601 & 1373 & 1316 & 1200 & 1561 & 0.86 & 0.82 & 0.75 & 0.98 \\
NcII-4 & 1584 & 1395 & 1260 & 1183 & 1452 & 0.88 & 0.80 & 0.75 & 0.92 \\
NcII-9 & 1592 & 1517 & 1168 & 1157 & 1393 & 0.95 & 0.73 & 0.73 & 0.87 \\
Nr-6 & 716 & 620 & 671 & 524 & 694 & 0.87 & 0.94 & 0.73 & 0.97 \\
Nr-12 & 800 & 610 & 598 & 497 & 628 & 0.76 & 0.75 & 0.62 & 0.79 \\
Nr-20 & 639 & 596 & 481 & 439 & 679 & 0.93 & 0.75 & 0.69 & 1.06 \\
Ns4-3 & 1217 & 1119 & 1107 & 898 & 1283 & 0.92 & 0.91 & 0.74 & 1.05 \\
Ns4-6 & 1198 & 1109 & 1043 & 882 & 1169 & 0.93 & 0.87 & 0.74 & 0.98 \\
Ns4-10 & 1204 & 1096 & 953 & 845 & 1107 & 0.91 & 0.79 & 0.70 & 0.92 \\
Ns2-6 & 266 & 282 & 204 & 193 & 295 & 1.06 & 0.77 & 0.73 & 1.11 \\
Ns2-9 & 296 & 281 & 259 & 270 & 507 & 0.95 & 0.87 & 0.91 & 1.71 \\
Ns2-12 & 318 & 279 & 216 & 234 & 598 & 0.88 & 0.68 & 0.74 & 1.88 \\
Ns2-16 & 296 & 278 & 267 & 224 & 297 & 0.94 & 0.90 & 0.76 & 1.00 \\
Ns2-20 & 309 & 277 & 177 & 176 & 337 & 0.90 & 0.57 & 0.57 & 1.09 \\
\hline
\end{tabular}

Table 5.6 shows calculated axial strength of NC-filled CFST columns from the Richart et al.based model proposed by Lachemi et al. (2006b) in Eq. 4.28 compared with design procedures from CSA (2009), AISC (2005), and Eurocode (2004) from Eqs. 4.23, 4.24, and 4.25 respectively. The Lachemi et al. (2006b) predicts axial capacity of NC-filled CFST columns 
closest to experimental results in most cases. Eurocode (2004) tends to over-estimate strength of square and rectangular columns in-filled with NC. The AISC (2005) is slightly conservative with $\mathrm{P}_{\mathrm{p}} / \mathrm{P}_{\mathrm{u}}$ ratios as low as 0.57 . Later chapters will evaluate performance of analytical and code-based equations when CFST columns are in-filled with various other types of concrete.

\subsection{Comparison of CFST columns with UHSC and NC}

Under axial compression, the load-displacement response and stress-strain characteristics of UHSC-filled tube columns are reported here. Performance of CFST with UHSC are compared with NC. Calculated values for confined concrete strength and axial capacity of CFST columns using analytical and code-based design equations are compared with experimental values.

\subsubsection{Axial load-displacement response and failure modes}

The effect of slenderness on axial load-displacement response of several tested circular, square, and rectangular CFST columns are shown in Figure 5.4. Columns with equal dimensions, differing only by concrete in-fill material of either NC or UHSC, are shown for cI, cII, r, s4, and s2 types. In every case, UHSC-filled CFST columns showed higher strength compared with corresponding NC-filled columns of the same type and shape, because of higher compressive strength $\left(\mathrm{f}_{\mathrm{c}}{ }_{\mathrm{c}}\right)$ of UHSC (127 MPa) compared to NC (66 MPa). However, the shapes of loaddisplacement curves are similar between CFST columns in-filled with different concretes. This suggests that UHSC filled columns can achieve comparable ductility as NC-filled CFST, and this is attributed to the presence of steel fibres (Khaloo et al., 2014). Similar trends are observed between NC and UHSC-filled columns of different cross-sectional shapes. Load decrease after first peak tends to decrease at a higher rate in rectangular CFST columns as illustrated in Figure 5.4b. In contrast, circular columns do not show significant decrease in axial load after the first 
peak is reached as shown Figure 5.4a. This suggests that rectangular CFST columns have the least ductility, while those with circular sections show greatest ductile behaviour.

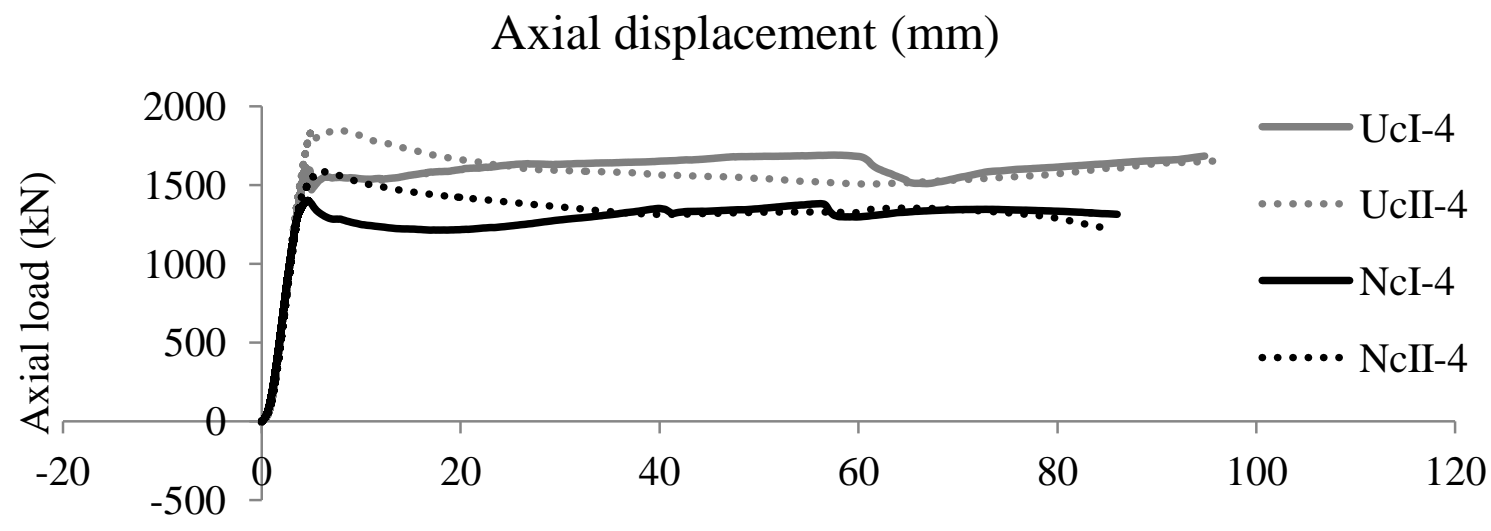

a) Axial load-displacement response for circular columns

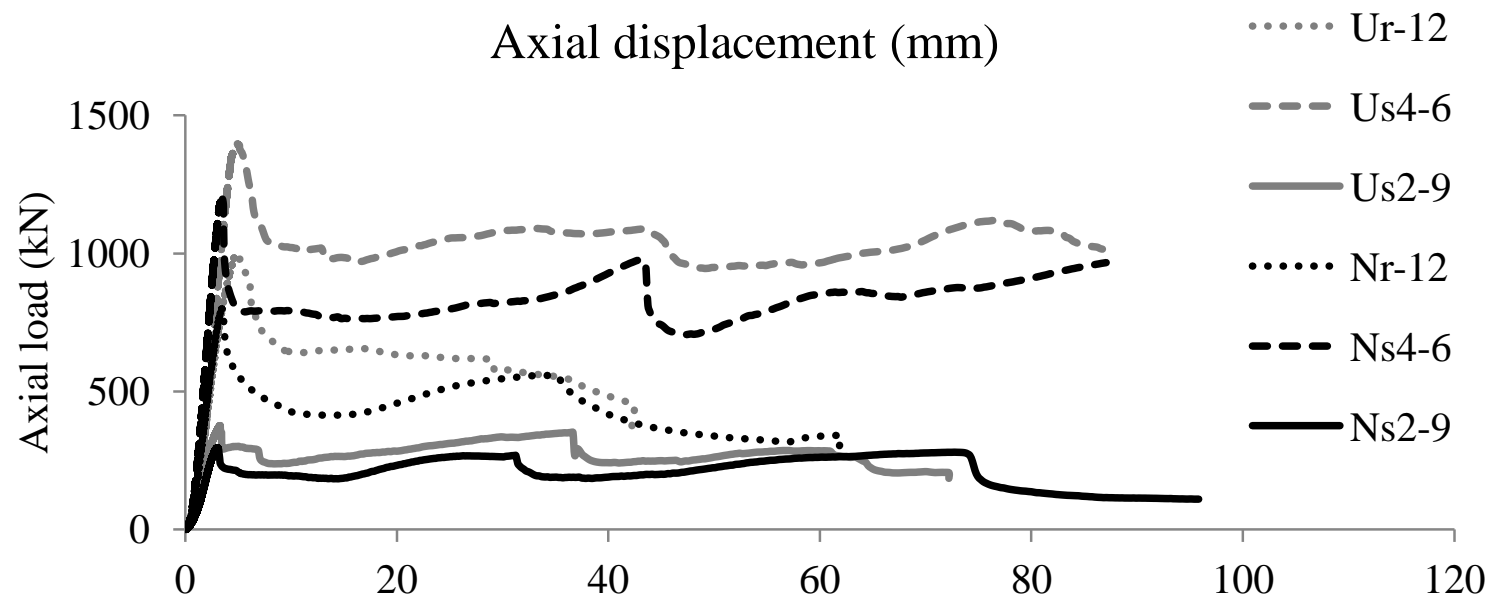

b) Axial load-displacement response for square and rectangular columns

Figure 5.4: Load-displacement responses of UHSC and NC CFST columns

UHSC-filled CFST columns after failure are shown in Figure 5.5 and failure modes are listed in Table 5.7. CFST columns with slenderness ratios of 3 failed by radial expansion as concrete pushed outwards against the steel tube causing the steel tube to take a barrel-like shape. Radial expansion often resulted in the steel tube eventually tearing at failure. CFST columns with slenderness ratio from 4 to 12 failed by local buckling or shear. Columns with slenderness ratio 
of 20 in-filled with NC mainly failed by shear, however, those in-filled with UHSC failed by global buckling.

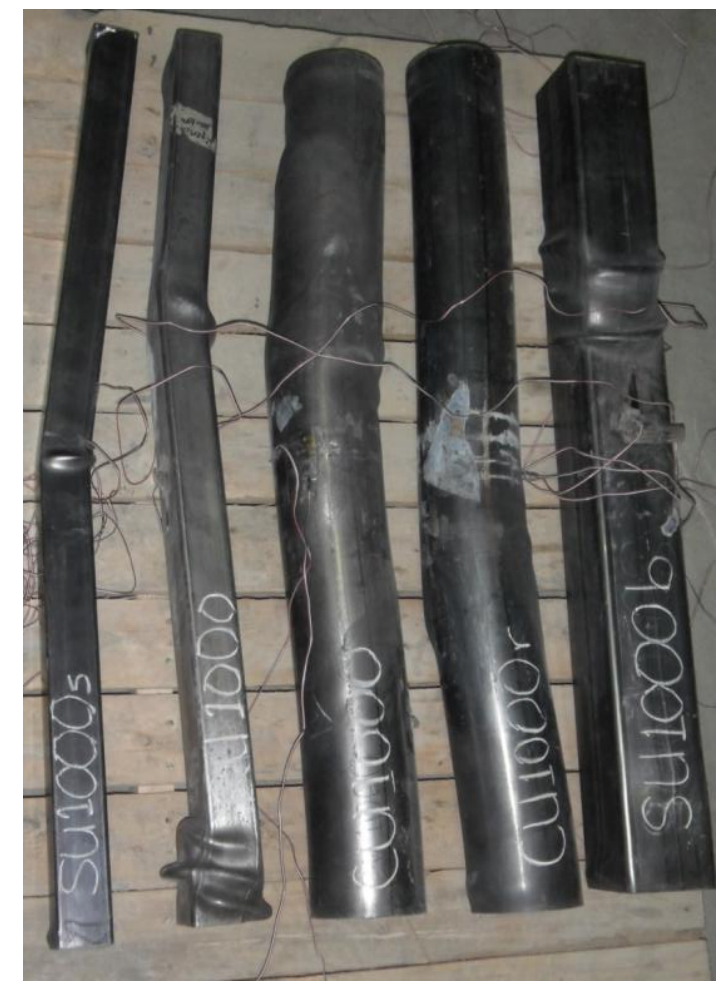

Us2-20 Ur-20 UcI-9 UcII-9 Us4-10

Figure 5.5: Failure modes of UHSC-filled CFST columns

Table 5.7 lists the axial capacities of UHSC and NC filled CFST columns $\left(\mathrm{P}_{\mathrm{u}, \text { UHSC }}\right.$ and $\mathrm{P}_{\mathrm{u}, \mathrm{NC}}$ respectively), where $\mathrm{P}_{\mathrm{u}}, \mathrm{UHSC} / \mathrm{P}_{\mathrm{u}, \mathrm{NC}}$ ratios are used to compare axial strength of columns that differ only by in-filled concrete. The ratio of UHSC to NC unconfined concrete cylinder compressive strength is 1.93 , where UHSC has almost double the compressive strength compared to NC. However, none of the UHSC filled tubes were able to achieve axial capacity 1.93 times that of CFST columns with NC. The highest $\mathrm{P}_{\mathrm{u}, \mathrm{UHSC}} / \mathrm{P}_{\mathrm{u}, \mathrm{NC}}$ ratio was 1.27 in square columns of $51 \mathrm{~mm}$ dimensions, and the short square $102 \mathrm{~mm}$ dimensions followed with $\mathrm{P}_{\mathrm{u}}$ $\mathrm{UHSC}_{\mathrm{u}} / \mathrm{P}_{\mathrm{NC}}$ ratio of 1.26 . These numbers indicate that increase of unconfined compressive 
strength $\left(\mathrm{f}^{\prime}{ }_{\mathrm{c}}\right)$ is not directly proportional to the increasing axial capacity of CFST columns due to the effects of concrete confinement. However, $\mathrm{P}_{\mathrm{u}}, \mathrm{UHSC} / \mathrm{P}_{\mathrm{u}}, \mathrm{NC}_{\mathrm{N}}$ ratios are higher in square and rectangular CFST columns compared with those of circular cross-section. This provides evidence that the effects of confinement are less prominent in CFST columns with square or rectangular cross-section.

Table 5.7: UHSC and NC CFST column capacity and concrete strength increase

\begin{tabular}{|c|c|c|c|c|c|}
\hline $\begin{array}{c}\text { Column } \\
\text { Designation } \\
\end{array}$ & $\begin{array}{c}\mathbf{P}_{\mathbf{u}, \mathbf{N C}}, \\
\mathbf{k N} \\
\end{array}$ & $\begin{array}{c}\text { Failure mode } \\
\text { (NC) }\end{array}$ & $\begin{array}{c}\mathbf{P}_{\mathbf{u}, \text { UHSC }}, \\
\mathbf{k N} \\
\end{array}$ & $\begin{array}{c}\begin{array}{c}\text { Failure mode } \\
\text { (UHSC) }\end{array} \\
\end{array}$ & $\begin{array}{c}\mathbf{P}_{\mathbf{u}, \text { uHSC }} \\
\mathbf{P}_{\mathbf{u}, \text { NC }} \\
\end{array}$ \\
\hline cI-3 & 1410 & Radial expansion & 1681 & Radial expansion & 1.19 \\
\hline cI-4 & 1403 & Shear & 1610 & Shear & 1.15 \\
\hline cI-9 & 1511 & Shear & 1573 & Shear & 1.04 \\
\hline cII-3 & 1601 & Radial expansion & 1853 & Radial expansion & 1.16 \\
\hline cII-4 & 1584 & Shear & 1849 & Shear & 1.17 \\
\hline cII-9 & 1592 & Shear & 1751 & Global buckling & 1.10 \\
\hline r-6 & 716 & Radial expansion & 809 & Shear & 1.13 \\
\hline r-12 & 800 & Plastic hinge & 987 & Shear & 1.23 \\
\hline $\mathbf{r}-20$ & 639 & Shear & 754 & Global buckling & 1.18 \\
\hline$s 4-3$ & 1217 & Radial expansion & 1535 & Radial expansion & 1.26 \\
\hline$s 4-6$ & 1198 & Local buckling & 1397 & Local buckling & 1.17 \\
\hline s4-10 & 1204 & Local buckling & 1446 & Local buckling & 1.20 \\
\hline s2-6 & 266 & Shear & 330 & Shear & 1.24 \\
\hline s2-9 & 296 & Shear & 376 & Shear & 1.27 \\
\hline s2-12 & 318 & Global buckling & 348 & Shear & 1.10 \\
\hline s2-16 & 296 & Shear & 366 & Global buckling & 1.24 \\
\hline s2-20 & 309 & Shear & 326 & Global buckling & 1.05 \\
\hline
\end{tabular}

\subsubsection{Analysis of stress-strain behaviour}

Figure 5.6 shows typical stress-strain development in the steel tube of columns in-filled with NC and UHSC. As expected, axial strain increases at earlier stages of loading, since load is applied 
in this direction. Transverse strain develops at later stages of loading when concrete begins to dilate. The strain development is similar between filled steel tube columns in-filled with NC and UHSC. However, strain in the NC-filled column began to increase at a lower axial load. This is reasonable, since compressive strength of NC is lower than that of UHSC.

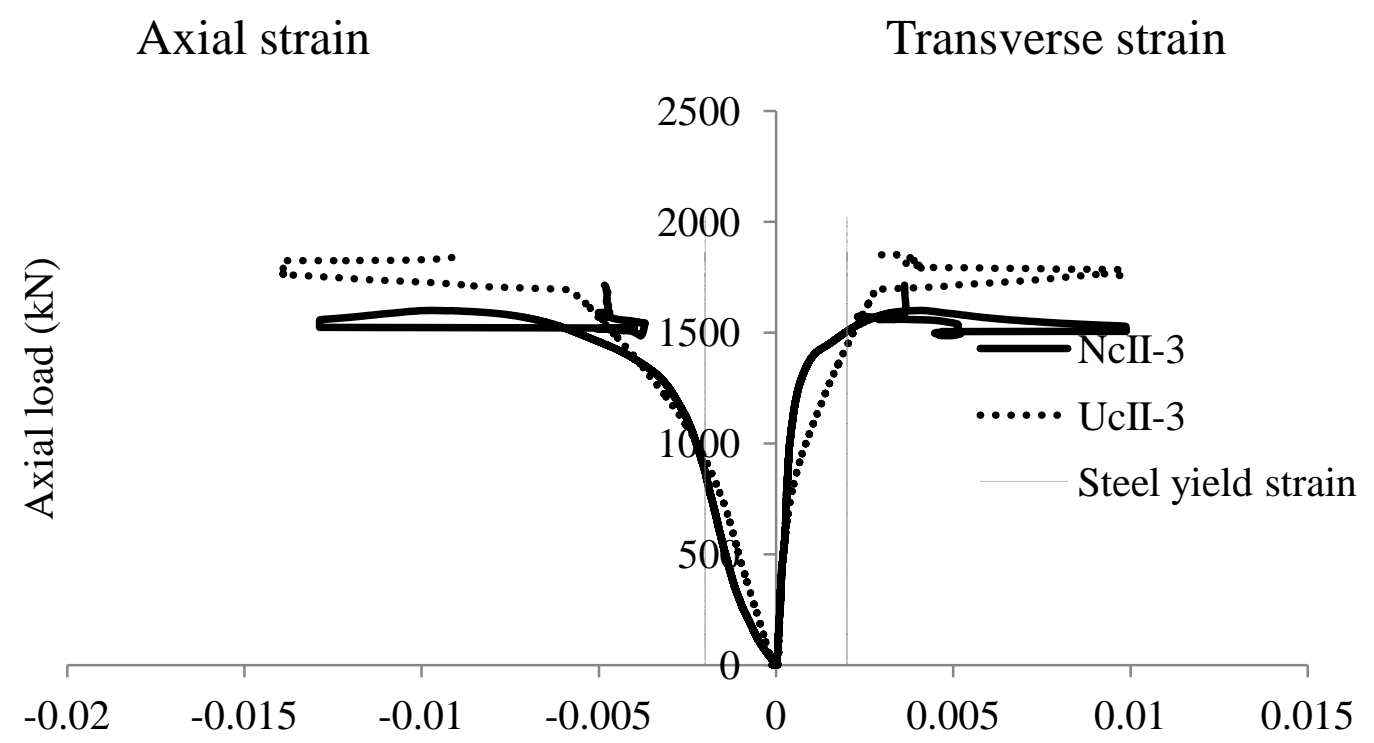

Figure 5.6: Strain development in steel tube of columns filled with UHSC and NC

Table 5.8 summarizes the ultimate axial load $\left(\mathrm{P}_{\mathrm{u}}\right)$, axial strain at ultimate axial load $\left(\varepsilon_{\mathrm{u}}\right)$, load at biaxial yielding $\left(\mathrm{P}_{\mathrm{ys}}\right)$, and axial strain at biaxial yielding $\left(\varepsilon_{\mathrm{ys}}\right)$ of tested CFST columns in-filled with UHSC or NC. The point of biaxial yielding where $\mathrm{P}_{\mathrm{ys}}$ and $\varepsilon_{\mathrm{ys}}$ are determined based on vonMises failure criterion described previously in Eq. 4.1. $\mathrm{P}_{\mathrm{ys}} / \mathrm{P}_{\mathrm{u}}$ ratios indicate that load at biaxial yielding can occur at as low as 0.15 times the axial strength of the CFST column (column Us43). Biaxial yielding often occurred at 0.65 or less of the axial capacity of CFST columns, indicating that yielding is not the final cause of failure of CFST columns. In all columns, steel yielded both uniaxially and biaxially before failure. Shorter columns had especially lower $\mathrm{P}_{\mathrm{ys}} / \mathrm{P}_{\mathrm{u}}$ ratios while the ratio for longer columns was higher, and ratios for NC-filled columns were 
almost always higher than those of UHSC-filled columns. These results show that shorter columns and those in-filled with NC have the ability to take on relatively larger amounts of additional load even after biaxial yielding occurs. $\varepsilon_{\mathrm{ys}} / \varepsilon_{\mathrm{u}}$ are always less than 1 , as biaxial yielding always occurred before axial capacity of the columns. It should be noted that strain values were often dependent on the type and direction of failure with respect to the strain gauge location.

Table 5.8: Observed steel yield in UHSC and NC CFST columns

\begin{tabular}{ccccccc}
\hline Column & $\mathbf{P}_{\mathbf{u}}, \mathbf{k N}$ & $\boldsymbol{\varepsilon}_{\mathbf{u}}$ & $\mathbf{P}_{\mathbf{y s}}, \mathbf{k N}$ & $\boldsymbol{\varepsilon}_{\mathbf{y s}}$ & $\mathbf{P}_{\mathbf{y s}} / \mathbf{P}_{\mathbf{u}}$ & $\boldsymbol{\varepsilon}_{\mathbf{y s}} / \boldsymbol{\varepsilon}_{\mathbf{u}}$ \\
\hline UcI-3 & 1681 & 0.004486 & 761 & 0.001682 & 0.45 & 0.37 \\
UcI-9 & 1573 & 0.010181 & 750 & 0.001600 & 0.48 & 0.16 \\
NcI-3 & 1410 & 0.006110 & 692 & 0.001663 & 0.49 & 0.27 \\
NcI-9 & 1511 & 0.004027 & 950 & 0.001555 & 0.63 & 0.39 \\
UcII-3 & 1853 & 0.009041 & 778 & 0.001594 & 0.42 & 0.18 \\
UcII-9 & 1751 & 0.009562 & 880 & 0.001757 & 0.50 & 0.18 \\
NcII-3 & 1601 & 0.009704 & 680 & 0.001708 & 0.42 & 0.18 \\
NcII-9 & 1592 & 0.003898 & 1038 & 0.001532 & 0.65 & 0.39 \\
Ur-6 & 809 & 0.004329 & 343 & 0.001514 & 0.42 & 0.35 \\
Ur-20 & 754 & 0.003912 & 446 & 0.001464 & 0.59 & 0.37 \\
Nr-6 & 716 & 0.003442 & 366 & 0.001485 & 0.51 & 0.43 \\
Nr-20 & 639 & 0.002560 & 404 & 0.001538 & 0.63 & 0.60 \\
Us4-3 & 1535 & 0.006991 & 224 & 0.001589 & 0.15 & 0.23 \\
Us4-10 & 1446 & 0.004261 & 505 & 0.001521 & 0.35 & 0.36 \\
Ns4-3 & 1217 & 0.003740 & 405 & 0.001490 & 0.33 & 0.40 \\
Ns4-10 & 1204 & 0.003073 & 679 & 0.001535 & 0.56 & 0.50 \\
Us2-6 & 330 & 0.002772 & 204 & 0.001551 & 0.62 & 0.56 \\
Us2-20 & 326 & 0.007134 & 195 & 0.001567 & 0.60 & 0.22 \\
Ns2-6 & 266 & 0.001844 & 211 & 0.001566 & 0.79 & 0.85 \\
Ns2-20 & 309 & 0.002617 & 178 & 0.001605 & 0.58 & 0.61 \\
\hline
\end{tabular}

$\mathrm{P}_{\mathrm{u}}$ : axial load capacity; $\varepsilon_{\mathrm{u}}$ : steel axial strain at axial load capacity; $\mathrm{P}_{\mathrm{ys}}$ : axial load at biaxial steel yielding; $\varepsilon_{y s}$ : axial strain at biaxial steel yielding.

Biaxial stress factors for UHSC filled columns are shown in Table 5.9. Similar to NC-filled tube columns, $\beta$ is always greater than $\alpha$. However, there is no obvious difference between UHSC and NC filled tube column biaxial stress factors. 
Table 5.9: Biaxial stress factors in UHSC CFST columns

\begin{tabular}{cccccc}
\hline & Slenderness ratio & \multicolumn{4}{c}{ Stress concentration factors } \\
\hline Shape & L/D or L/d & $\alpha$ & $\beta$ & $0.89-0.85$ \\
\hline cI & $3-9$ & $0.17-0.23$ & $0.84-0.93$ \\
cII & $3-9$ & $0.24-0.10$ & $0.96-0.93$ \\
r & $6-20$ & $0.07-0.13$ & $0.93-0.89$ \\
s4 & $3-10$ & $0.13-0.19$ & $0.88-0.89$ \\
s2 & $6-20$ & $0.21-0.20$ & &
\end{tabular}

Experimental confined concrete strength, $\mathrm{f}_{\mathrm{cc}}$, is obtained by stress-strain graphs (shown previously in Figure 4.3) at ultimate axial load of CFST columns. Values of $\mathrm{f}_{\mathrm{cc}}$ for UHSC and NC are listed in Table 5.10 along with corresponding unconfined concrete cylinder compressive strength $\left(f_{c}^{\prime}\right)$ in order to compare $f^{\prime}{ }_{c c} / f^{\prime}$ ratios. Ratios $f_{c c}^{\prime} / f_{c}^{\prime}$ are higher for NC compared with UHSC in columns with the same dimensions, and increase with increasing tube thickness. Thus the confinement effect is greater in NC-filled columns, as NC dilates more effectively. UHSC does not soften as readily, and is less effective in mobilizing the steel tube for strength enhancement ( $\mathrm{Yu}$ et al., 2008). It is also noted that CFST columns with bar reinforcements experience greater confinement due to the combined effect of hoops and tube.

In addition, $\mathrm{f}_{2 \max }$ (maximum lateral pressure) was calculated for each of the columns according to Eq. 4.7 and provided in Table 5.10. Calculations show significantly greater lateral pressure as expected in columns with reinforcements (cII) in addition to lateral pressure acting on the steel tube. 
Table 5.10: Quantified concrete confined strength and lateral pressure in UHSC and NC CFST columns

\begin{tabular}{|c|c|c|c|c|}
\hline Column & $\mathbf{f}_{c}^{\prime}, \mathbf{M P a}$ & $\mathbf{f}_{\text {cc, }}^{\prime}, \mathbf{M P a}$ & $\mathbf{f}^{\prime}{ }_{c c} / f^{\prime}{ }_{c}$ & $\mathbf{f}_{2 \max }, \mathrm{MPa}$ \\
\hline UcI-3 & 127 & 139 & 1.09 & 5.2 \\
\hline UcI-9 & 127 & 125 & 0.99 & 7.0 \\
\hline NcI-3 & 66 & 108 & 1.64 & 5.6 \\
\hline NeI-9 & 66 & 126 & 1.91 & 8.0 \\
\hline UcII-3 & 127 & 161 & 1.27 & 108.0 \\
\hline UcII-9 & 127 & 140 & 1.11 & 97.3 \\
\hline NcII-3 & 66 & 128 & 1.96 & 115.3 \\
\hline NcII-9 & 66 & 127 & 1.94 & 109.3 \\
\hline Ur-6 & 127 & 113 & 0.89 & 2.2 \\
\hline Ur-20 & 127 & 102 & 0.81 & 4.1 \\
\hline Nr-6 & 66 & 92 & 1.41 & 3.3 \\
\hline Nr-20 & 66 & 71 & 1.09 & 1.5 \\
\hline Us4-3 & 127 & 124 & 0.98 & 2.7 \\
\hline Us4-10 & 127 & 117 & 0.92 & 4.0 \\
\hline Ns4-3 & 66 & 92 & 1.40 & 4.7 \\
\hline Ns4-10 & 66 & 89 & 1.36 & 3.8 \\
\hline Us2-6 & 127 & 102 & 0.80 & 4.5 \\
\hline Us2-20 & 127 & 99 & 0.78 & 4.3 \\
\hline Ns2-6 & 66 & 73 & 1.11 & 4.3 \\
\hline Ns2-20 & 66 & 91 & 1.38 & 3.6 \\
\hline $\begin{array}{r}\mathrm{f}_{\mathrm{c}} \text { : unconfin } \\
\text { experimen }\end{array}$ & $\begin{array}{l}\text { crete co } \\
\text { ined co }\end{array}$ & $\begin{array}{l}\text { ol cylinder } \\
\text { ete strengt } \\
\text { stress. }\end{array}$ & mpressi & $\begin{array}{l}\text { strength; } \mathrm{f}_{\mathrm{cc}} \text { : } \\
\text { num lateral }\end{array}$ \\
\hline
\end{tabular}

Three models for total confinement in CFST columns proposed by Lachemi et al. (2006b) based on the work of Richart et al. (1928), Mander et al. (1988), O'Shea and Bridge (2000) provided in Eqs. $4.20,4.21$, and 4.22 respectively are used to determine $\mathrm{f}^{\prime}$ cct in Table 5.11. Eq. 4.14 from Hossain (2003b) is also applied in Table 5.11 for considering tube confinement only. Calculated $\mathrm{f}^{\prime}{ }_{\text {cct }}$ is compared with experimental values by theoretical/test ratios. Theoretical/test ratios for total confinement of shorter NC-filled CFST columns are generally quite close to a value of 1 , indicating that all four models perform well for these cases. On the other hand, theoretical/test 
ratios for UHSC-filled CFST columns were often over-estimated, especially as slenderness increased. The four models were not developed for CFST columns with higher slenderness, since these columns typically fail due to global instability. The Mander et al.-based and O'Shea and Bridge-based models yielded $\mathrm{f}_{\text {cct }}$ values that were especially greater than experimental confinement. This may be attributed to the assumption from these two models that confined strength is directly proportional to concrete compressive strength. However, this was found not to be the case for UHSC-filled CFST columns. Thus, Richart et al.-based and Hossain (2003b) models, which did not assume direct proportionality between unconfined strength and total confinement, performed better. In general, analytical models for total confinement performed best in estimating confined strength of circular and square CFST columns with slenderness of 3.

Table 5.11: Validation of models for confined concrete strength in UHSC-filled CFST columns

\begin{tabular}{|c|c|c|c|c|c|c|c|c|c|}
\hline \multirow{3}{*}{ Column } & \multicolumn{5}{|c|}{$\begin{array}{c}\text { Confined concrete strength }\left(\mathbf{f}^{\prime}{ }{ }^{\prime}\right) \text {, } \\
\mathrm{MPa}\end{array}$} & \multirow{2}{*}{\multicolumn{4}{|c|}{ Ratio Theoretical/Test }} \\
\hline & \multicolumn{5}{|c|}{ Theoretical models } & & & & \\
\hline & Test & $\begin{array}{l}\text { Eq. } \\
4.20\end{array}$ & $\begin{array}{l}\text { Eq. } \\
4.21\end{array}$ & $\begin{array}{l}\text { Eq. } \\
4.22\end{array}$ & $\begin{array}{c}\text { Eq. } \\
4.14\end{array}$ & $\begin{array}{l}\text { Eq. } \\
4.20\end{array}$ & $\begin{array}{l}\text { Eq. } \\
4.21\end{array}$ & $\begin{array}{l}\text { Eq. } \\
4.22\end{array}$ & $\begin{array}{l}\text { Eq. } \\
4.14\end{array}$ \\
\hline UcI-3 & 139 & 148 & 160 & 149 & 149 & 1.07 & 1.15 & 1.07 & 1.07 \\
\hline UcI-9 & 125 & 156 & 170 & 158 & 156 & 1.24 & 1.36 & 1.26 & 1.24 \\
\hline UcII-3 & 161 & 158 & 246 & 231 & 149 & 0.98 & 1.52 & 1.43 & 0.92 \\
\hline UcII-9 & 140 & 140 & 220 & 208 & 156 & 1.00 & 1.57 & 1.48 & 1.11 \\
\hline Ur-6 & 113 & 136 & 142 & 133 & 141 & 1.21 & 1.26 & 1.18 & 1.25 \\
\hline Ur-20 & 102 & 144 & 153 & 143 & 148 & 1.41 & 1.50 & 1.40 & 1.45 \\
\hline Us4-3 & 124 & 138 & 145 & 136 & 138 & 1.11 & 1.16 & 1.09 & 1.11 \\
\hline Us4-10 & 117 & 143 & 153 & 142 & 143 & 1.23 & 1.31 & 1.22 & 1.23 \\
\hline Us2-6 & 102 & 145 & 156 & 145 & 155 & 1.43 & 1.53 & 1.43 & 1.52 \\
\hline Us2-20 & 99 & 144 & 154 & 144 & 154 & 1.45 & 1.55 & 1.45 & 1.55 \\
\hline
\end{tabular}




\subsubsection{Identification of best model for UHSC CFST column strength prediction}

CFST axial strength models proposed by Lachemi et al. (2006b) based on Richart et al. (1928), Mander et al. (1988), and O'Shea and Bridge (2000) were used to estimate axial capacity of CFST columns using Eqs. 4.28, 4.29, and 4.30 respectively. Eq. 4.26, the model for axial strength of CFST columns proposed by Hossain (2003b) was also applied to columns tested. Theoretical models were compared with experimental strength of UHSC and NC filled CFST columns by $\mathrm{P}_{\mathrm{p}} / \mathrm{P}_{\mathrm{u}}$ ratios in Table 5.12. Although all models performed well for estimating strength of NC-filled CFST columns of different shapes and configurations, they generally overestimated the axial strength of UHSC-filled CFST columns.

Table 5.12: Comparative study of UHSC-filled CFST column strength prediction by analytical models

\begin{tabular}{cccccccccc}
\hline & $\begin{array}{c}\text { Tested } \\
\text { axial } \\
\text { strength }\end{array}$ & \multicolumn{9}{c}{$\begin{array}{c}\text { Theoretical strength } \mathbf{P}_{\mathbf{p}}, \mathbf{k N} \\
\text { Richart Mander } \mathbf{O} \text { O'Shea } \mathbf{H o s s a i n} \\
\text { \&Bridge }\end{array}$} & \multicolumn{3}{c}{$\mathbf{P}_{\mathbf{p}} / \mathbf{P}_{\mathbf{u}}$} \\
\\
\hline Column & $\mathbf{P}_{\mathbf{u}}$, $\mathbf{k N}$ & Eq. & Eq. & Eq. & Eq. & Eq. & Eq. & Eq. & Eq. \\
& & 4.28 & 4.29 & 4.30 & 4.26 & 4.28 & 4.29 & 4.30 & 4.26 \\
UcI-3 & 1681 & 1764 & 1864 & 1768 & 1766 & 1.05 & 1.11 & 1.05 & 1.05 \\
UcI-4 & 1610 & 1776 & 1883 & 1785 & 1778 & 1.10 & 1.17 & 1.11 & 1.10 \\
UcI-9 & 1573 & 1805 & 1929 & 1823 & 1808 & 1.15 & 1.23 & 1.16 & 1.15 \\
UcII-3 & 1853 & 1950 & 2705 & 2576 & 1809 & 1.05 & 1.46 & 1.39 & 0.98 \\
UcII-4 & 1849 & 1916 & 2655 & 2533 & 1779 & 1.04 & 1.44 & 1.37 & 0.96 \\
UcII-9 & 1751 & 1840 & 2530 & 2427 & 1703 & 1.05 & 1.45 & 1.39 & 0.97 \\
Ur-6 & 809 & 874 & 899 & 860 & 895 & 1.08 & 1.11 & 1.06 & 1.11 \\
Ur-12 & 987 & 885 & 917 & 876 & 905 & 0.90 & 0.93 & 0.89 & 0.92 \\
Ur-20 & 754 & 899 & 941 & 896 & 920 & 1.19 & 1.25 & 1.19 & 1.22 \\
Us4-3 & 1535 & 1633 & 1695 & 1610 & 1635 & 1.06 & 1.10 & 1.05 & 1.06 \\
Us4-6 & 1397 & 1646 & 1720 & 1630 & 1649 & 1.18 & 1.23 & 1.17 & 1.18 \\
Us4-10 & 1446 & 1665 & 1751 & 1657 & 1667 & 1.15 & 1.21 & 1.15 & 1.15 \\
Us2-6 & 330 & 424 & 448 & 423 & 445 & 1.28 & 1.36 & 1.28 & 1.35 \\
Us2-9 & 376 & 423 & 447 & 423 & 445 & 1.13 & 1.19 & 1.12 & 1.18 \\
Us2-12 & 348 & 423 & 446 & 422 & 445 & 1.22 & 1.28 & 1.21 & 1.28 \\
Us2-16 & 366 & 423 & 446 & 422 & 444 & 1.15 & 1.22 & 1.15 & 1.21 \\
Us2-20 & 326 & 422 & 445 & 421 & 444 & 1.29 & 1.36 & 1.29 & 1.36 \\
\hline
\end{tabular}


As mentioned before, models were not developed to account for global instability failures, therefore performance worsened as slenderness of CFST columns increased. For both NC and UHSC filled tube columns, the Mander et al.-based and O'Shea and Bridge-based strength models tended to over-estimate axial capacity to a greater degree. Hossain (2003b) and Richart et al.-based models yielded similar results. Comparatively, the Richart et al.-based model was slightly more conservative, and considered safer.

The Richart et al.-based strength model proposed by Lachemi et al. (2006b) from Eq. 4.28 was then compared with code-based design equations from CSA (2009), AISC (2005), and Eurocode (2004) (Eqs. 4.23, 4.24, and 4.25 respectively) in Table 5.13.

Table 5.13: UHSC-filled CFST column strength predictions from model and design codes

\begin{tabular}{cccccc}
\hline & $\begin{array}{c}\text { Tested } \\
\text { axial } \\
\text { strength }\end{array}$ & Lachemi & $\begin{array}{c}\text { Theoretical axial strength } \mathbf{P}_{\mathbf{p}}, \mathbf{k N} \\
\text { AISC }\end{array}$ & Eurocode \\
\hline Column & $\mathbf{P}_{\mathbf{u}}, \mathbf{k N}$ & Eq. 4.28 & Eq. 4.23 & Eq. 4.24 & Eq. 4.25 \\
UcI-3 & 1681 & 1764 & 1624 & 1569 & 2029 \\
UcI-4 & 1610 & 1776 & 1564 & 1541 & 1913 \\
UcI-9 & 1573 & 1805 & 1382 & 1417 & 1858 \\
UcII-3 & 1853 & 1950 & 1624 & 1692 & 2155 \\
UcII-4 & 1849 & 1916 & 1564 & 1660 & 2039 \\
UcII-9 & 1751 & 1840 & 1382 & 1516 & 1984 \\
Ur-6 & 809 & 874 & 825 & 743 & 991 \\
Ur-12 & 987 & 885 & 739 & 690 & 956 \\
Ur-20 & 754 & 899 & 577 & 578 & 1115 \\
Us4-3 & 1535 & 1633 & 1434 & 1370 & 1925 \\
Us4-6 & 1397 & 1646 & 1366 & 1334 & 1809 \\
Us4-10 & 1446 & 1665 & 1252 & 1251 & 1791 \\
Us2-6 & 330 & 424 & 347 & 337 & 456 \\
Us2-9 & 376 & 423 & 326 & 322 & 452 \\
Us2-12 & 348 & 423 & 300 & 303 & 458 \\
Us2-16 & 366 & 423 & 249 & 218 & 282 \\
Us2-20 & 326 & 422 & 231 & 209 & 283 \\
\hline
\end{tabular}


Ratios between theoretical models and experimental results are compared in Figure 5.7. Despite performing well in estimating strength of NC-filled CFST columns, the Lachemi et al. (2006b) model based on the work of Richart et al. (1928) from Eq. 4.28 was found to overestimate strength of UHSC-filled steel tube columns. On the other hand, the AISC (2005) code from Eq. 4.24 which was found to be conservative when estimating strength of NC-filled CSFT columns was capable of predicting axial strength of UHSC-filled CFST columns well. Models which converted sectional shape of CFST columns to an equivalent circle instead of accounting for shape differences, namely the Lachemi et al. (2006b) model, CSA (2009) from Eq. 4.23, and Eurocode (2004) from E1. 4.25, tended to especially over-predict strength of rectangular and square CFST columns in-filled with UHSC. Thus, the AISC (2005) code equation was comparably more suitable for applications with UHSC-filled CFST columns, and those of square and rectangular cross-sectional shape.

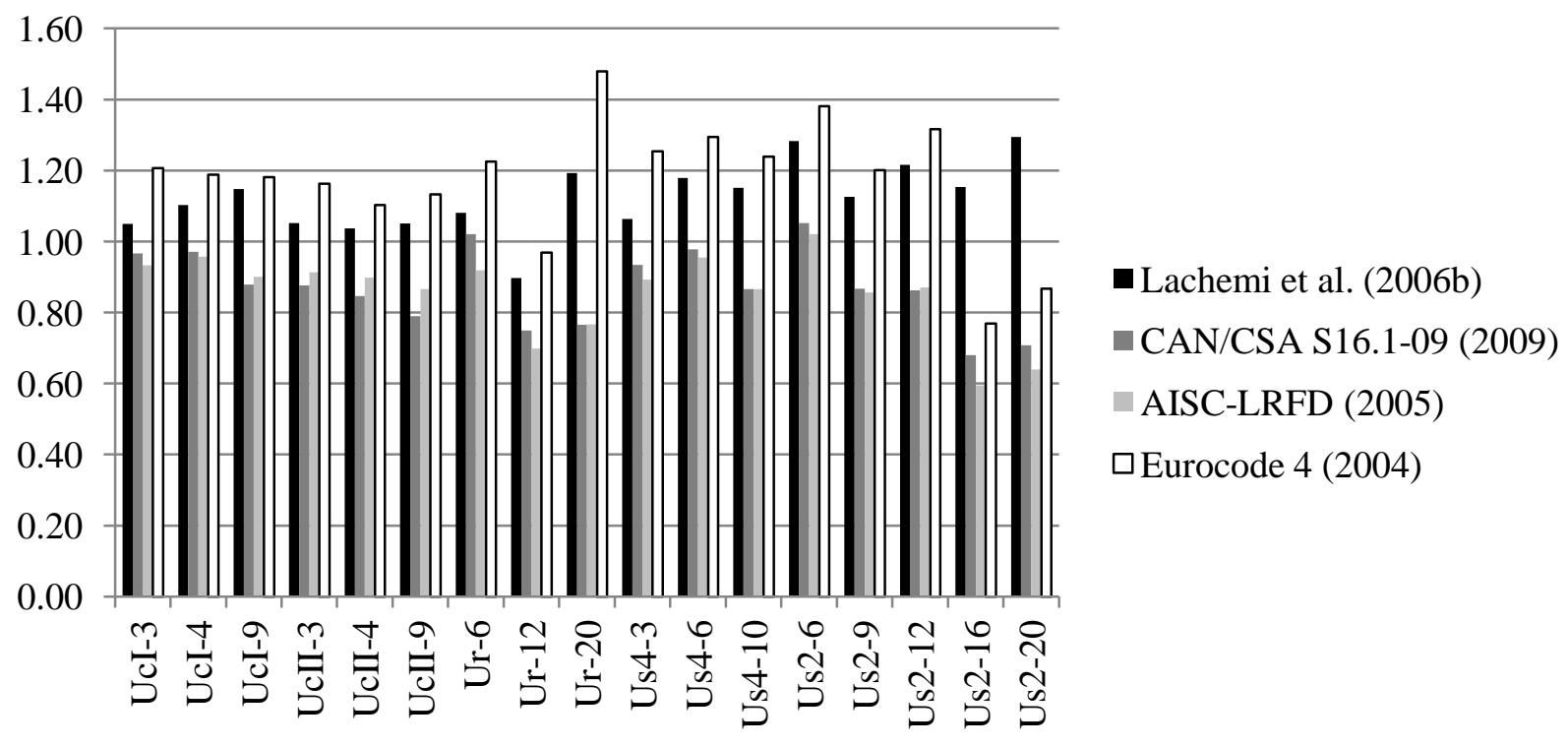

Figure 5.7: Performance of model for prediction of UHSC-filled CFST column strength 


\subsection{Comparison of CFST columns with ECC and NC}

Under axial compression, the load-displacement response and stress-strain characteristics of ECC-filled tube columns are reported here. Performance of CFST with ECC are compared with NC. Calculated values for confined concrete strength and axial capacity of CFST columns using analytical and code-based design equations are compared with experimental values.

\subsubsection{Axial load-displacement response and failure modes}

The effect of slenderness on axial load displacement response of selected ECC and NC CFST columns are shown in Figure 5.8. Since typical unconfined compressive strength $\left(\mathrm{f}_{\mathrm{c}}\right)$ of ECC is lower than that of the NC (50 MPa and $66 \mathrm{MPa}$, respectively), the strength of ECC-filled CFST columns was less than their NC-filled counterparts. Graphs for circular specimens shown in Figure 5.8a have relatively rounded first peak, suggesting rather ductile behaviour. Square columns show a relatively sharp first peak in load-displacement curves, followed by a comparably flat plateau in Figure 5.8b. The shapes of load displacement graphs are similar between rectangular and square CFST columns (shown in Figure 5.8b). However, load displacement graphs for CFST columns did not take the same shape in NC and ECC-filled tubes. The first peak load was often relatively less prominent in ECC-filled CFST columns, suggesting greater ductility. 


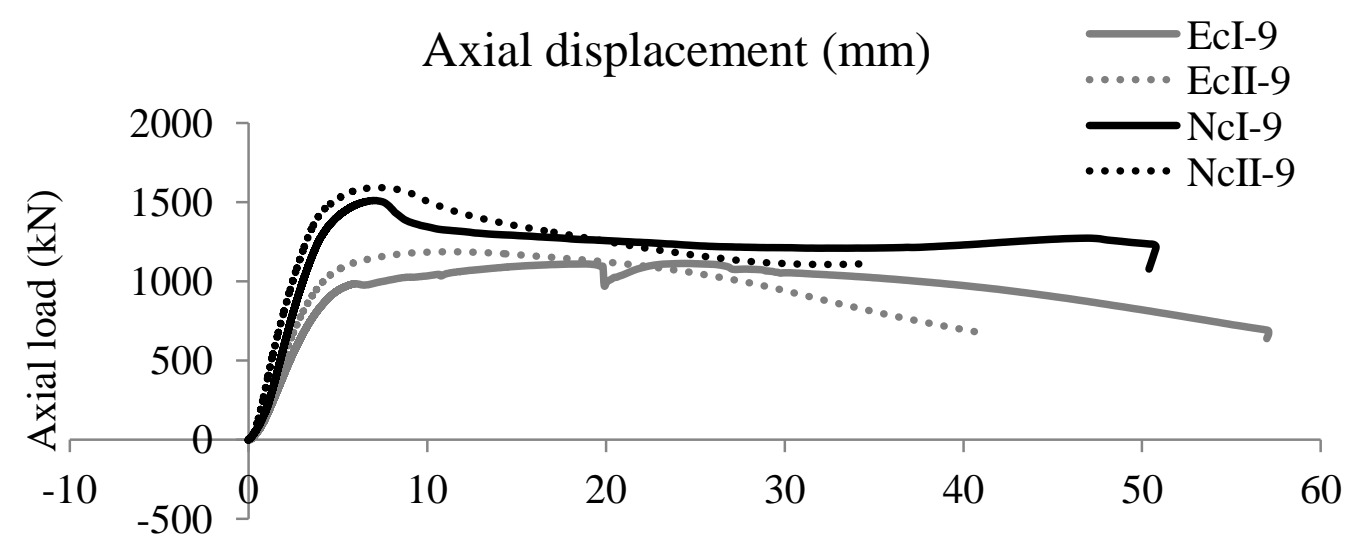

a) Axial load-displacement response for circular columns

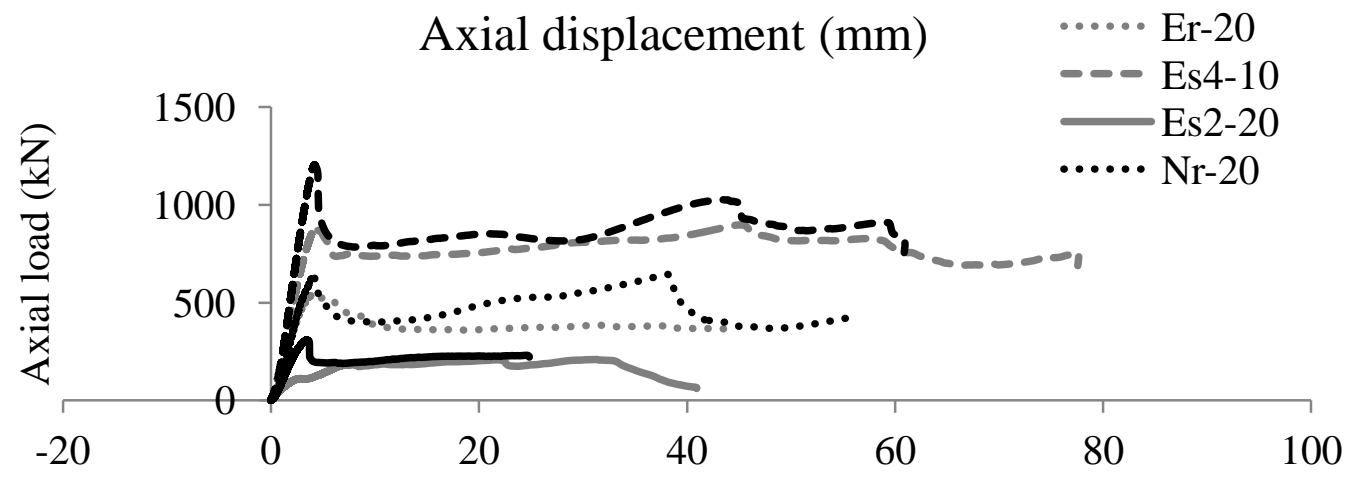

b) Axial load-displacement response for square and rectangular columns

Figure 5.8: Load-displacement responses of ECC and NC CFST columns

ECC-filled CFST columns after failure are shown in Figure 5.9. Axial load capacity of NC-filled columns $\left(\mathrm{P}_{\mathrm{u}, \mathrm{NC}}\right.$ and ECC CFST $\left(\mathrm{P}_{\mathrm{u}, \mathrm{ECC}}\right)$ are provided in Table 5.14 with corresponding failure modes listed. $\mathrm{P}_{\mathrm{u}, \mathrm{ECC}} / \mathrm{P}_{\mathrm{u}, \mathrm{NC}}$ ratios are used to compare the axial strength of columns with the same dimensions that only differ by concrete in-fill. ECC-filled columns with slenderness ranging from 4 to 20 failed by local or global buckling in most cases. However, NC-filled columns with slenderness of the same range failed most often due to shear. These observations suggest that stress concentrations often occur in NC-filled CFST columns, while ECC-filled columns are able to better distribute loads throughout the column height. Columns with slenderness ratio of 3 failed by radial expansion, whether in-filled with NC or ECC. 


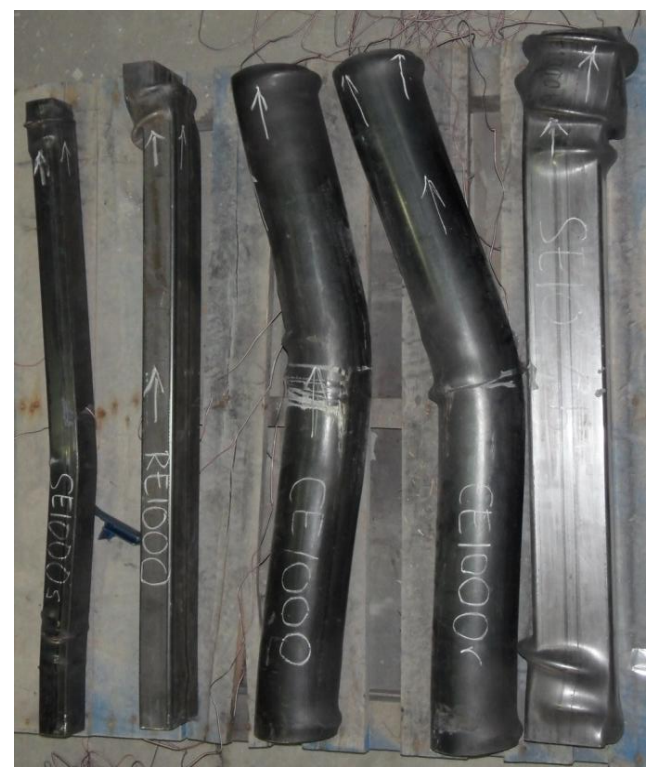

Es2-20 Er-20 EcI-9 EcII-9 Es4-10

Figure 5.9: Failure modes of ECC-filled CFST columns

Table 5.14: ECC and NC CFST column capacity and concrete strength increase

\begin{tabular}{|c|c|c|c|c|c|}
\hline $\begin{array}{c}\text { Column } \\
\text { Designation }\end{array}$ & $\begin{array}{c}\mathbf{P}_{\mathbf{u}, \mathbf{N C}}, \\
\mathbf{k N}\end{array}$ & $\begin{array}{c}\text { Failure mode } \\
\text { (NC) }\end{array}$ & $\begin{array}{c}\mathbf{P}_{\mathrm{u}, \mathrm{ECC}} \\
\mathbf{k N}\end{array}$ & $\begin{array}{c}\text { Failure mode } \\
\text { (ECC) }\end{array}$ & $\begin{array}{c}\mathbf{P}_{\mathrm{u}, \mathrm{ECC}} \\
\mathbf{P}_{\mathrm{u}, \mathrm{NC}} \\
\end{array}$ \\
\hline cI-3 & 1410 & Radial expansion & 1027 & Radial expansion & 0.73 \\
\hline cI-4 & 1403 & Shear & 1059 & Local buckling & 0.75 \\
\hline cI-9 & 1511 & Shear & 1113 & Global buckling & 0.74 \\
\hline cII-3 & 1601 & Radial expansion & 801 & Radial expansion & 0.50 \\
\hline cII-4 & 1584 & Shear & 794 & Global buckling & 0.50 \\
\hline cII-9 & 1592 & Shear & 1186 & Global buckling & 0.74 \\
\hline r-6 & 716 & Radial expansion & 480 & Local buckling & 0.67 \\
\hline r-12 & 800 & Plastic hinge & 578 & Shear & 0.72 \\
\hline r-20 & 639 & Shear & 539 & Shear & 0.84 \\
\hline$s 4-3$ & 1217 & Radial expansion & 941 & Radial expansion & 0.77 \\
\hline$s 4-6$ & 1198 & Local buckling & 833 & Local buckling & 0.70 \\
\hline s4-10 & 1204 & Local buckling & 886 & Local buckling & 0.74 \\
\hline s2-6 & 266 & Shear & 176 & Local buckling & 0.66 \\
\hline s2-9 & 296 & Shear & 190 & Local buckling & 0.64 \\
\hline s2-12 & 318 & Global buckling & 175 & Global buckling & 0.55 \\
\hline s2-16 & 296 & Shear & 181 & Plastic hinge & 0.61 \\
\hline s2-20 & 309 & Shear & 184 & Global buckling & 0.59 \\
\hline & & $\begin{array}{r}\text { lled CFST } \\
\text { CFS }\end{array}$ & $\begin{array}{l}\text { ns; P } \\
\text { nns. }\end{array}$ & Axial strength & C-fill \\
\hline
\end{tabular}


ECC control cylinder compressive strength was 0.76 times that of NC. However, $\mathrm{P}_{\mathrm{u}}$, ECC $/ \mathrm{P}_{\mathrm{u}}$, NC ratios show that most ECC-filled CFST columns achieved strength less than 0.76 times that of NC-filled CFST columns of the same height and sectional shape. Thus, the increase in axial strength of CFST columns was not directly proportional to ECC compressive strength due to the effects from concrete confinement.

\subsubsection{Analysis of stress-strain behaviour}

Figure 5.10 shows typical steel tube strain development of columns in-filled with ECC and NC, taking specimens NcI-3 and EcI-3 as examples.

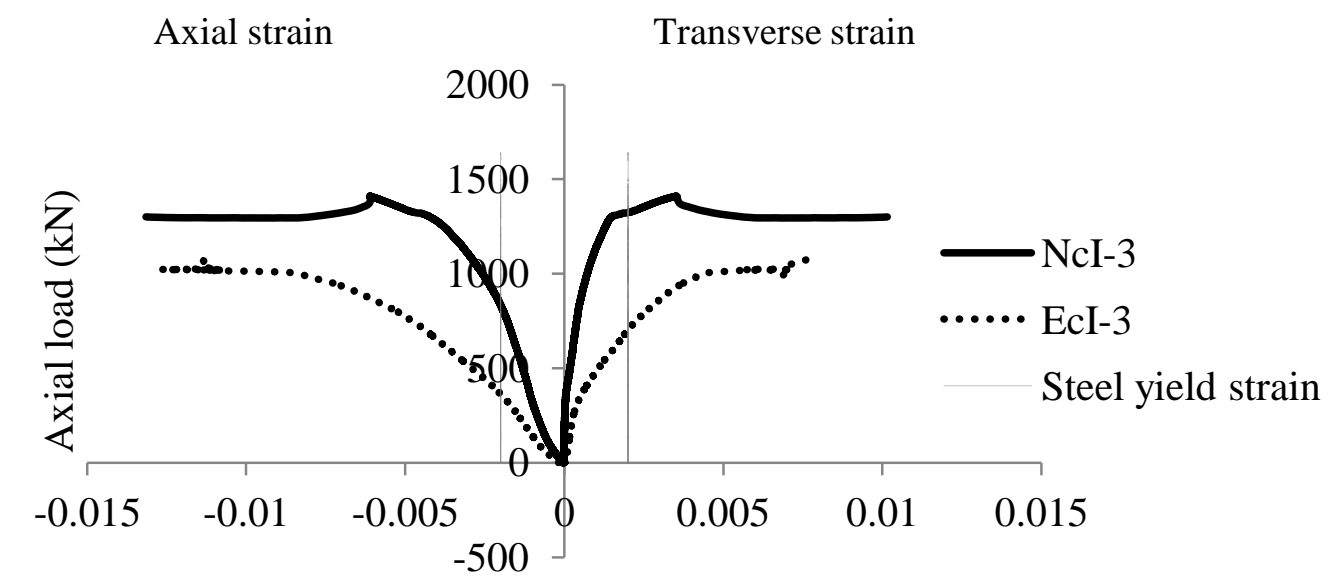

Figure 5.10: Strain development in steel tube of columns filled with ECC and NC

A significant difference is observed between strain in steel tube of columns in-filled with ECC and NC. The ECC-filled steel tube experiences large axial and transverse strain even under small load. This may be due to high deformation capacity which is characteristic of ECC.

The point of steel yielding is determined based on the von-Mises failure criterion previously explained in Eq. 4.1. Strain and load values at biaxial yielding $\left(\varepsilon_{y \mathrm{~s}}\right.$ and $\left.\mathrm{P}_{\mathrm{ys}}\right)$ are provided in Table 5.15, in addition to axial strain and strength at ultimate axial load $\left(\varepsilon_{\mathrm{u}}\right.$ and $\left.\mathrm{P}_{\mathrm{u}}\right) . \varepsilon_{\mathrm{ys}} / \varepsilon_{\mathrm{u}}$ ratios are 
always less than 1, showing how steel uniaxial and biaxial yielding occurs before the axial capacity of CSFT columns, even in ECC-filled tubes. $\mathrm{P}_{\mathrm{ys}} / \mathrm{P}_{\mathrm{u}}$ ratios follow a similar trend between ECC and NC filled tube columns, as ratios typically increase with increasing slenderness.

Table 5.15: Observed steel yield in ECC and NC CFST columns

\begin{tabular}{ccccccc}
\hline Column & $\mathbf{P}_{\mathbf{u}}, \mathbf{k N}$ & $\boldsymbol{\varepsilon}_{\mathbf{u}}$ & $\mathbf{P}_{\mathbf{y s}}, \mathbf{k N}$ & $\boldsymbol{\varepsilon}_{\mathbf{y s}}$ & $\mathbf{P}_{\mathbf{y s}} / \mathbf{P}_{\mathbf{u}}$ & $\boldsymbol{\varepsilon}_{\mathbf{y s}} / \boldsymbol{\varepsilon}_{\mathbf{u}}$ \\
\hline EcI-3 & 1027 & 0.010845 & 297 & 0.001663 & 0.29 & 0.15 \\
EcI-9 & 1113 & 0.003164 & 571 & 0.001713 & 0.51 & 0.54 \\
NcI-3 & 1410 & 0.006110 & 692 & 0.001663 & 0.49 & 0.27 \\
NcI-9 & 1511 & 0.004027 & 950 & 0.001555 & 0.63 & 0.39 \\
EcII-3 & 801 & 0.013614 & 403 & 0.001619 & 0.50 & 0.12 \\
EcII-9 & 1186 & 0.004312 & 791 & 0.001693 & 0.67 & 0.39 \\
NcII-3 & 1601 & 0.009704 & 680 & 0.001708 & 0.42 & 0.18 \\
NcII-9 & 1592 & 0.003898 & 1038 & 0.001532 & 0.65 & 0.39 \\
Er-6 & 480 & 0.005044 & 262 & 0.001510 & 0.55 & 0.30 \\
Er-20 & 539 & 0.003724 & 315 & 0.001514 & 0.59 & 0.41 \\
Nr-6 & 716 & 0.003442 & 366 & 0.001485 & 0.51 & 0.43 \\
Nr-20 & 639 & 0.002560 & 404 & 0.001538 & 0.63 & 0.60 \\
Es4-3 & 941 & 0.012472 & 422 & 0.001611 & 0.45 & 0.13 \\
Es4-10 & 886 & 0.003085 & 619 & 0.001659 & 0.70 & 0.54 \\
Ns4-3 & 1217 & 0.003740 & 405 & 0.001490 & 0.33 & 0.40 \\
Ns4-10 & 1204 & 0.003073 & 679 & 0.001535 & 0.56 & 0.50 \\
Es2-6 & 176 & 0.002628 & 111 & 0.001597 & 0.63 & 0.61 \\
Es2-20 & 184 & 0.002059 & 91 & 0.001603 & 0.50 & 0.78 \\
Ns2-6 & 266 & 0.001844 & 211 & 0.001566 & 0.79 & 0.85 \\
Ns2-20 & 309 & 0.002617 & 178 & 0.001605 & 0.58 & 0.61 \\
\hline P $:$ axial load capacity; $\boldsymbol{\varepsilon}_{\mathrm{u}}:$ steel axial strain at axial load capacity; $\mathbf{P}_{\mathrm{ys}}:$ \\
axial load at biaxial steel yielding; $\boldsymbol{\varepsilon}_{\mathrm{ys}}:$ axial strain at biaxial steel \\
\hline
\end{tabular}

Table 5.16 presents biaxial stress factors obtained based on the Von-Mises failure criterion described previously in Eq. 4.1. There is no significant different between biaxial stress factors of ECC and NC filled tube columns. However, ECC-filled circular columns with slenderness of 3 had higher $\alpha$ values compared with NC. 
Table 5.16: Biaxial stress factors in ECC CFST columns

\begin{tabular}{ccccc}
\hline & Slenderness ratio & \multicolumn{3}{c}{ Stress concentration factors } \\
\hline Shape & L/D or L/d & $\alpha$ & $\beta$ \\
\hline cI & $3-9$ & $0.20-0.14$ & $0.88-0.91$ \\
cII & $3-9$ & $0.24-0.18$ & $0.86-0.9$ \\
r & $6-20$ & $0.17-0.07$ & $0.96-0.96$ \\
s4 & $3-10$ & $0.11-0.06$ & $0.94-0.97$ \\
s2 & $6-20$ & $0.17-0.17$ & $0.90-0.91$ \\
\hline
\end{tabular}

Experimental concrete confined strengths $\left(\mathrm{f}_{\mathrm{cc}}\right)$ were extracted from stress-strain diagrams as mentioned earlier in Figure 4.3. $\mathrm{f}_{\mathrm{cc}}$ values were compared with unconfined control cylinder compressive strength $\left(f^{\prime}\right)$ by $f_{c c}^{\prime} / f_{c}^{\prime}$ ratios in order to compare strength enhancement of CFST columns due to confinement effects. Ratios of $\mathrm{f}_{\mathrm{cc}}^{\prime} / \mathrm{f}_{\mathrm{c}}{ }_{\mathrm{c}}$ values reached up to 1.96 in NC-filled CFST columns with bar reinforcements. On the other hand, ratios for ECC-filled tube columns achieved a maximum of 1.37 , with values less than 1 in some cases. As $\mathrm{f}_{\mathrm{cc}} \mathrm{f}_{\mathrm{c}} \mathrm{f}_{\mathrm{c}}$ were found to be higher in NC-filled CFST columns, it is concluded that CFST columns in-filled with ECC were less efficient in confining concrete and improving strength. ECC-filled CFST column concrete confinement was better as tube thickness increased, a pattern also observed in NC-filled columns. Calculated maximum lateral pressure $\left(f_{2 \max }\right)$, provided previously in Eq. 4.7 , is also shown in Table 5.17. $\mathrm{f}_{2 \max }$ calculations indicate significant increase in lateral pressure due to the presence of bar reinforcements. 
Table 5.17: Quantified concrete confined strength and lateral pressure in ECC and NC CFST columns

\begin{tabular}{|c|c|c|c|c|}
\hline Column & $\mathbf{f}^{\prime}, \mathbf{M P a}$ & $\mathbf{f}_{\mathrm{cc}}, \mathbf{M P a}$ & $\mathbf{f}^{\prime}{ }_{\mathrm{cc}} / \mathbf{f}^{\prime}{ }_{\mathrm{c}}$ & $\mathbf{f}_{2 \max }, \mathrm{MPa}$ \\
\hline EcI-3 & 50 & 60 & 1.21 & 5.9 \\
\hline ECI-9 & 50 & 68 & 1.37 & 4.4 \\
\hline NcI-3 & 66 & 108 & 1.64 & 5.6 \\
\hline NcI-9 & 66 & 126 & 1.91 & 8.0 \\
\hline EcII-3 & 50 & 34 & 0.69 & 108.1 \\
\hline EcII-9 & 50 & 77 & 1.55 & 99.7 \\
\hline NcII-3 & 66 & 128 & 1.96 & 110.9 \\
\hline NcII-9 & 66 & 127 & 1.94 & 100.8 \\
\hline Er-6 & 50 & 35 & 0.71 & 5.4 \\
\hline Er-20 & 50 & 49 & 0.98 & 2.4 \\
\hline Nr-6 & 66 & 92 & 1.41 & 3.3 \\
\hline Nr-20 & 66 & 71 & 1.09 & 1.5 \\
\hline Es4-3 & 50 & 58 & 1.17 & 2.3 \\
\hline Es4-10 & 50 & 51 & 1.02 & 1.3 \\
\hline Ns4-3 & 66 & 92 & 1.40 & 4.7 \\
\hline Ns4-10 & 66 & 89 & 1.36 & 3.8 \\
\hline Es2-6 & 50 & 32 & 0.65 & 3.7 \\
\hline Es2-20 & 50 & 35 & 0.71 & 3.6 \\
\hline Ns2-6 & 66 & 73 & 1.11 & 4.3 \\
\hline Ns2-20 & 66 & 91 & 1.38 & 3.6 \\
\hline $\begin{array}{r}f_{c}^{\prime} \text { : unconfi } \\
\text { experime }\end{array}$ & $\begin{array}{l}\text { crete } c \\
\text { fined } c\end{array}$ & $\begin{array}{l}\text { ol cylinde } \\
\text { ete strens } \\
\text { stress. }\end{array}$ & $\begin{array}{l}\text { npressi } \\
\text { amax: ma }\end{array}$ & $\begin{array}{l}\text { trength; } \mathrm{f}_{\mathrm{cc}} \text { : } \\
\text { num lateral }\end{array}$ \\
\hline
\end{tabular}

Table 5.18 summarizes experimental concrete confinement for ECC-filled tube columns in comparison with analytical models based on theoretical/test ratios. Results from analytical models for confined concrete strength based on Richart et al. (1928), Mander et al. (1988), and O'Shea and Bridge (2000) from Eqs. 4.20, 4.21, and 4.22 are displayed in Table 5.18. The Hossain (2003b) model was also applied for estimating confined strength of CFST columns tested according to Eq. 4.14. Theoretical/test ratios ranged from 0.99 to 2.26 (Er-6 specimen) for confined strength of ECC-filled CFST columns without bar reinforcements, while ratios for NC- 
filled columns ranged from 0.77 to 1.25 . Therefore, although analytical models performed well especially for circular NC-filled columns with lower slenderness, equations were not found applicable for ECC-filled columns. Theoretical/test ratios for cII ECC-filled columns reached up to 3.52 , however, experimental error occurred during testing which may have resulted in much lower strength than expected. The Mander et al.-based and O'Shea and Bridge-based models had a tendency to over-estimate confined strength, while over-predictions were less emphasized by Richart et al.-based and Hossain (2003b). The Richart et al.-based model was slightly more conservative, and considered safer with respect structural design. Analytical models for concrete confinement prediction performed well for rectangular and square columns in-filled with ECC, especially for column Es4-3. This may suggest that ECC is more effective for confinement in square and rectangular sections compared with other types of concrete.

Table 5.18: Validation of models for confined concrete strength in ECC-filled CFST columns

\begin{tabular}{|c|c|c|c|c|c|c|c|c|c|}
\hline \multirow{3}{*}{ Column } & \multicolumn{5}{|c|}{$\begin{array}{l}\text { Confined concrete strength }\left(f^{\prime}{ }^{\prime} c t\right) \\
\text { MPa }\end{array}$} & \multicolumn{4}{|c|}{ Ratio Theoretical/Test } \\
\hline & \multirow[b]{2}{*}{ Test } & \multicolumn{4}{|c|}{ Theoretical models } & & & & \\
\hline & & $\begin{array}{l}\text { Eq. } \\
4.20\end{array}$ & $\begin{array}{l}\text { Eq. } \\
4.21\end{array}$ & $\begin{array}{l}\text { Eq. } \\
4.22\end{array}$ & $\begin{array}{l}\text { Eq. } \\
4.14\end{array}$ & $\begin{array}{l}\text { Eq. } \\
4.20\end{array}$ & $\begin{array}{l}\text { Eq. } \\
4.21\end{array}$ & $\begin{array}{l}\text { Eq. } \\
4.22\end{array}$ & $\begin{array}{l}\text { Eq. } \\
4.14\end{array}$ \\
\hline EcI-3 & 60 & 74 & 82 & 76 & 74 & 1.24 & 1.37 & 1.26 & 1.24 \\
\hline EcI-9 & 68 & 68 & 75 & 69 & 68 & 0.99 & 1.10 & 1.01 & 0.99 \\
\hline EcII-3 & 34 & 83 & 121 & 112 & 74 & 2.42 & 3.52 & 3.27 & 2.16 \\
\hline EcII-9 & 77 & 75 & 112 & 104 & 68 & 0.97 & 1.45 & 1.35 & 0.87 \\
\hline Er-6 & 46 & 67 & 74 & 68 & 68 & 1.43 & 1.59 & 1.47 & 1.47 \\
\hline Er-20 & 49 & 42 & 35 & 34 & 44 & 0.85 & 0.71 & 0.69 & 0.89 \\
\hline Es4-3 & 60 & 59 & 64 & 60 & 59 & 0.98 & 1.07 & 0.99 & 0.99 \\
\hline Es4-10 & 52 & 55 & 58 & 54 & 55 & 1.06 & 1.12 & 1.04 & 1.06 \\
\hline Es2-6 & 32 & 65 & 72 & 66 & 69 & 2.01 & 2.21 & 2.05 & 2.12 \\
\hline Es2-20 & 35 & 65 & 71 & 66 & 68 & 1.83 & 2.01 & 1.86 & 1.93 \\
\hline
\end{tabular}




\subsubsection{Identification of best model for ECC CFST column strength prediction}

Table 5.19 shows axial strength of ECC-filled CFST columns under concentric loading estimated by three models applied to Eq. 4.27, in addition to one proposed by Hossain (2003b) in Eq. 4.26. Three analytical models for hoop and tube confinement applied to Eqs. 4.28, 4.29, and 4.30 are based on research from Richart et al. (1928), Mander et al. (1988), and O'Shea and Bridge (2000) respectively.

Table 5.19: Comparative study of ECC-filled CFST column strength prediction by analytical models

\begin{tabular}{|c|c|c|c|c|c|c|c|c|c|}
\hline & $\begin{array}{c}\text { Tested } \\
\text { axial } \\
\text { strength }\end{array}$ & $\begin{array}{r}\text { Theo } \\
\text { Richart }\end{array}$ & $\begin{array}{l}\text { retical s } \\
\text { Mande }\end{array}$ & $\begin{array}{l}\text { ength I } \\
\text { 'shea } \\
\text { Bridg }\end{array}$ & $\begin{array}{l}\text { kN } \\
\text { [ossain }\end{array}$ & & & & \\
\hline Column & $\mathbf{P}_{\mathrm{u}}, \mathbf{k N}$ & $\begin{array}{l}\text { Eq. } \\
4.28\end{array}$ & $\begin{array}{l}\text { Eq. } \\
4.29\end{array}$ & $\begin{array}{l}\text { Eq. } \\
4.30\end{array}$ & $\begin{array}{l}\text { Eq. } \\
4.26\end{array}$ & $\begin{array}{l}\text { Eq. } \\
4.28\end{array}$ & $\begin{array}{l}\text { Eq. } \\
4.29\end{array}$ & $\begin{array}{l}\text { Eq. } \\
4.30\end{array}$ & $\begin{array}{l}\text { Eq. } \\
4.26\end{array}$ \\
\hline EcI-3 & 1027 & 1120 & 1190 & 1133 & 1121 & 1.09 & 1.16 & 1.10 & 1.09 \\
\hline EcI-4 & 1059 & 1108 & 1177 & 1122 & 1109 & 1.05 & 1.11 & 1.06 & 1.05 \\
\hline EcI-9 & 1113 & 1078 & 1141 & 1091 & 1079 & 0.97 & 1.03 & 0.98 & 0.97 \\
\hline EcII-3 & 801 & 1311 & 1638 & 1562 & 1153 & 1.64 & 2.05 & 1.95 & 1.44 \\
\hline EcII-4 & 794 & 1294 & 1620 & 1547 & 1140 & 1.63 & 2.04 & 1.95 & 1.44 \\
\hline EcII-9 & 1186 & 1260 & 1582 & 1515 & 1108 & 1.06 & 1.33 & 1.28 & 0.93 \\
\hline Er-6 & 480 & 569 & 600 & 575 & 577 & 1.19 & 1.25 & 1.20 & 1.20 \\
\hline Er-12 & 578 & 523 & 539 & 521 & 531 & 0.91 & 0.93 & 0.90 & 0.92 \\
\hline Er-20 & 539 & 462 & 430 & 426 & 470 & 0.86 & 0.80 & 0.79 & 0.87 \\
\hline Es4-3 & 941 & 912 & 957 & 916 & 913 & 0.97 & 1.02 & 0.97 & 0.97 \\
\hline Es4-6 & 833 & 900 & 939 & 900 & 901 & 1.08 & 1.13 & 1.08 & 1.08 \\
\hline Es4-10 & 886 & 885 & 913 & 878 & 885 & 1.00 & 1.03 & 0.99 & 1.00 \\
\hline Es2-6 & 176 & 241 & 257 & 244 & 250 & 1.37 & 1.46 & 1.38 & 1.42 \\
\hline Es2-9 & 190 & 241 & 257 & 244 & 250 & 1.27 & 1.35 & 1.29 & 1.31 \\
\hline Es2-12 & 175 & 241 & 257 & 244 & 250 & 1.38 & 1.47 & 1.40 & 1.43 \\
\hline Es2-16 & 181 & 241 & 256 & 244 & 249 & 1.33 & 1.42 & 1.35 & 1.38 \\
\hline Es2-20 & 184 & 241 & 256 & 244 & 249 & 1.31 & 1.39 & 1.33 & 1.36 \\
\hline
\end{tabular}

Predicted strength $\left(\mathrm{P}_{\mathrm{p}}\right)$ is compared with ultimate axial load of columns obtained from tests $\left(\mathrm{P}_{\mathrm{u}}\right)$. Ratios of $\mathrm{P}_{\mathrm{p}} / \mathrm{P}_{\mathrm{u}}$ in Table 5.19 show that models which performed well in predicting strength of 
NC-filled CFST columns over-estimated the strength of ECC-filled CFST columns, as was the case for predicting concrete confined strength previously shown in Table 5.18. This was especially emphasized in estimating ultimate axial load of cII and s2 columns. It is noted that estimation of axial strength in EcII-3 and EcII-4 columns was especially higher than experimental values due to experimental error during testing. Mander et al.-based and O'Shea and Bridge-based models, which had greater tendency to over-estimate confined strength of ECC, over-predicted axial strength of columns to a greater degree compared with other models. The Hossain (2003b) model yielded results similar to the Richart et al.-based model, however the latter was slightly more conservative in the majority of cases. Thus, the Richart et al.-based model is compared with code-based design equations in Table 5.20.

Table 5.20: ECC-filled CFST column strength predictions from model and design codes

\begin{tabular}{cccccc}
\hline & $\begin{array}{c}\text { Tested } \\
\text { axial } \\
\text { strength }\end{array}$ & Lachemi & $\begin{array}{c}\text { Theoretical axial strength } \mathbf{P}_{\mathbf{p}}, \mathbf{k N} \\
\text { AISC }\end{array}$ & Eurocode \\
\hline Column & $\mathbf{P}_{\mathbf{u}}, \mathbf{k N}$ & Eq. 4.28 & Eq. 4.23 & Eq. 4.24 & Eq. 4.25 \\
EcI-3 & 1027 & 1120 & 1225 & 948 & 1277 \\
EcI-4 & 1059 & 1108 & 1168 & 935 & 1166 \\
EcI-9 & 1113 & 1078 & 1017 & 881 & 1055 \\
EcII-3 & 801 & 1311 & 1225 & 1071 & 1403 \\
EcII-4 & 794 & 1294 & 1168 & 1056 & 1292 \\
EcII-9 & 1186 & 1260 & 1017 & 986 & 1180 \\
Er-6 & 480 & 569 & 624 & 467 & 616 \\
Er-12 & 578 & 523 & 553 & 443 & 546 \\
Er-20 & 539 & 462 & 443 & 392 & 583 \\
Es4-3 & 941 & 912 & 1008 & 775 & 1112 \\
Es4-6 & 833 & 900 & 945 & 761 & 997 \\
Es4-10 & 886 & 885 & 856 & 729 & 932 \\
Es2-6 & 176 & 241 & 242 & 194 & 216 \\
Es2-9 & 190 & 241 & 225 & 188 & 216 \\
Es2-12 & 175 & 241 & 207 & 180 & 216 \\
Es2-16 & 181 & 241 & 249 & 218 & 253 \\
Es2-20 & 184 & 241 & 231 & 209 & 253 \\
\hline
\end{tabular}


CSA (2009), AISC (2005), and Eurocode (2004) (Eqs. 4.23, 4.24, and 4.25) used for estimating design strength $\left(\mathrm{P}_{\mathrm{p}}\right)$ of CFST columns are compared with the Richart et al.-based model proposed by Lachemi et al. (2006b) (Eq. 4.28). Ratios of $\mathrm{P}_{\mathrm{p}} / \mathrm{P}_{\mathrm{u}}$ are compared in Figure 5.11. The Lachemi et al. (2006b), CSA (2005), and Eurocode (2004) equations, which were capable of estimating design strength of NC-filled CFST columns well, over-predicted axial strength of ECC-filled columns up to $40 \%$ higher than experimental values (excluding cII columns for which results were unreliable). This was especially the case for rectangular and square columns. The AISC (2005) model was considered conservative in estimating strength of NC-filled CFST columns. On the other hand, the AISC (2005) model performed well for estimating strength of ECC-filled columns, with $\mathrm{P}_{\mathrm{p}} / \mathrm{P}_{\mathrm{u}}$ often ranging between 0.80 and 1.10. Particularly, for columns of square and rectangular sections, the AISC (2005) code procedures were applicable due to incorporation of a factor accounting for sectional shape.

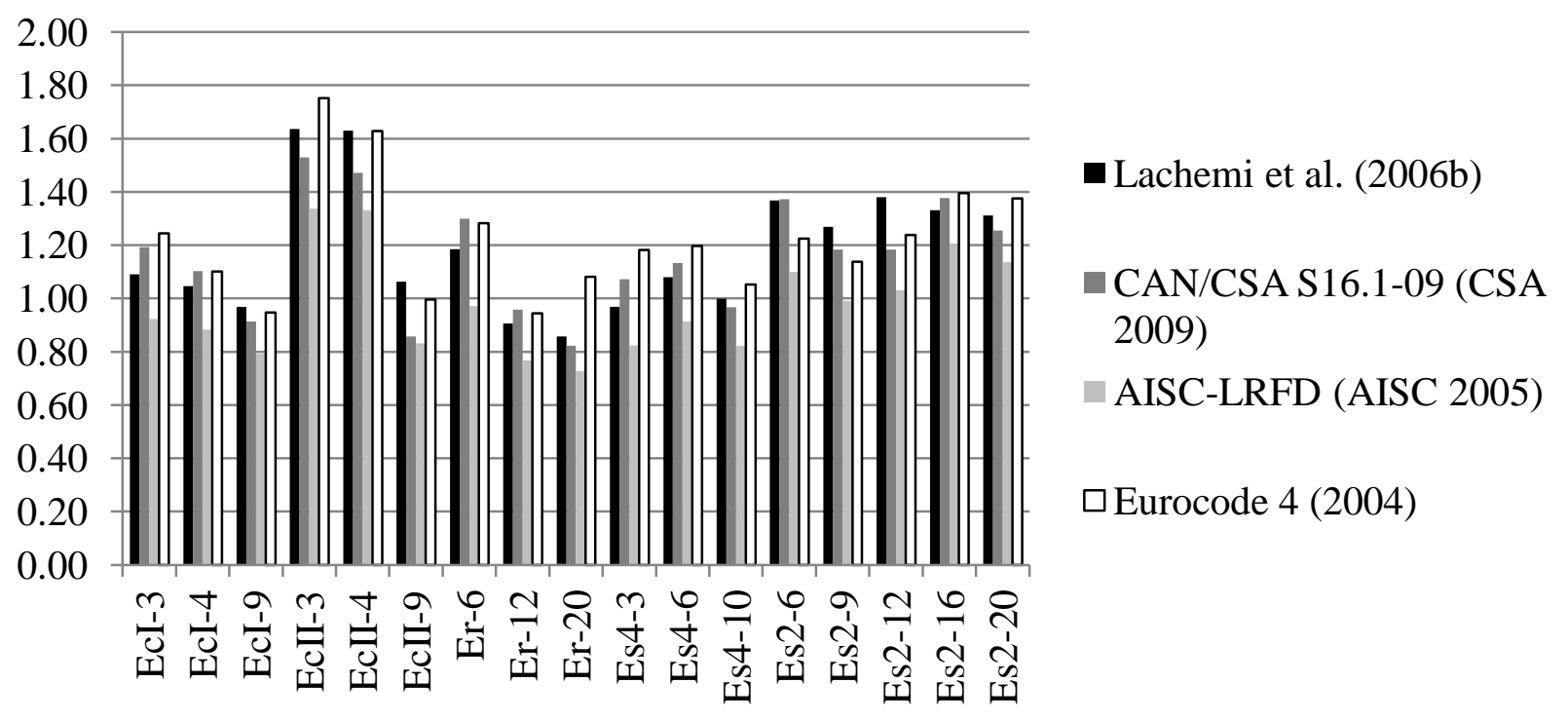

Figure 5.11: Performance of model for prediction of ECC-filled CFST column strength 


\subsection{Comparison of CFST columns with LWC and NC}

Under axial compression, the load-displacement response and stress-strain characteristics of LWC-filled tube columns are reported here. Performance of CFST with LWC are compared with NC. Calculated values for confined concrete strength and axial capacity of CFST columns using analytical and code-based design equations are compared with experimental values.

\subsubsection{Axial load-displacement response and failure modes}

Figure 5.12 illustrates the effect of slenderness on axial load-displacement curves for LWC and NC filled columns under axial loading.

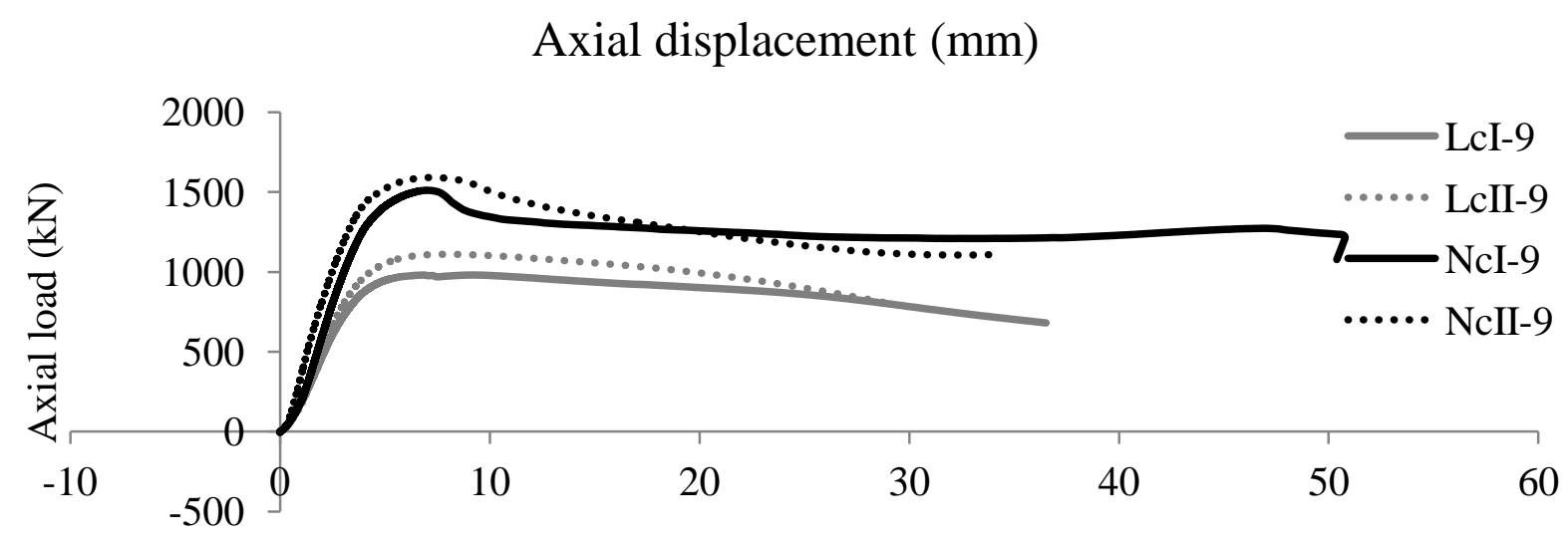

a) Axial load-displacement response for circular columns

Axial displacement ( $\mathrm{mm})$

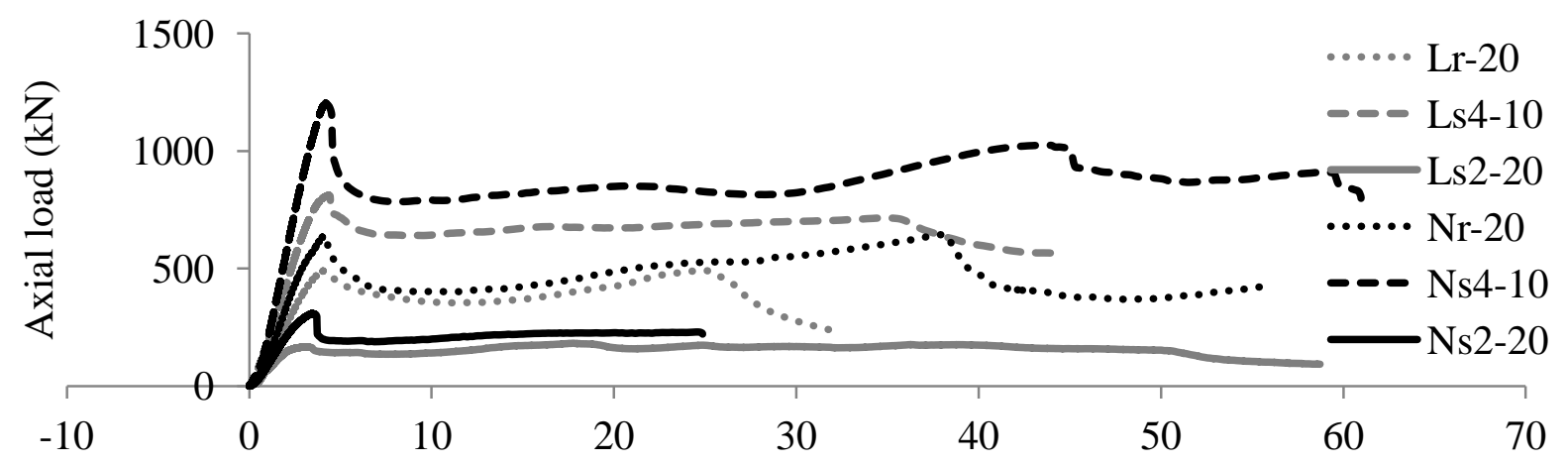

b) Axial load-displacement response for square and rectangular columns

Figure 5.12: Load-displacement responses of LWC and NC CFST columns 
Columns with equal dimensions resulted in graphs with similar shape, despite different concrete in-fill material. This suggests that CFST columns in-filled with LWC have behaviour similar to that of NC-filled columns. Circular CFST columns with LWC or NC in-fill resulted in load displacement curves in Figure 5.12a with smooth transition between elastic and plastic stages, compared to a significant decrease in load after the first peak as seen in square and rectangular columns shown Figure 5.12b.

LWC-filled CFST columns after testing are shown in Figure 5.13. Ultimate axial load of NC and LWC filled columns $\left(\mathrm{P}_{\mathrm{u}, \mathrm{NC}}\right.$ and $\left.\mathrm{P}_{\mathrm{u}, \mathrm{LWC}}\right)$ are recorded in Table 5.21 along with their corresponding failure modes. Failure modes were found to mainly depend on column slenderness. In columns with slenderness ratio of 3, concrete typically pushed outwards on the steel tube forming a barrel-like shape. Due to this radial expansion, steel often tore at failure. As slenderness increased, failure modes differed between LWC and NC filled tube columns. From slenderness ratio of 4 to 6, LWC-filled tube columns failed by local buckling at multiple locations along the column length. Multiple buckles formed at a certain location, forming a plastic hinge at failure of several LWC filled columns with slenderness from 9 to 20. For these columns, global buckling failure was also common. On the other hand, NC filled tube columns of slenderness from 4 to 20 mainly failed by shear, with some cases of local buckling and other modes of failure listed in Table 5.21. 


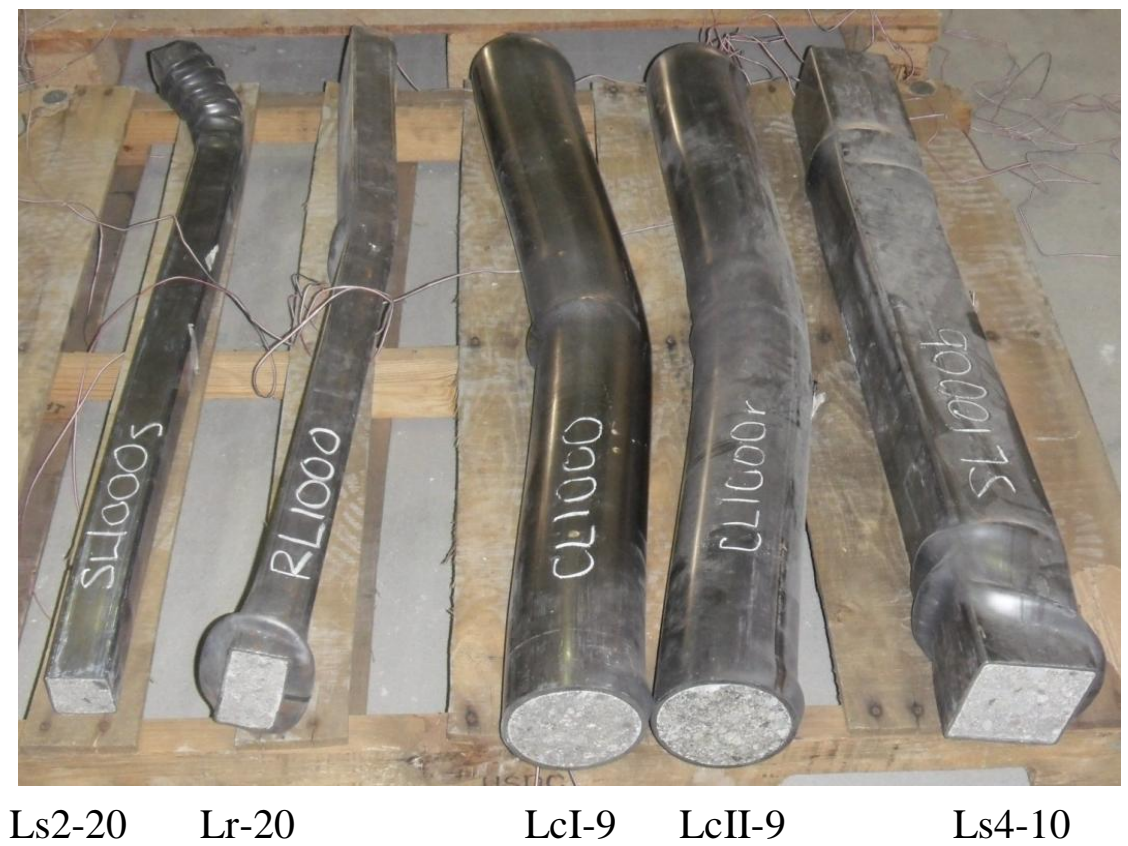

Figure 5.13: Failure modes of LWC-filled CFST columns

Table 5.21: LWC and NC CFST column capacity and concrete strength increase

\begin{tabular}{|c|c|c|c|c|c|}
\hline $\begin{array}{c}\text { Column } \\
\text { Designation }\end{array}$ & $\begin{array}{c}\mathbf{P}_{\mathbf{u}, \mathbf{N C}}, \\
\mathbf{k N}\end{array}$ & $\begin{array}{c}\text { Failure mode } \\
\text { (NC) }\end{array}$ & $\begin{array}{c}\mathbf{P}_{\mathrm{u}, \mathbf{L W C}}, \\
\mathbf{k N}\end{array}$ & $\begin{array}{c}\begin{array}{c}\text { Failure mode } \\
(\mathrm{LWC})\end{array} \\
\end{array}$ & $\begin{array}{c}\mathbf{P}_{\mathrm{u}, \mathrm{LWC}} \\
\mathbf{P}_{\mathrm{u}, \mathrm{NC}}\end{array}$ \\
\hline cI-3 & 1410 & Radial expansion & 1148 & Radial expansion & 0.81 \\
\hline cI-4 & 1403 & Shear & 1078 & Local buckling & 0.77 \\
\hline cI-9 & 1511 & Shear & 982 & Global buckling & 0.65 \\
\hline cII-3 & 1601 & Radial expansion & 1271 & Radial expansion & 0.79 \\
\hline cII-4 & 1584 & Shear & 1132 & Local buckling & 0.71 \\
\hline cII-9 & 1592 & Shear & 1112 & Global buckling & 0.70 \\
\hline$r-6$ & 716 & Radial expansion & 518 & Local buckling & 0.72 \\
\hline r-12 & 800 & Plastic hinge & 519 & Plastic hinge & 0.65 \\
\hline r-20 & 639 & Shear & 489 & Global buckling & 0.77 \\
\hline$s 4-3$ & 1217 & Radial expansion & 889 & Local buckling & 0.73 \\
\hline$s 4-6$ & 1198 & Local buckling & 791 & Local buckling & 0.66 \\
\hline s4-10 & 1204 & Local buckling & 812 & Local buckling & 0.67 \\
\hline s2-6 & 266 & Shear & 187 & Local buckling & 0.70 \\
\hline s2-9 & 296 & Shear & 203 & Plastic hinge & 0.69 \\
\hline s2-12 & 318 & Global buckling & 183 & Plastic hinge & 0.58 \\
\hline s2-16 & 296 & Shear & 191 & Plastic hinge & 0.65 \\
\hline s2-20 & 309 & Shear & 167 & Plastic hinge & 0.54 \\
\hline
\end{tabular}


A ratio of $\mathrm{P}_{\mathrm{u}, L W C} / \mathrm{P}_{\mathrm{u}, \mathrm{NC}}$ values show the relative axial capacities of $\mathrm{LWC}$ and $\mathrm{NC}$ filled tube columns. These ratios can be compared with ratio of LWC unconfined cylinder compressive strength to that of $\mathrm{NC}, \mathrm{f}^{\prime}{ }_{c, \mathrm{LWC}} / \mathrm{f}^{\prime}{ }_{c, \mathrm{NC}}$, which has a value of 0.55 . In all cases but one, $\mathrm{P}_{\mathrm{u}, \mathrm{LWC}} / \mathrm{P}_{\mathrm{u}}$, NC ratios exceeded a value of 0.55 . This suggests that although LWC unconfined compressive strength is only about half the compressive strength of NC, the axial capacity of CFST columns in-filled with LWC can achieve strength greater than 0.55 that of CFST columns in-filled with $\mathrm{NC}$, even up to 0.81 . This is possible potentially because CFST concrete confinement is expressed more effectively in LWC-filled columns. Thus, the strength enhancement of CFST columns due to confinement is not directly proportional to concrete compressive strength when LWC and NC are compared.

\subsubsection{Analysis of stress-strain behaviour}

An example of typical strain development in steel tubes in-filled with NC and LWC is shown in Figure 5.14.

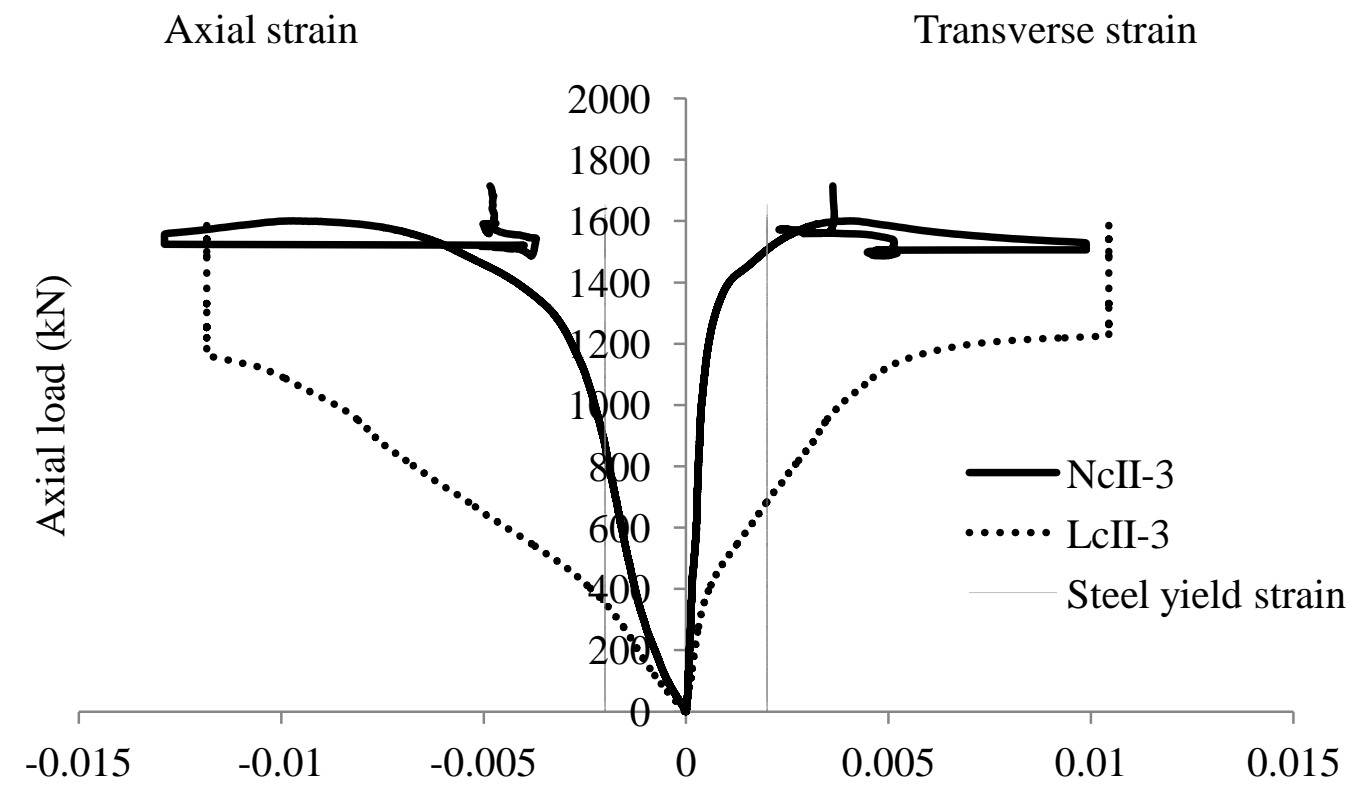

Figure 5.14: Strain development in steel tube of columns filled with LWC and NC 
Strain in specimen LcII-3 in-filled with LWC develops soon after small load has been applied to the column. On the other hand, strain in NcII-3 did not show much increase at initial stages of loading. Both axial and transverse strains are greater in the column in-filled with LWC compared with $\mathrm{NC}$ at the same amount of load.

The ultimate axial load of LWC and NC CFST columns $\left(\mathrm{P}_{\mathrm{u}}\right)$ are listed again in Table 5.22, and compared with axial load corresponding to biaxial yielding $\left(\mathrm{P}_{\mathrm{ys}}\right)$ based on von-Mises failure criterion described previously in Eq. 4.1.

Table 5.22: Observed steel yield in LWC and NC CFST columns

\begin{tabular}{ccccccc}
\hline Column & $\mathbf{P}_{\mathbf{u}}, \mathbf{k N}$ & $\boldsymbol{\varepsilon}_{\mathbf{u}}$ & $\mathbf{P}_{\mathbf{y s}}, \mathbf{k N}$ & $\boldsymbol{\varepsilon}_{\mathbf{y s}}$ & $\mathbf{P}_{\mathbf{y s}} / \mathbf{P}_{\mathbf{u}}$ & $\boldsymbol{\varepsilon}_{\mathbf{y s}} \boldsymbol{\varepsilon}_{\mathbf{u}}$ \\
\hline LcI-3 & 1148 & 0.014285 & 447 & 0.001629 & 0.39 & 0.11 \\
LcI-9 & 982 & 0.008961 & 603 & 0.001599 & 0.61 & 0.18 \\
NcI-3 & 1410 & 0.006110 & 692 & 0.001663 & 0.49 & 0.27 \\
NcI-9 & 1511 & 0.004027 & 950 & 0.001555 & 0.63 & 0.39 \\
LcII-3 & 1271 & 0.011842 & 301 & 0.001685 & 0.24 & 0.14 \\
LcII-9 & 1112 & 0.002579 & 774 & 0.001693 & 0.70 & 0.66 \\
NcII-3 & 1601 & 0.009704 & 680 & 0.001708 & 0.42 & 0.18 \\
NcII-9 & 1592 & 0.003898 & 1038 & 0.001532 & 0.65 & 0.39 \\
Lr-6 & 518 & 0.006554 & 263 & 0.001345 & 0.51 & 0.21 \\
Lr-20 & 489 & 0.002323 & 358 & 0.001391 & 0.73 & 0.60 \\
Nr-6 & 716 & 0.003442 & 366 & 0.001485 & 0.51 & 0.43 \\
Nr-20 & 639 & 0.002560 & 404 & 0.001538 & 0.63 & 0.60 \\
Ls4-3 & 889 & 0.006148 & 310 & 0.001619 & 0.35 & 0.26 \\
Ls4-10 & 812 & 0.003152 & 463 & 0.001518 & 0.57 & 0.48 \\
Ns4-3 & 1217 & 0.003740 & 405 & 0.001490 & 0.33 & 0.40 \\
Ns4-10 & 1204 & 0.003073 & 679 & 0.001535 & 0.56 & 0.50 \\
Ls2-6 & 187 & 0.003591 & 92 & 0.001542 & 0.49 & 0.43 \\
Ls2-20 & 167 & 0.002029 & 152 & 0.001645 & 0.91 & 0.81 \\
Ns2-6 & 266 & 0.001844 & 211 & 0.001566 & 0.79 & 0.85 \\
Ns2-20 & 309 & 0.002617 & 178 & 0.001605 & 0.58 & 0.61 \\
\hline P: axial load capacity; $\varepsilon_{\mathrm{u}}:$ steel axial strain at axial load capacity; $\mathrm{P}_{\mathbf{y s}}:$ axial \\
load at biaxial steel yielding; $\varepsilon_{\mathbf{y s}}:$ axial strain at biaxial steel yielding. \\
\hline
\end{tabular}


Axial strain at ultimate axial load and at biaxial yielding $\left(\varepsilon_{\mathrm{u}}\right.$ and $\left.\varepsilon_{\mathrm{ys}}\right)$ are also provided. $\mathrm{P}_{\mathrm{ys}} / \mathrm{P}_{\mathrm{u}}$ and $\varepsilon_{\mathrm{ys}} / \varepsilon_{\mathrm{u}}$ ratios ore often higher in more slender columns in-filled with either of two concretes, as steel yielding becomes more closely associated with ultimate failure when global instability occurs. However, in all cases, steel yielded both uniaxially and biaxially before failure.

Biaxial stress factors for LWC filled columns are tabulated in Table 5.23. NC and LWC biaxial stress factors are quite similar. However, $\alpha$ values are often slightly higher for LWC filled tubes, suggesting greater transverse/hoop stress development.

Table 5.23: Biaxial stress factors in LWC CFST columns

\begin{tabular}{ccccc}
\hline & Slenderness ratio & \multicolumn{4}{c}{ Stress concentration factors } \\
\hline Shape & L/D or L/d & $\alpha$ & $\beta$ & $0.86-0.85$ \\
\hline cI & $3-9$ & $0.23-0.23$ & $0.89-0.9$ \\
cII & $3-9$ & $0.18-0.19$ & $0.85-0.88$ \\
r & $6-20$ & $0.25-0.2$ & $0.94-0.89$ \\
s4 & $3-10$ & $0.10-0.2$ & $0.87-0.93$ \\
s2 & $6-20$ & $0.22-0.13$ &
\end{tabular}

Experimental confined concrete strengths $\left(\mathrm{f}_{\mathrm{cc}}\right)$ of LWC and NC tube columns are determined by stress-strain curves explained earlier in Figure 4.3, and are listed in Table 5.24. Concrete control cylinder strength $\left(\mathrm{f}_{\mathrm{c}}\right)$ is also provided so that $\mathrm{f}_{\mathrm{cc}}^{\prime} / \mathrm{f}_{\mathrm{c}}^{\prime}$ ratios can be used to express strength enhancement of CFST columns due to confinement. Ratios of $\mathrm{f}^{\prime}{ }_{\mathrm{cc}} / \mathrm{f}^{\prime}{ }_{\mathrm{c}}$ for circular CFST columns were notably higher when in-filled with LWC compared with those in-filled with NC. However, for square and rectangular CFST columns, and as slenderness increased, $\mathrm{f}^{\prime}{ }_{\mathrm{cc}} / \mathrm{f}^{\prime}{ }_{\mathrm{c}}$ ratios between NC and LWC filled columns became quite similar in most cases. These results indicate that LWC infill has more effective confinement in circular CFST columns compared to NC filled CFST columns. However, trends for confined strength increase were similar between LWC and NC 
filled CFST columns, as cII columns had greater confined strength compared with cI columns. Also, confined strength tended to decrease with tube thickness. Calculated maximum lateral pressure according to Eq. 4.7 mentioned before, show higher values for circular CFST columns in-filled with LWC or NC. Lateral pressure is greatly increased with the presence of bar reinforcements.

Table 5.24: Quantified concrete confined strength and lateral pressure in LWC and NC CFST columns

\begin{tabular}{|c|c|c|c|c|}
\hline Column & $\mathbf{f}^{\prime}{ }^{\prime}, \mathbf{M P a}$ & $\mathbf{f}^{\prime}{ }_{\mathrm{cc}}, \mathbf{M P a}$ & $\mathbf{f}_{\mathrm{cc}} \mathbf{f}^{\mathbf{f}_{\mathrm{c}}}$ & $\mathbf{f}_{2 \max }, \mathbf{M P a}$ \\
\hline LCI-3 & 36 & 79 & 2.18 & 6.8 \\
\hline LcI-9 & 36 & 57 & 1.59 & 6.9 \\
\hline NcI-3 & 66 & 108 & 1.64 & 5.6 \\
\hline NcI-9 & 66 & 126 & 1.91 & 8.0 \\
\hline LcII-3 & 36 & 91 & 2.53 & 106.3 \\
\hline LcII-9 & 36 & 69 & 1.91 & 100.1 \\
\hline NcII-3 & 66 & 128 & 1.96 & 115.3 \\
\hline NcII-9 & 66 & 127 & 1.94 & 109.3 \\
\hline Lr-6 & 36 & 53 & 1.47 & 7.8 \\
\hline Lr-20 & 36 & 44 & 1.21 & 6.4 \\
\hline Nr-6 & 66 & 92 & 1.41 & 3.3 \\
\hline Nr-20 & 66 & 71 & 1.09 & 1.5 \\
\hline Ls4-3 & 36 & 52 & 1.45 & 2.1 \\
\hline Ls4-10 & 36 & 47 & 1.30 & 4.0 \\
\hline Ns4-3 & 66 & 92 & 1.40 & 4.7 \\
\hline Ns4-10 & 66 & 89 & 1.36 & 3.8 \\
\hline Ls2-6 & 36 & 39 & 1.07 & 4.7 \\
\hline Ls2-20 & 36 & 34 & 0.94 & 2.8 \\
\hline Ns2-6 & 66 & 73 & 1.11 & 4.3 \\
\hline Ns2-20 & 66 & 91 & 1.38 & 3.6 \\
\hline $\begin{array}{l}\mathrm{f}_{\mathrm{c}} \text { : unconfin } \\
\text { experimen }\end{array}$ & $\begin{array}{l}\text { crete c } \\
\text { ined } c\end{array}$ & $\begin{array}{l}\text { ol cylinde } \\
\text { ete stren } \\
\text { stress. }\end{array}$ & npress & $\begin{array}{l}\text { strength; } \mathrm{f}^{\prime} \mathrm{cc} \text { : } \\
\text { num lateral }\end{array}$ \\
\hline
\end{tabular}

Models for total confinement ( $\mathrm{f}^{\prime}$ cct $)$ in CFST columns based on research of Richart et al. (1928), Mander et al. (1988), and O'Shea and Bridge (2000), and a model developed by Hossain (2003b) 
were used to calculate theoretical confined strength values (provided before in Eqs. 4.20, 4.21, 4.22 and 4.14). Values of $\mathrm{f}^{\prime}$ cct are provided in Table 5.25.

Table 5.25 Validation of models for confined concrete strength in LWC-filled CFST columns

\begin{tabular}{|c|c|c|c|c|c|c|c|c|c|}
\hline \multirow{3}{*}{ Column } & \multicolumn{5}{|c|}{$\begin{array}{c}\text { Confined concrete strength }\left(\mathbf{f}^{\prime} \text { cct}\right) \text {, } \\
\text { MPa }\end{array}$} & \multicolumn{4}{|c|}{ Ratio Theoretical/Test } \\
\hline & \multirow[b]{2}{*}{ Test } & \multicolumn{4}{|c|}{ Theoretical models } & & & & \\
\hline & & $\begin{array}{l}\text { Eq. } \\
4.20\end{array}$ & $\begin{array}{l}\text { Eq. } \\
4.21\end{array}$ & $\begin{array}{l}\text { Eq. } \\
4.22\end{array}$ & $\begin{array}{l}\text { Eq. } \\
4.14\end{array}$ & $\begin{array}{l}\text { Eq. } \\
4.20\end{array}$ & $\begin{array}{l}\text { Eq. } \\
4.21\end{array}$ & $\begin{array}{l}\text { Eq. } \\
4.22\end{array}$ & $\begin{array}{l}\text { Eq. } \\
4.14\end{array}$ \\
\hline LcI-3 & 79 & 62 & 68 & 62 & 62 & 0.79 & 0.86 & 0.79 & 0.79 \\
\hline LcI-9 & 57 & 62 & 68 & 62 & 62 & 1.08 & 1.19 & 1.08 & 1.09 \\
\hline LcII-3 & 91 & 61 & 89 & 82 & 62 & 0.67 & 0.98 & 0.90 & 0.68 \\
\hline LcII-9 & 69 & 61 & 89 & 82 & 62 & 0.89 & 1.29 & 1.19 & 0.90 \\
\hline Lr-6 & 53 & 68 & 73 & 67 & 69 & 1.29 & 1.38 & 1.26 & 1.31 \\
\hline Lr-20 & 44 & 62 & 68 & 62 & 64 & 1.43 & 1.56 & 1.43 & 1.46 \\
\hline Ls4-3 & 52 & 45 & 49 & 45 & 45 & 0.85 & 0.93 & 0.86 & 0.85 \\
\hline Ls4-10 & 47 & 53 & 58 & 54 & 53 & 1.12 & 1.25 & 1.15 & 1.13 \\
\hline Ls2-6 & 39 & 55 & 61 & 56 & 58 & 1.43 & 1.59 & 1.46 & 1.50 \\
\hline Ls2-20 & 34 & 47 & 52 & 48 & 50 & 1.40 & 1.54 & 1.43 & 1.48 \\
\hline
\end{tabular}

Most of the time, models were over-estimating confined strength of columns with slenderness ratio from 6 to 20 (up to $59 \%$ greater than the experimental value for specimen Ls2-6, as shown in Table 5.25). This is reasonable as confinement models were not developed in consideration of global instability failure. For the case of shorter columns with slenderness ratio of 3 , models which performed well for estimating total confinement in NC filled tube columns were also able to predict confined strength of LWC filled tube columns close to experimental values. Theoretical/test total confinement ratios ranged from 0.77 to 0.93 for models estimating confined strength of CFST columns without bar reinforcements. The Mander et al.-based and O'Shea and Bridge-based models had tendency to predict higher confined strength compared with the Richart et al.-based model and Hossain model. Thus, the Richart et al. - based and Hossain (2003b) 
models are considered safer (providing strength from $67 \%$ to $90 \%$ of experimental values as seen in Table 5.25) for predicting total confinement of CFST columns.

\subsubsection{Identification of the best model for LWC CFST columns strength prediction}

Models for estimating axial strength of CFST columns were provided beforehand in Eq. 4.28, 4.29, and 4.30, where $\mathrm{f}^{\prime}{ }_{\mathrm{cc}}$ and $\mathrm{f}^{\prime}{ }_{\mathrm{cch}}$ were obtained based on confinement models of Richart et al. (1928), Mander et al. (1988), and O'Shea and Bridge (2000). The axial strength model from Hossain (2003b) was also provided in Eq. 4.26. Theoretical axial strength $\left(\mathrm{P}_{\mathrm{p}}\right)$ is compared with axial compressive strength of CFST columns obtained from experimental tests $\left(\mathrm{P}_{\mathrm{u}}\right)$ by $\mathrm{P}_{\mathrm{p}} / \mathrm{P}_{\mathrm{u}}$ ratios in Table 5.26.

Table 5.26 Comparative study of LWC-filled CFST column strength prediction by analytical models

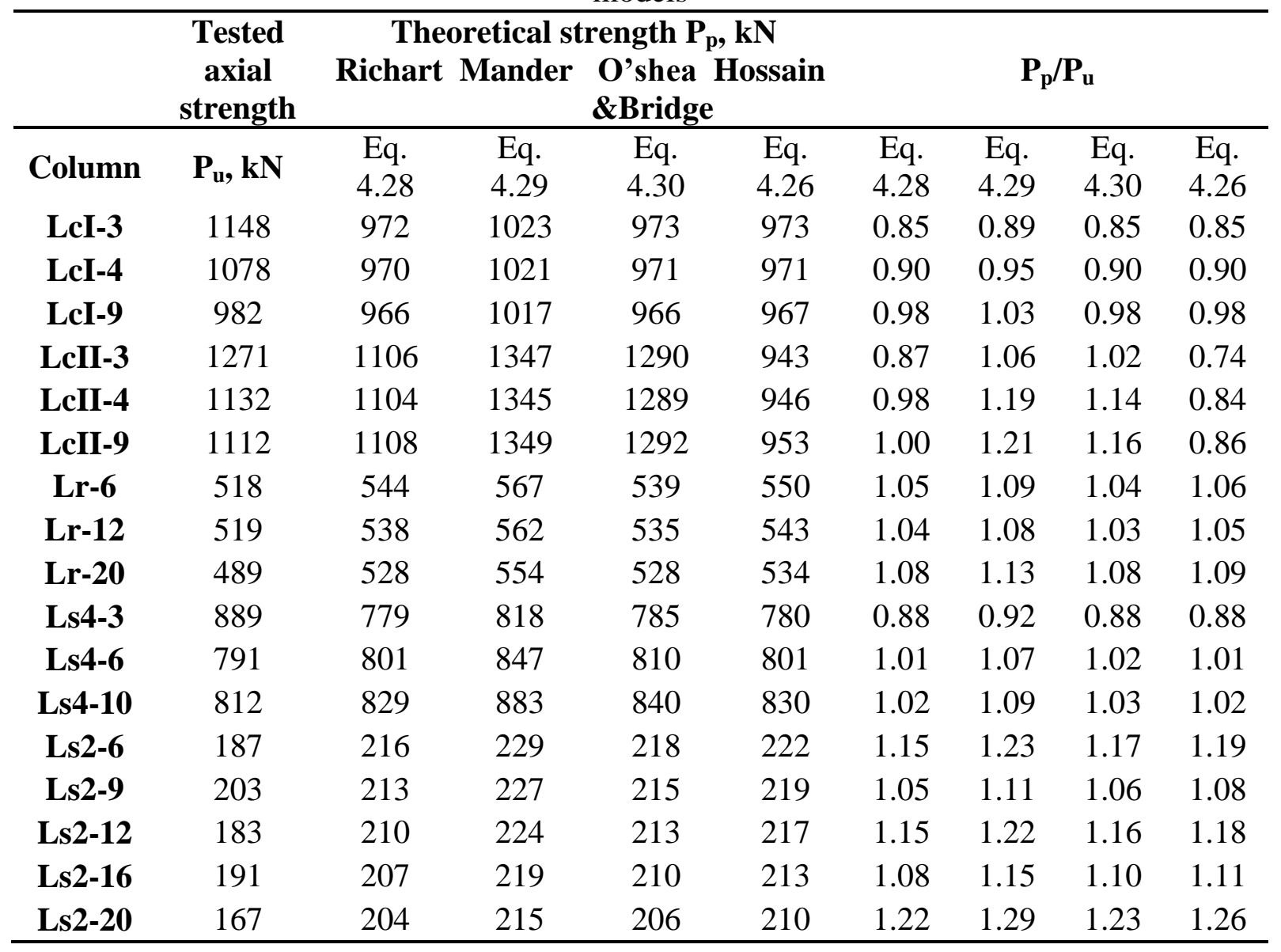


The Mander et al.-based and O'Shea and Bridge-based models were slightly over-estimating axial strength of cII columns (with either NC or LWC in-fill), especially those with higher slenderness. As mentioned before, this is reasonable since models were not developed in consideration of global instability failures which are typically observed in most slender columns. On the other hand, most analytical models performed well in estimating axial strength of square and rectangular NC-filled CFST columns, but over-predicted axial capacity of those in-filled with LWC $\left(\mathrm{P}_{\mathrm{p}} / \mathrm{P}_{\mathrm{u}}\right.$ ratios ranged from 0.88 to 1.29$)$. In most cases in Table 5.26, over-predictions of square and rectangular LWC-filled tube column axial strengths were still close to experimental values when slenderness remained within values of 3 to 6 . As with predictions of LWC-filled column total confinement, the Richart et al.-based model and Hossain (2003b) model were comparatively conservative, and the Richart et al.-based model to a greater extent.

Thus the Richart et al. - based model proposed by Lachemi et al. (2006b) was compared with code-based design equations in Table 5.27. The Lachemi et al. (2006b) model for axial capacity of CFST columns based on the work of Richart et al. (1928) (Eq. 4.28) was compared with design code equations from CSA (2009), AISC (2005), and Eurocode (2004) provided beforehand in Eqs. 4.23 to 4.25. Ratios for theoretical to experimental values $\left(\mathrm{P}_{\mathrm{p}} / \mathrm{P}_{\mathrm{u}}\right)$ are graphed in Figure 5.15. All equations performed well in estimating axial strength of circular CFST columns in-filled with LWC and $\mathrm{NC}$, as most $\mathrm{P}_{\mathrm{p}} / \mathrm{P}_{\mathrm{u}}$ values ranged from 0.80 to 1.10. However, models from Lachemi et al. (2006b), CSA (2009), and Eurocode (2004) often over-predicted axial strength of rectangular and square columns. In order for these equations to be applied to square and rectangular CFST columns, an equivalent circular section had to be used. On the other hand, AISC (2005) provided a factor to account for different cross-sectional shapes, and 
performed comparatively well in predicted axial strength of LWC filled tube columns with square and circular section as long as slenderness of columns remained less than a value of 16 .

Table 5.27: LWC-filled CFST column strength predictions from model and design codes

\begin{tabular}{cccccc}
\hline & $\begin{array}{c}\text { Tested axial } \\
\text { strength }\end{array}$ & Lachemi & $\begin{array}{c}\text { Theoretical axial strength } \mathbf{P}_{\mathbf{p}}, \mathbf{k N} \\
\text { AISC }\end{array}$ & Eurocode \\
\hline Column & $\mathbf{P}_{\mathbf{u}}, \mathbf{k N}$ & Eq. 4.28 & Eq. 4.23 & Eq. 4.24 & Eq. 4.25 \\
LcI-3 & 1148 & 972 & 1078 & 797 & 1097 \\
LcI-4 & 1078 & 970 & 1025 & 789 & 996 \\
LcI-9 & 982 & 966 & 891 & 750 & 872 \\
LcII-3 & 1271 & 1106 & 1078 & 922 & 1223 \\
LcII-4 & 1132 & 1104 & 1025 & 910 & 1122 \\
LcII-9 & 1112 & 1108 & 891 & 858 & 997 \\
Lr-6 & 518 & 544 & 581 & 417 & 553 \\
Lr-12 & 519 & 538 & 513 & 399 & 477 \\
Lr-20 & 489 & 528 & 415 & 359 & 490 \\
Ls4-3 & 889 & 779 & 916 & 668 & 974 \\
Ls4-6 & 791 & 801 & 854 & 659 & 864 \\
Ls4-10 & 812 & 829 & 772 & 636 & 787 \\
Ls2-6 & 187 & 216 & 220 & 168 & 221 \\
Ls2-9 & 203 & 213 & 203 & 164 & 204 \\
Ls2-12 & 183 & 210 & 187 & 159 & 200 \\
Ls2-16 & 191 & 207 & 249 & 218 & 282 \\
Ls2-20 & 167 & 204 & 231 & 209 & 283 \\
\hline
\end{tabular}

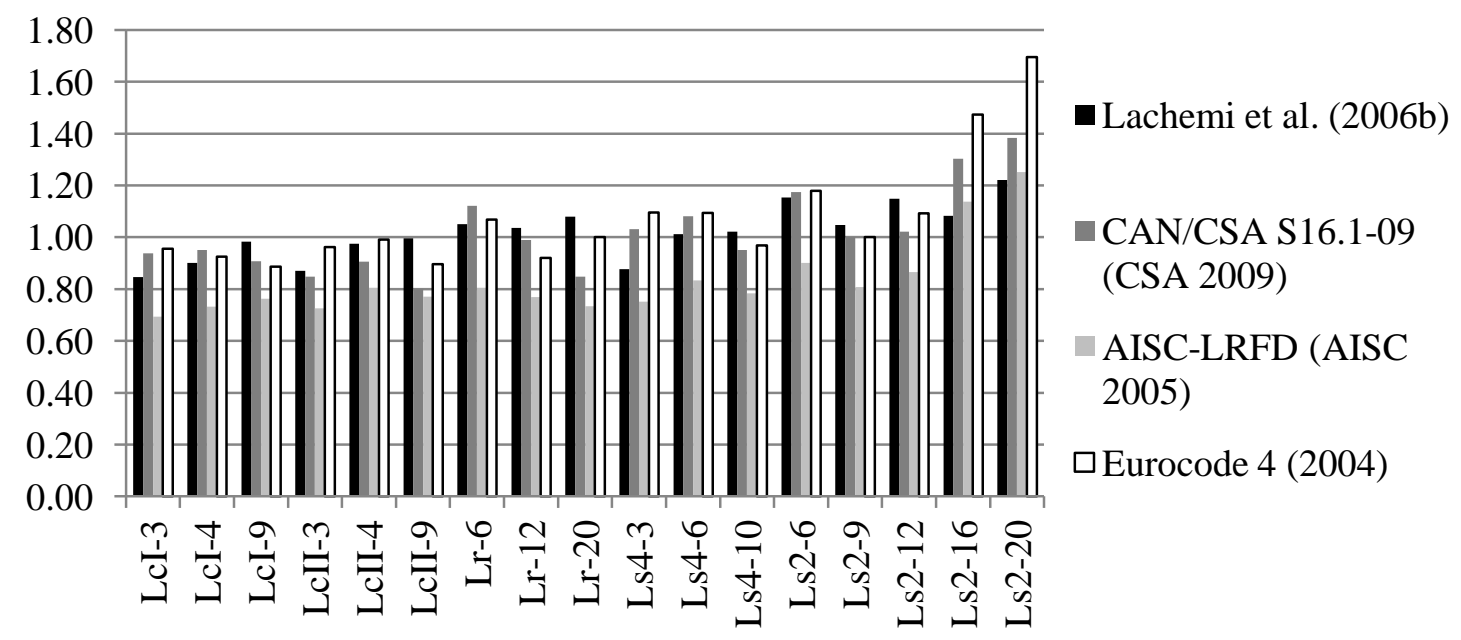

Figure 5.15: Performance of model for prediction of LWC-filled CFST column strength 


\subsection{Comparison of CFST columns with CRC and NC}

Under axial compression, the load-displacement response and stress-strain characteristics of CRC-filled tube columns are reported here. Performance of CFST with CRC are compared with NC. Calculated values for confined concrete strength and axial capacity of CFST columns using analytical and code-based design equations are compared with experimental values.

\subsubsection{Axial load-displacement response and failure modes}

The effect of slenderness on axial load displacement responses from $\mathrm{NC}$ and $\mathrm{CRC}$ filled tube columns are shown in Figure 5.16. The axial load-displacement response for NC and CRC filled tubes are similar for columns with equal dimensions and shapes, suggesting that behaviour of CRC filled tube columns was similar to that of NC filled tube columns. However, the CRC-filled circular columns showed slightly more ductile behaviour as seen by a smooth transition from elastic to plastic regions in the load-displacement curve compared with NC-filled circular columns (see Figure 5.16a). Circular columns showed greater ductility compared with square columns. Square columns in turn showed more ductile behaviour compared with rectangular columns illustrated in Figure 5.16b, whether they were in-filled with NC or CRC. The higher peak load of NC-filled columns is attributed to the higher unconfined compressive strength. 


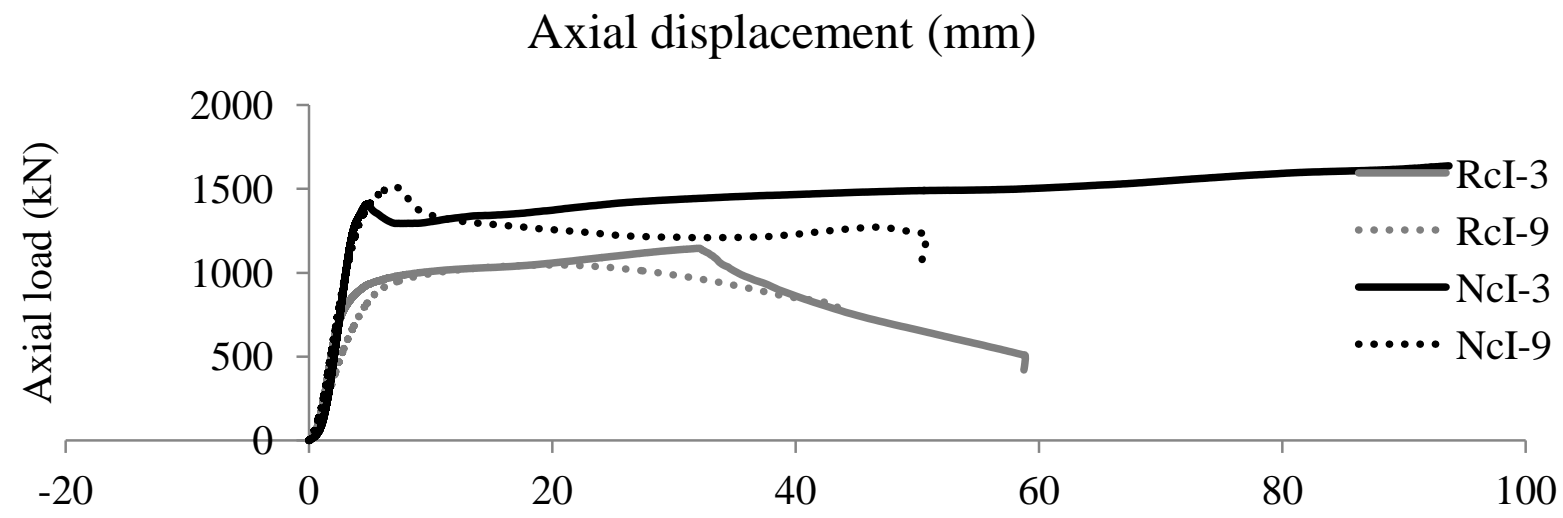

a) Axial load-displacement response for circular columns

Axial displacement ( $\mathrm{mm})$

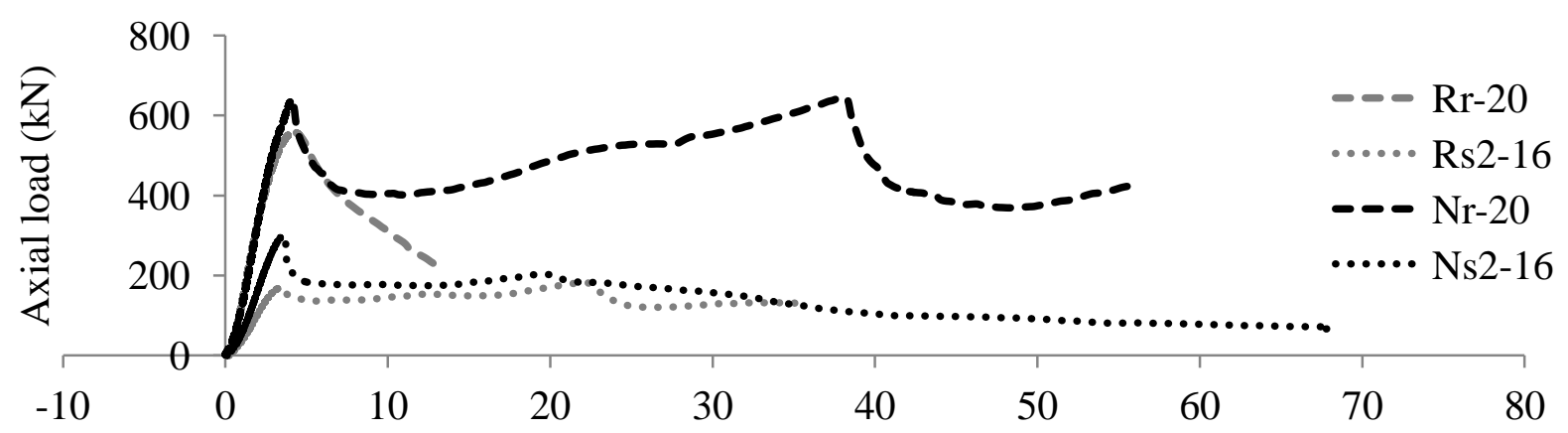

b) Axial load-displacement response for square and rectangular columns

Figure 5.16: Load-displacement responses of CRC and NC CFST columns

CRC-filled columns after testing are shown in Figure 5.17. Failure modes of NC and CRC filled tube columns are recorded in Table 5.28. Change in failure modes of NC filled steel tube columns with increasing slenderness ratio began by radial expansion in shorter columns, then by shear for those with slenderness ratio from 6 to 9 , and finally by global buckling for highest slenderness ratios. On the other hand, CRC filled tube columns failed by local buckling for shorter columns, global buckling for longer columns, and cases of shear failure occurred in columns from slenderness ratio of 6 to 16. Shear failure often found in CFST columns in-filled with NC indicate stress concentrations in the concrete. However local buckling often occurring in CRC filled columns show stress concentrations occurring in the steel. This may be attributed 
to the higher deformability caused from presence of crumb rubber. The CRC core deforms under axial compression which may allow for higher axial stress in the steel tube.

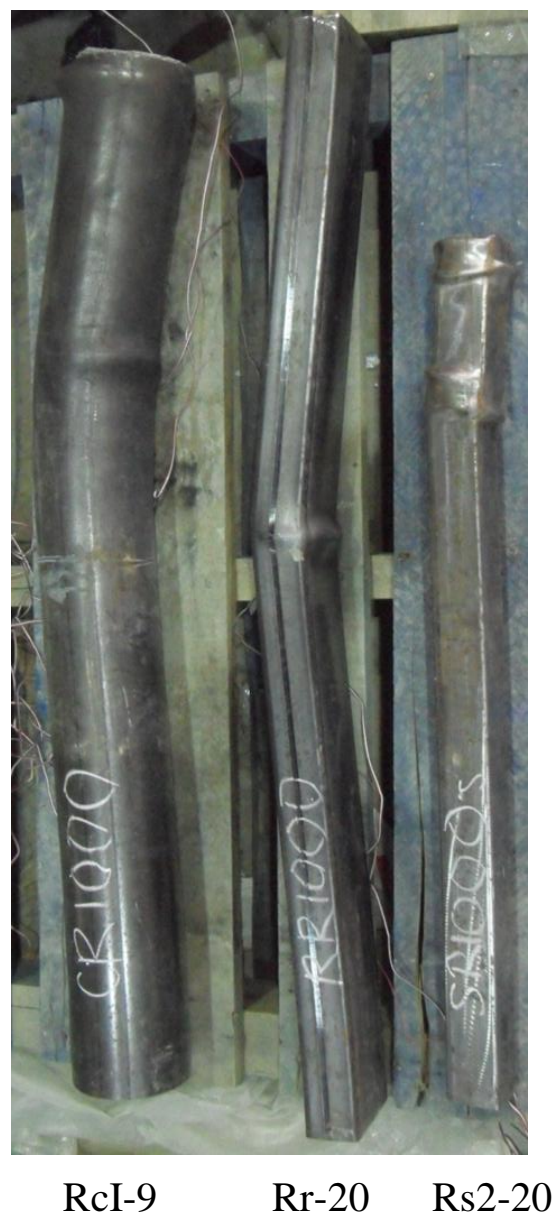

Figure 5.17: Failure modes of CRC-filled CFST columns

Table 5.28: CRC and NC CFST column capacity and concrete strength increase

\begin{tabular}{cccccc}
\hline $\begin{array}{c}\text { Column } \\
\text { Designation }\end{array}$ & $\begin{array}{c}\mathbf{P}_{\mathbf{u}, \mathbf{N C}}, \\
\mathbf{k N}\end{array}$ & $\begin{array}{c}\text { Failure mode } \\
(\mathbf{N C})\end{array}$ & $\begin{array}{c}\mathbf{P}_{\mathbf{u}, \mathbf{C R C}}, \\
\mathbf{k N}\end{array}$ & $\begin{array}{c}\text { Failure mode } \\
(\mathbf{C R C})\end{array}$ & $\begin{array}{c}\mathbf{P}_{\mathbf{u}, \mathbf{C R C}} / \\
\mathbf{P}_{\mathbf{u}, \mathbf{N C}}\end{array}$ \\
\hline $\mathbf{c I - 3}$ & 1410 & Radial expansion & 1146 & Local buckling & 0.81 \\
$\mathbf{c I - 9}$ & 1511 & Shear & 1046 & Global buckling & 0.69 \\
$\mathbf{r - 6}$ & 716 & Shear & 522 & Shear & 0.73 \\
$\mathbf{r - 2 0}$ & 639 & Global buckling & 558 & Global buckling & 0.87 \\
$\mathbf{s 2 - 6}$ & 266 & Shear & 168 & Local buckling & 0.63 \\
$\mathbf{s 2 - 1 6}$ & 296 & Global buckling & 168 & Shear & 0.57 \\
\hline $\mathrm{P}_{\mathrm{u}, \text { NC: }}$ Axial strength of NC-filled CFST columns; $\mathrm{P}_{\mathrm{u}, \text { CRC: }}$ Axial strength of CRC-filled \\
\multicolumn{5}{c}{ CFST columns. } \\
\hline
\end{tabular}


The unconfined cylinder compressive strength $\left(\mathrm{f}_{\mathrm{c}}{ }_{\mathrm{c}}\right)$ of CRC is 0.71 times that of NC. Axial load capacity is also provided in Table 5.28 for NC-filled columns $\left(\mathrm{P}_{\mathrm{u}, \mathrm{NC}}\right)$ and CRC-filled columns $\left(\mathrm{P}_{\mathrm{u}, \mathrm{CRC}}\right) . \mathrm{P}_{\mathrm{u}, \mathrm{CRC}} / \mathrm{P}_{\mathrm{u}, \mathrm{NC}}$ ratios comparing axial strength of CRC filled columns with that of NC filled columns was higher than 0.71 for the case of circular non-reinforced short columns, showing that axial strength of CRC filled tube columns is not directly proportional to concrete compressive strength. However, in most cases $\mathrm{P}_{\mathrm{u}, \mathrm{CRC}} / \mathrm{P}_{\mathrm{u}, \mathrm{NC}}$ values were close to or less than 0.71, suggesting that confinement is less effective in CRC-filled tube columns. As tube thickness decreased, $\mathrm{P}_{\mathrm{u}, \mathrm{CRC}} / \mathrm{P}_{\mathrm{u}, \mathrm{NC}}$ ratios decreased as well.

\subsubsection{Analysis of stress-strain behaviour}

Figure 5.18 shows strain development of specimens RcI-3 (in-filled with CRC) and NcI-3 (infilled with NC) to illustrate typical response of columns.

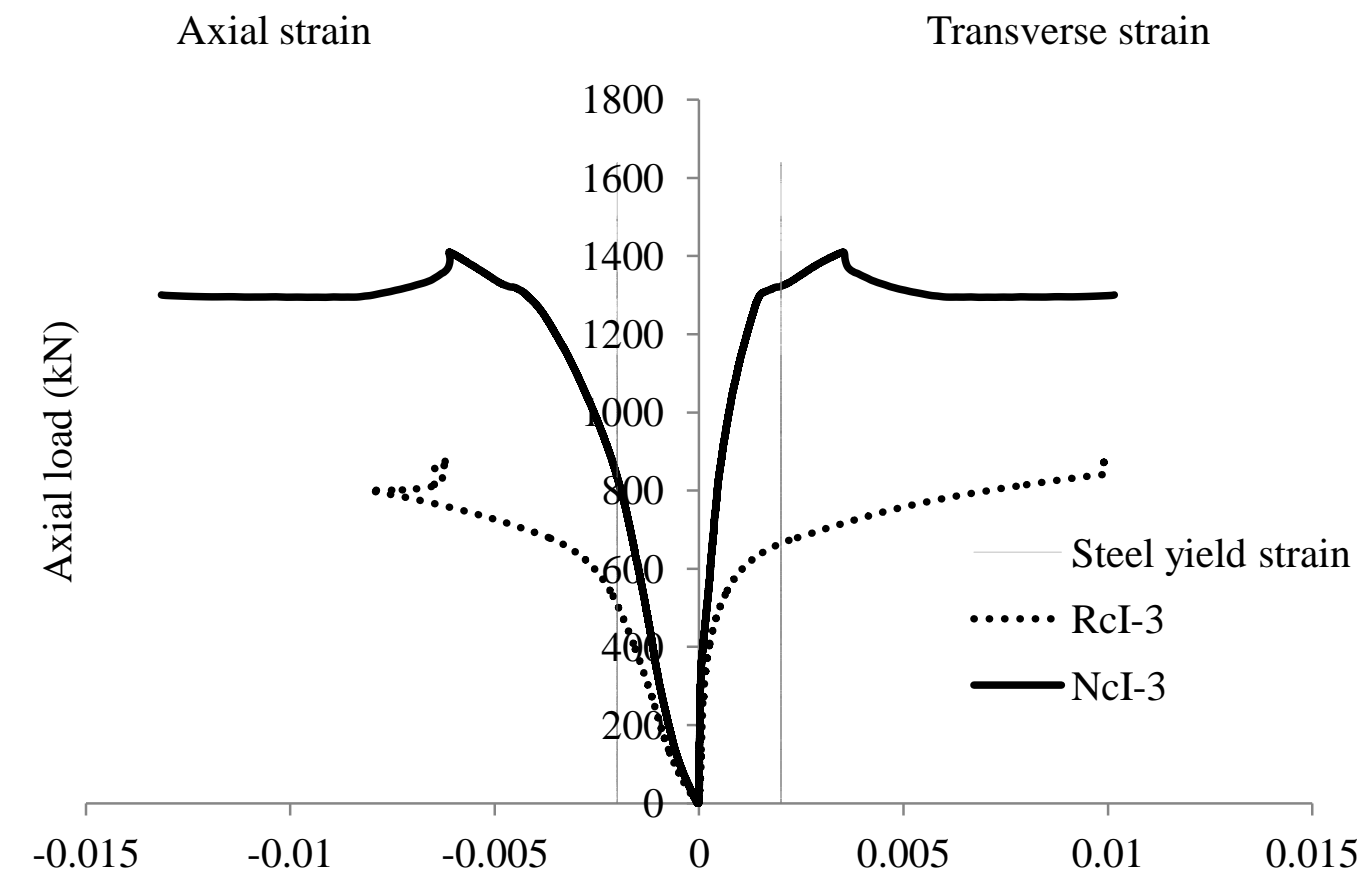

Figure 5.18: Strain development in steel tube of columns filled with CRC and NC 
At initial stages of loading, tube columns in-filled with NC and CRC behave similarly with respect to strain development. However, since NC compressive strength is higher, strain begins to increase significantly at a lower load for CRC-filled tube columns.

Axial load and axial strain at axial capacity of columns $\left(\mathrm{P}_{\mathrm{u}}\right.$ and $\left.\varepsilon_{\mathrm{u}}\right)$ are provided in Table 5.29. Axial load and axial strain are also listed for the point of biaxial steel yielding $\left(\mathrm{P}_{\mathrm{ys}}\right.$ and $\left.\varepsilon_{\mathrm{ys}}\right)$ determined based on von-Mises failure criterion described previously in Eq. 4.1.

Table 5.29: Observed steel yield in CRC and NC CFST columns

\begin{tabular}{|c|c|c|c|c|c|c|}
\hline Column & $\begin{array}{l}\mathbf{P}_{\mathbf{u}}, \\
\mathbf{k N}\end{array}$ & $\varepsilon_{\mathrm{u}}$ & $\begin{array}{l}\mathbf{P}_{\mathbf{y s}}, \\
\mathbf{k N}\end{array}$ & $\varepsilon_{\mathrm{ys}}$ & $\mathbf{P}_{\mathbf{y s}} / \mathbf{P}_{\mathbf{u}}$ & $\varepsilon_{\mathrm{ys}} / \varepsilon_{\mathrm{u}}$ \\
\hline RcI-3 & 1146 & 0.003669 & 423 & 0.000291 & 0.37 & 0.08 \\
\hline RcI-9 & 1046 & 0.003209 & 622 & 0.000232 & 0.59 & 0.07 \\
\hline NeI-3 & 1410 & 0.006110 & 692 & 0.000349 & 0.49 & 0.06 \\
\hline NcI-9 & 1511 & 0.004027 & 950 & 0.000497 & 0.63 & 0.12 \\
\hline Rr-6 & 522 & 0.005563 & 147 & 0.000195 & 0.28 & 0.04 \\
\hline Rr-20 & 558 & 0.002164 & 409 & 0.000162 & 0.73 & 0.07 \\
\hline $\mathrm{Nr}-6$ & 716 & 0.003442 & 366 & 0.000166 & 0.51 & 0.05 \\
\hline $\mathrm{Nr}-20$ & 639 & 0.002560 & 404 & 0.000073 & 0.63 & 0.03 \\
\hline Rs2-6 & 168 & 0.002255 & 139 & 0.000173 & 0.83 & 0.08 \\
\hline Rs2-16 & 168 & 0.001998 & 122 & 0.000252 & 0.73 & 0.13 \\
\hline Ns2-6 & 266 & 0.001844 & 211 & 0.000357 & 0.79 & 0.19 \\
\hline Ns2-20 & 309 & 0.002617 & 178 & 0.000295 & 0.58 & 0.11 \\
\hline $\begin{array}{l}\mathrm{P}_{\mathrm{u}}: \operatorname{axi} \\
\mathrm{P}_{\mathrm{ys}}: \mathrm{ax}\end{array}$ & $\mathrm{dc}$ & tity $\varepsilon_{\mathrm{u}}$ & an & $\begin{array}{l}\text { train at } \\
; \varepsilon_{\mathrm{ys}}: \text { ax } \\
\end{array}$ & 1 loa & $\begin{array}{l}\text { pacity } \\
\text { iaxial }\end{array}$ \\
\hline
\end{tabular}

CRC-filled tube columns usually have lower $\mathrm{P}_{\mathrm{ys}} / \mathrm{P}_{\mathrm{u}}$ ratios compared with NC-filled tube columns. These observations suggest that at initial stages of loading, CRC tends to take on less axial load compared with the steel tube, so that steel yields at load as low as 0.28 times the axial capacity of the column. $\mathrm{P}_{\mathrm{ys}} / \mathrm{P}_{\mathrm{u}}$ ratios also tend to be higher for increasing slenderness ratio of columns in-filled with either $\mathrm{CRC}$ or $\mathrm{NC}$, since longer columns tend to fail by global instability. 
For both $\mathrm{NC}$ and $\mathrm{CRC}$ filled columns, $\varepsilon_{\mathrm{ys}} / \varepsilon_{\mathrm{u}}$ ratios do not reach above 0.19 , indicating that majority of axial strain occurs after biaxial yielding. Steel always yielded both uniaxially and biaxially before failure.

Table 5.30 shows biaxial stress factors for CRC filled tube columns. Although $\beta$ factors are not significantly different between NC and CRC filled columns, $\alpha$ values differed. In CRC filled columns, $\alpha$ factors were generally lower than for NC. For example, for cI columns in-filled with NC having L/D ranging from 3 to $9, \alpha$ factors were between 0.17 and 0.23 . On the other hand, $\alpha$ factors for columns of the same shape and slenderness in-filled with CRC ranged from 0.15 to 0.12. This suggests that transverse stresses did not develop as well for columns in-filled with CRC. These results may be due to the presence of rubber that allows more transverse stress transfer to CRC rather than to the steel tube.

Table 5.30: Biaxial stress factors in CRC CFST columns

\begin{tabular}{cccccc}
\hline & Slenderness ratio & \multicolumn{5}{c}{ Stress concentration factors } \\
\hline Shape & L/D or L/d & $\alpha$ & $\beta$ \\
\hline cI & $3-9$ & $0.15-0.12$ & $0.88-0.93$ \\
r & $4-12$ & $0.12-0.10$ & $0.93-0.94$ \\
s2 & $5-14$ & $0.10-0.14$ & $0.95-0.92$ \\
\hline
\end{tabular}

Confinement is expressed by $\mathrm{f}^{\prime}{ }_{c c} / \mathrm{f}^{\prime}$ ratios where $\mathrm{f}^{\prime}{ }_{c c}$ is experimental confined concrete strength obtained from stress strain graphs shown in Figure 4.3 , and $\mathrm{f}_{\mathrm{c}} \mathrm{c}$ is the unconfined concrete cylinder compressive strength. Table 5.31 lists concrete strength and confinement for CRC and NC filled tube columns. In most cases, confinement was greater in NC-filled tube columns. CRC may have less efficiency for transferring lateral stresses to the steel tube, since crumb rubber can take stresses in concrete rather than transferring them to the steel tube. Maximum lateral pressure listed in Table 5.31, $\mathrm{f}_{2 \max }$ calculated based on Eq. 4.7, shows values corresponding to CRC filled tube columns are lower compared with NC. As tube thickness decreased, $\mathrm{f}_{\mathrm{cc}}^{\prime} / \mathrm{f}_{\mathrm{c}}^{\prime}$ and $\mathrm{f}_{2 \max }$ 
increased. Confinement was not effective in CRC square and rectangular columns, since $f_{c c}^{\prime} / f^{\prime}{ }_{c}$ fell close to or below a value of 1 .

Table 5.31: Quantified concrete confined strength and lateral pressure in CRC and NC CFST columns

\begin{tabular}{ccccc}
\hline Column & $\mathbf{f}^{\prime}, \mathbf{M P a}$ & $\mathbf{f}^{\prime}{ }_{\mathbf{c c}}, \mathbf{M P a}$ & $\mathbf{f}^{\prime}{ }_{\mathbf{c c}} \mathbf{f}_{\mathbf{c}}{ }_{\mathbf{c}}$ & $\mathbf{f}_{\mathbf{2 m a x}}, \mathbf{M P a}$ \\
\hline RcI-3 & 46 & 77 & 1.66 & 4.7 \\
RcI-9 & 46 & 62 & 1.34 & 3.7 \\
NcI-3 & 66 & 108 & 1.64 & 5.6 \\
NcI-9 & 66 & 126 & 1.91 & 8.0 \\
Rr-6 & 46 & 47 & 1.02 & 3.9 \\
Rr-20 & 46 & 55 & 1.18 & 3.2 \\
Nr-6 & 66 & 92 & 1.41 & 3.3 \\
Nr-20 & 66 & 71 & 1.09 & 1.5 \\
Rs2-6 & 46 & 26 & 0.57 & 2.1 \\
Rs2-16 & 46 & 28 & 0.60 & 3.0 \\
Ns2-6 & 66 & 73 & 1.11 & 4.3 \\
Ns2-20 & 66 & 91 & 1.38 & 3.6 \\
\hline
\end{tabular}

$\mathrm{f}_{\mathrm{c}}$ : unconfined concrete control cylinder compressive strength; $\mathrm{f}_{\mathrm{cc}}{ }_{\mathrm{c}}$ : experimental confined concrete strength; $f_{2 \max }$ : maximum lateral stress.

Experimental confinement was then compared with calculated values of $\mathrm{f}^{\prime}$ cct based on Richart et al. (1928), Mander et al. (1988), O’Shea and Bridge (2000), and Hossain (2003b) (Eqs. 4.20, 4.21, 4.22, and 4.14 respectively). As shown in Table 5.32, all equations performed well for estimating confined strength of NC and CRC circular filled tube columns (theoretical/test ratios ranged from 0.80 to 1.10 ), but over-estimated for square and rectangular columns in-filled with CRC. Over-estimations were more significant when using the Mander et al. - based, O'Shea and Bridge-based, and Hossain (2003b) models. Square (s2) CRC-filled column confined strength was particularly over-predicted (up to $46 \%$ greater than the experimental value), but to a lesser degree when using the Richart et al.-based equation which yielded a value $32 \%$ greater than the experimental value. 
Table 5.32: Validation of models for confined concrete strength in CRC and NC filled CFST columns

\begin{tabular}{|c|c|c|c|c|c|c|c|c|c|}
\hline \multirow[t]{3}{*}{ Column } & \multicolumn{5}{|c|}{$\begin{array}{c}\text { Confined concrete strength }\left(\mathbf{f}^{\prime}{ }_{\text {cct }}\right) \text {, } \\
\text { MPa }\end{array}$} & \multicolumn{4}{|c|}{ Ratio Theoretical/Test } \\
\hline & \multirow[t]{2}{*}{ Test } & \multicolumn{4}{|c|}{ Theoretical models } & \multirow[b]{2}{*}{$\begin{array}{l}\text { Eq. } \\
4.20\end{array}$} & \multirow[b]{2}{*}{$\begin{array}{l}\text { Eq. } \\
4.21\end{array}$} & \multirow[b]{2}{*}{$\begin{array}{l}\text { Eq. } \\
4.22\end{array}$} & \multirow[b]{2}{*}{$\begin{array}{l}\text { Eq. } \\
4.14\end{array}$} \\
\hline & & $\begin{array}{l}\text { Eq. } \\
4.20\end{array}$ & $\begin{array}{l}\text { Eq. } \\
4.21\end{array}$ & $\begin{array}{l}\text { Eq. } \\
4.22\end{array}$ & $\begin{array}{l}\text { Eq. } \\
4.14\end{array}$ & & & & \\
\hline RcI-3 & 77 & 65 & 73 & 67 & 66 & 0.85 & 0.94 & 0.87 & 0.85 \\
\hline RcI-9 & 62 & 62 & 68 & 63 & 62 & 0.99 & 1.09 & 1.01 & 0.99 \\
\hline NcI-3 & 108 & 89 & 98 & 90 & 89 & 0.82 & 0.91 & 0.84 & 0.82 \\
\hline NcI-9 & 126 & 98 & 109 & 100 & 98 & 0.78 & 0.87 & 0.80 & 0.78 \\
\hline Rr-6 & 47 & 62 & 69 & 64 & 64 & 1.32 & 1.46 & 1.35 & 1.36 \\
\hline Rr-20 & 55 & 60 & 66 & 61 & 61 & 1.09 & 1.20 & 1.11 & 1.12 \\
\hline Nr-6 & 92 & 79 & 86 & 80 & 82 & 0.86 & 0.93 & 0.87 & 0.88 \\
\hline Nr-20 & 71 & 72 & 75 & 70 & 74 & 1.00 & 1.05 & 0.99 & 1.04 \\
\hline Rs2-6 & 26 & 55 & 59 & 55 & 58 & 2.09 & 2.26 & 2.11 & 2.22 \\
\hline Rs2-16 & 28 & 59 & 65 & 60 & 62 & 2.12 & 2.33 & 2.15 & 2.24 \\
\hline Ns2-6 & 73 & 83 & 92 & 85 & 88 & 1.14 & 1.25 & 1.16 & 1.21 \\
\hline Ns2-20 & 91 & 80 & 88 & 81 & 85 & 0.88 & 0.96 & 0.90 & 0.94 \\
\hline
\end{tabular}

\subsubsection{Identification of best model for CRC CFST column strength prediction}

Axial strength of CFST columns in-filled with CRC and NC are calculated by applying confinement models based on the work of Richart et al. (1928), Mander et al. (1988), and O'Shea and Bridge (2000) in Eqs. 4.28, 4.29, and 4.30, and the Hossain (2003b) model in Eq. 4.26. Theoretical to experimental axial strength ratio $\left(\mathrm{P}_{\mathrm{p}} / \mathrm{P}_{\mathrm{u}}\right)$ shown in Table 5.33 is used to compare various CFST axial strength models in calculating ultimate axial load of CRC and NC filled columns. Analytical models from Eqs. 4.26, 4.28, 4.29, and 4.30 generally were able to predict within 0.86 to 1.10 times the axial capacity obtained experimentally. However for square (s2) columns, $\mathrm{P}_{\mathrm{p}} / \mathrm{P}_{\mathrm{u}}$ ratios rose up to values of 1.39 for shorter columns and 1.44 for longer columns in-filled with CRC. All models had a similar problem when estimating strength of square CRCfilled tube columns. However, the Richart et al. - based model over-predicted to a lesser degree. 
For example, $\mathrm{P}_{\mathrm{p}} / \mathrm{P}_{\mathrm{u}}$ of 1.36 for column Rs2-16 based on the Richart model was lower than 1.44 of Mander based one. This is likely because the Richart et al. model does not assume concrete compressive strength to be directly proportional to the confined strength of CFST columns.

Table 5.33: Comparative study of CRC and NC CFST column strength prediction by analytical models

\begin{tabular}{|c|c|c|c|c|c|c|c|c|c|}
\hline & \multirow{3}{*}{$\begin{array}{c}\begin{array}{c}\text { Tested } \\
\text { axial } \\
\text { strength }\end{array} \\
\mathbf{P}_{\mathrm{u}}, \mathrm{kN}\end{array}$} & \multicolumn{4}{|c|}{ Theoretical strength $P_{p}, k N$} & \multirow{2}{*}{\multicolumn{4}{|c|}{$\mathbf{P}_{\mathbf{p}} / \mathbf{P}_{\mathbf{u}}$}} \\
\hline & & Richart & Mander & O'Shea & Hossain & & & & \\
\hline Column & & $\begin{array}{l}\text { Eq. } \\
4.28\end{array}$ & $\begin{array}{l}\text { Eq. } \\
4.29\end{array}$ & $\begin{array}{l}\text { Eq. } \\
4.30\end{array}$ & $\begin{array}{c}\text { Eq. } \\
4.26\end{array}$ & $\begin{array}{l}\text { Eq. } \\
4.28\end{array}$ & $\begin{array}{c}\text { Eq. } \\
4.29\end{array}$ & $\begin{array}{l}\text { Eq. } \\
4.30\end{array}$ & $\begin{array}{l}\mathrm{Eq} . \\
4.26\end{array}$ \\
\hline RcI-3 & 1146 & 1046 & 1108 & 1058 & 1046 & 0.91 & 0.97 & 0.92 & 0.91 \\
\hline RcI-9 & 1046 & 1040 & 1097 & 1052 & 1041 & 0.99 & 1.05 & 1.01 & 1.00 \\
\hline NcI-3 & 1410 & 1244 & 1325 & 1261 & 1245 & 0.88 & 0.94 & 0.89 & 0.88 \\
\hline NcI-9 & 1511 & 1296 & 1389 & 1313 & 1298 & 0.86 & 0.92 & 0.87 & 0.86 \\
\hline Rr-6 & 522 & 543 & 572 & 549 & 551 & 1.04 & 1.10 & 1.05 & 1.05 \\
\hline Rr-20 & 558 & 534 & 561 & 539 & 542 & 0.96 & 1.01 & 0.97 & 0.97 \\
\hline Nr-6 & 716 & 620 & 650 & 623 & 631 & 0.87 & 0.91 & 0.87 & 0.88 \\
\hline Nr-20 & 639 & 596 & 612 & 591 & 607 & 0.93 & 0.96 & 0.92 & 0.95 \\
\hline Rs2-6 & 168 & 223 & 233 & 223 & 230 & 1.33 & 1.39 & 1.33 & 1.37 \\
\hline Rs2-16 & 168 & 229 & 242 & 231 & 237 & 1.36 & 1.44 & 1.38 & 1.41 \\
\hline Ns2-6 & 266 & 282 & 301 & 285 & 293 & 1.06 & 1.13 & 1.07 & 1.10 \\
\hline Ns2-16 & 296 & 278 & 296 & 281 & 289 & 0.94 & 1.00 & 0.95 & 0.98 \\
\hline Ns2-20 & 309 & 277 & 294 & 279 & 288 & 0.90 & 0.95 & 0.90 & 0.93 \\
\hline
\end{tabular}

Predictions for axial strength of CFST columns from the Lachemi et al. (2006b) model based on confinement equations from the work of Richart et al. (1928) (Eq. 4.28) were compared with design strength obtained from CSA (2009), AISC (2005), and Eurocode (2004) (Eqs. 4.23, 4.24, and 4.25 respectively) in Table 5.34. Predicted to experimental ultimate axial load ratios $\left(\mathrm{P}_{\mathrm{p}} / \mathrm{P}_{\mathrm{u}}\right)$ are graphed if Figure 5.19. The Lachemi et al. (2006b) model, CSA (2009), and Eurocode (2004) over-estimated axial strength of rectangular and square CRC-filled CFST columns in several cases. These models were developed so that square and rectangular columns must be converted to an equivalent circular section in order for equations to be applicable. However, the AISC 
(2005) provided factors to account for cross-sectional shape, leading to more conservative results when predicting axial strength of square and rectangular CRC and NC filled CFST columns.

Table 5.34: CRC and NC CFST column strength predictions from model and design codes

\begin{tabular}{cccccc}
\hline & $\begin{array}{c}\text { Tested } \\
\text { axial } \\
\text { strength }\end{array}$ & Lachemi & $\begin{array}{c}\text { Theoretical axial strength } \mathbf{P}_{\mathbf{p}}, \mathbf{k N} \\
\text { CSA }\end{array}$ & AISC & Eurocode \\
\hline Column & $\mathbf{P}_{\mathbf{u}}$, $\mathbf{k N}$ & Eq. 4.28 & Eq. 4.23 & Eq. 4.24 & Eq. 4.25 \\
RcI-3 & 1146 & 1046 & 1204 & 920 & 1248 \\
RcI-9 & 1046 & 1040 & 1000 & 860 & 1014 \\
NcI-3 & 1410 & 1244 & 1317 & 1076 & 1438 \\
NcI-9 & 1511 & 1296 & 1108 & 1002 & 1220 \\
Rr-6 & 522 & 543 & 613 & 454 & 601 \\
Rr-20 & 558 & 534 & 438 & 386 & 556 \\
Nr-6 & 716 & 620 & 671 & 524 & 694 \\
Nr-20 & 639 & 596 & 481 & 439 & 679 \\
Rs2-6 & 168 & 223 & 237 & 188 & 246 \\
Rs2-16 & 168 & 229 & 179 & 164 & 235 \\
Ns2-6 & 266 & 282 & 267 & 224 & 297 \\
Ns2-16 & 296 & 278 & 204 & 193 & 295 \\
Ns2-20 & 309 & 277 & 177 & 176 & 337 \\
\hline
\end{tabular}

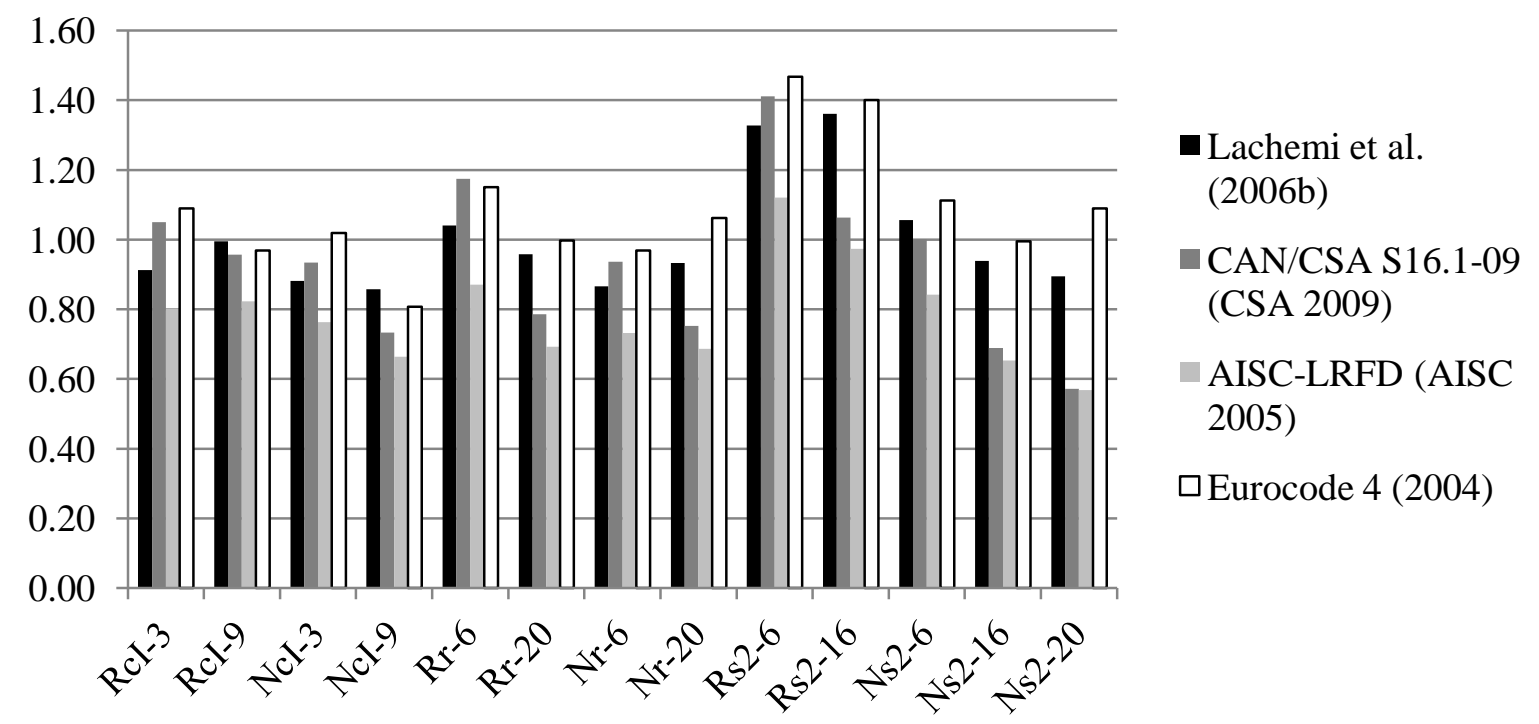

Figure 5.19: Performance of model for prediction of CRC and NC filled CFST column strength 


\subsection{Comparative study}

The axial load displacement response of steel tubes in-filled with different concretes varied based on concrete strength as shown in Figure 5.20. Columns with concretes having comparably higher strength (NC and UHSC) showed a more significant peak load. Columns in-filled with comparably lower strength concretes (ECC, CRC, and LWC) had relatively smooth transition from elastic to plastic regions without any significant load decrease.

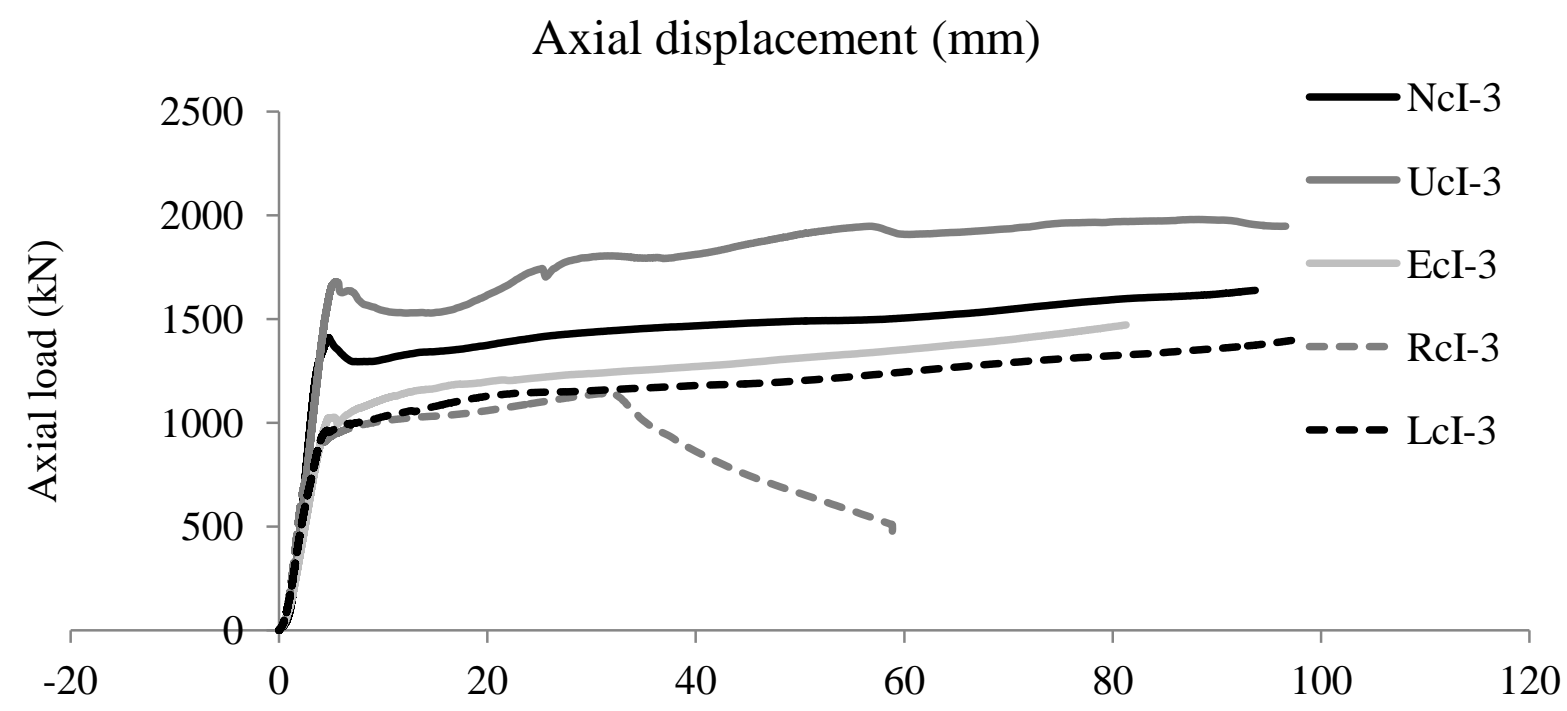

Figure 5.20: Axial load displacement of steel tubes in-filled with different concretes

The axial and transverse strain behaviour of steel tube columns in-filled with various concretes are compared in Figure 5.21. Strain characteristics also differed based on compressive strength of concrete in-fill. UHSC and NC did not show great increase in strain at early stages of loading, and both concretes had comparably higher compressive strength. On the other hand, ECC, CRC, and LWC had lower compressive strength, and high rate of strain increase even at early stages of loading. 


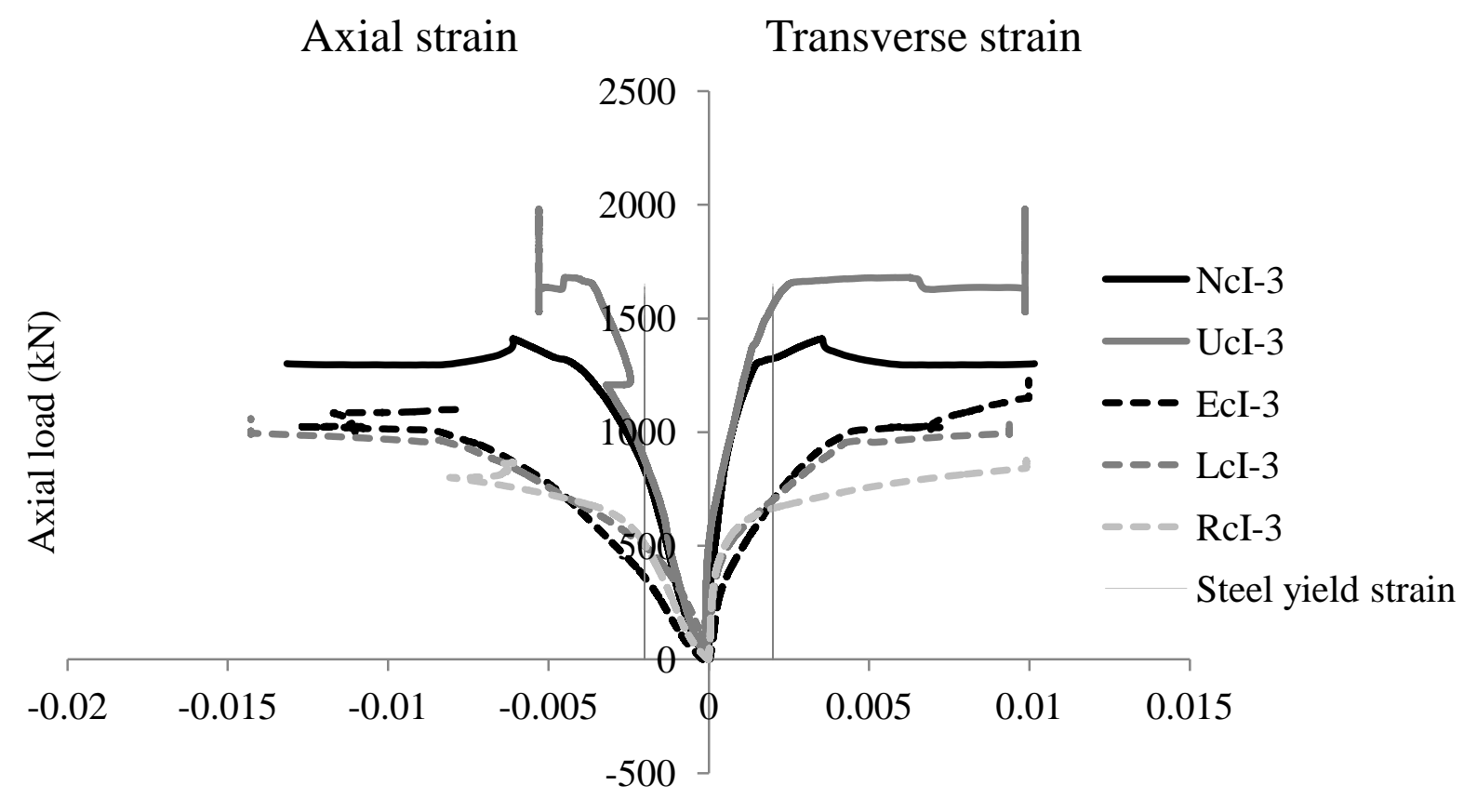

Figure 5.21: Steel strain for tube columns in-filled with different concretes

Axial strengths of NC-filled columns were taken as a basis in order to compare strengths of CFST columns in-filled with different types of concretes. $\mathrm{P}_{\mathrm{u}, \mathrm{x}} / \mathrm{P}_{\mathrm{u}, \mathrm{NC}}$ compares the increase in axial capacity of CFST columns in-filled with concrete $x\left(\mathrm{P}_{\mathrm{u}, \mathrm{x}}\right)$ with reference to axial strength of columns with the same dimensions in-filled with $\mathrm{NC}\left(\mathrm{P}_{\mathrm{u}, \mathrm{NC}}\right)$. The increase in unconfined compressive concrete strength of concrete $\mathrm{x}\left(\mathrm{f}_{\mathrm{c}, \mathrm{x}}{ }_{\mathrm{x}}\right)$ is also determined with respect to that of $\mathrm{NC}$ $\left(\mathrm{f}_{\mathrm{c}, \mathrm{NC}}\right)$ by $\mathrm{f}_{\mathrm{c}, \mathrm{x}} / \mathrm{f}_{\mathrm{c}, \mathrm{NC}}$ ratios. The strength enhancement factor, $\theta$, given in Eq. 5.1 compares the increase in axial capacity with the increase in concrete compressive strength where $\mathrm{x}$ is any concrete used as in-fill material in CFST columns. For $\theta=1$, the increase in axial capacity of CFST columns is equal to the increase in concrete compressive strength. When $\theta$ is less than 1 , the increase in axial strength of CFST columns is not as great as the increase in concrete compressive strength. Values of $\theta$ greater than 1 indicate that increased axial strength of CFST columns due to confinement is greater than the increase in concrete compressive strength. 
$\theta_{\mathrm{x}}=\frac{\mathrm{P}_{\mathrm{u}, \mathrm{x}}{ }^{\prime}{ }_{\mathrm{c}, \mathrm{NC}}}{\mathrm{P}_{\mathrm{u}, \mathrm{NC}} \mathrm{f}^{\prime} \mathrm{c}, \mathrm{x}}$

Strength enhancement factors shown in Table 5.35, $\theta$, were found to be greatest in LWC-filled CFST columns, followed by those of CRC-filled columns, NC-filled columns $(\theta=1)$, ECC-filled columns, and UHSC-filled columns. These results suggest that behaviour of CFST columns changes with different core materials, and that certain core materials are more efficient in increasing column strength (such as LWC). For concretes which lacked coarse aggregate (UHSC and ECC), axial strength enhancement was typically lower ( $\theta$ ranged from 0.54 to 1.11 ). In addition, concretes with lower compressive strength (LWC and CRC) showed greater strength enhancement. This may be because the geometric and material properties of steel sections used in this research were not optimized especially for fibre-reinforced concretes. The use of high strength steel or a section with greater thickness would have provided better confinement.

Table 5.35: Comparison of CFST axial strength with respect to NC-filled column capacity

\begin{tabular}{ccccc}
\hline $\begin{array}{c}\text { Column } \\
\text { Designation }\end{array}$ & $\boldsymbol{\theta}_{\text {UHSC }}$ & $\boldsymbol{\theta}_{\text {ECC }}$ & $\boldsymbol{\theta}_{\text {LWC }}$ & $\boldsymbol{\theta}_{\text {CRC }}$ \\
\hline CI-3 & 0.62 & 0.96 & 1.48 & 1.15 \\
cI-4 & 0.59 & 0.99 & 1.40 & NA \\
cI-9 & 0.54 & 0.97 & 1.18 & 0.98 \\
cII-3 & 0.60 & 0.66 & 1.44 & NA \\
cII-4 & 0.61 & 0.66 & 1.29 & NA \\
cII-9 & 0.57 & 0.97 & 1.28 & NA \\
r-6 & 0.58 & 0.88 & 1.31 & 1.03 \\
r-12 & 0.64 & 0.95 & 1.18 & NA \\
r-20 & 0.61 & 1.11 & 1.40 & 1.23 \\
s4-3 & 0.65 & 1.01 & 1.33 & NA \\
s4-6 & 0.61 & 0.92 & 1.20 & NA \\
$\mathbf{s 4 - 1 0}$ & 0.62 & 0.97 & 1.22 & NA \\
s2-6 & 0.64 & 0.87 & 1.28 & 0.89 \\
s2-9 & 0.66 & 0.84 & 1.26 & NA \\
s2-12 & 0.57 & 0.72 & 1.06 & NA \\
s2-16 & 0.64 & 0.80 & 1.18 & 0.81 \\
s2-20 & 0.54 & 0.78 & 0.98 & NA \\
\hline
\end{tabular}


Table 5.36 lists confined strength ratios of CFST columns in-filled with different concretes derived from experimental confined strength $\left(\mathrm{f}^{\prime}{ }_{\mathrm{cc}}\right)$ and concrete compressive strength $\left(\mathrm{f}^{\prime}{ }_{\mathrm{c}}\right)$. Ratios of $\mathrm{f}_{\mathrm{cc}}^{\prime} \mathrm{f}_{\mathrm{c}}{ }_{\mathrm{c}}$ are highest in LWC-filled CFST columns, meaning confinement is more effective. Once again, as concrete compressive strength increased, the effects from confinement lessened. Therefore, although NC has higher compressive strength, it is less efficient in CFST strength enhancement compared to weaker concretes such as LWC and CRC. Confinement is also lower in UHSC and ECC filled tube columns, in which coarse aggregates were not incorporated.

Table 5.36: Quantified concrete confined strength of CFST columns

\begin{tabular}{|c|c|c|c|c|c|}
\hline \multirow[t]{2}{*}{ Column } & \multicolumn{5}{|c|}{$\mathbf{f}_{\mathrm{cc}}^{\prime} / \mathbf{f}^{\prime}{ }_{\mathrm{c}}$} \\
\hline & $\mathbf{N C}$ & UHSC & ECC & LWC & $\overline{C R C}$ \\
\hline cI-3 & 1.64 & 1.09 & 1.21 & 2.18 & 1.66 \\
\hline cI-9 & 1.91 & 0.99 & 1.37 & 1.59 & 1.34 \\
\hline cII-3 & 1.96 & 1.27 & 0.69 & 2.53 & NA \\
\hline cII-9 & 1.94 & 1.11 & 1.55 & 1.91 & NA \\
\hline$r-6$ & 1.41 & 0.89 & 0.71 & 1.47 & 1.02 \\
\hline $\mathrm{r}-20$ & 1.09 & 0.81 & 0.98 & 1.21 & 1.18 \\
\hline s4-3 & 1.4 & 0.98 & 1.17 & 1.45 & NA \\
\hline s4-10 & 1.36 & 0.92 & 1.02 & 1.3 & NA \\
\hline s2-6 & 1.11 & 0.8 & 0.65 & 1.07 & 0.57 \\
\hline s2-16 & NA & NA & NA & NA & 0.6 \\
\hline s2-20 & 1.38 & 0.78 & 0.71 & 0.94 & NA \\
\hline
\end{tabular}




\section{Chapter Six}

\section{CONCLUSIONS AND RECOMMENDATIONS}

\subsection{Conclusions}

Circular, square, rectangular concrete filled steel tube (CFST) columns with various in-fill materials and slenderness (measured by length-to-diameter/depth ratio), with or without internal bar reinforcements, were tested under axial compression. Various concrete core materials included normal concrete (NC), and self-consolidating concretes such as fibre-reinforced ultrahigh-strength concrete (UHSC), Engineered Cementitious Composite (ECC), slag aggregate lightweight concrete (LWC), and crumb rubber concrete (CRC). The behaviour of CFST columns was analyzed with respect to failure modes, load-displacement responses, and stressstrain characteristics. Existing analytical models for confined concrete strength were evaluated against experimental results in order to determine their applicability for different types of CFST columns in-filled with various concretes. The performance of analytical and code-based design equations was evaluated for predicting axial strength of CFST columns. The following are conclusions obtained from this research:

- Failure modes of columns can be classified based on slenderness ratio, but also depending on compressive strength of concrete in-fill. CFST columns with slenderness ratio of 3 failed by radial expansion in most cases, regardless of type of concrete core. For slenderness ratio from 4 to 6, columns failed by shear or local buckling, and slenderness ratio ranging from 9 to 20 resulted in failure by shear or global buckling. CFST columns with higher concrete compressive strength failed more often due to shear, for example those filled with NC and UHSC. With weaker concrete in-fill such as CRC, LWC, and ECC, columns failed due to 
local buckling in most cases. This can be attributed to the less axial load transferred to the steel tube when concrete compressive strength was higher - thus concrete shear failure often resulted. However, the steel tube tended to take on more load when the concrete core was weaker, resulting in failure due to steel local buckling.

- Change in axial strain was greatest in steel tube columns in-filled with CRC, since steel yield strain was almost always less than $10 \%$ the strain at ultimate load. The CRC-filled tube columns were capable of taking large amounts of strain before ultimate load was reached. Yield strain as a percentage of strain at ultimate load increased with LWC, ECC, UHSC, and NC filled tube columns. NC-filled tubes yielded at up to $85 \%$ of strain at ultimate load, and were least effective in accommodating deformations. In all cases, steel yielded both uniaxially and biaxially before ultimate axial load was reached. Change in axial strain was typically lower in CFST columns with bar reinforcements, and increased in square and rectangular sections.

- Stress concentration factors ( $\alpha$ is the transverse stress factor, and $\beta$ is the axial stress factor) were determined from experimental strain development based on biaxial failure theory (vonMises criterion). These axial and transverse stress factors are used to quantify concrete confined strength and ultimate capacity of CFST columns. The axial stress factor was always greater than corresponding transverse stress factor in all cases, since load was applied in the axial direction. The axial stress factors did not change greatly with respect to concrete in-fill, as values remained within a range of 0.81 to 0.98 . The range of transverse stress factors was slightly greater from 0.05 to 0.25 . However, circular CFST columns often had slightly lower axial stress factors, and higher transverse stress factors. This was likely due to better concrete confinement in circular CFST columns. 
- The effect of concrete confinement was most significant in LWC filled tube columns, as confined concrete strength reached up to $153 \%$ of unconfined concrete compressive strength. The effect of confinement decreased for NC, CRC, ECC, and UHSC filled tube columns. UHSC filled tubes often achieved confined strength less than that of unconfined concrete strength with a maximum $20 \%$ decrease, which is likely attributed to failure by other methods besides concrete crushing (for example, local buckling or global buckling). Confined concrete strength increased with the presence of bar reinforcements, and decreased for columns with smaller steel tube thickness. Thus, confinement was most effective in concretes containing coarse aggregates without fibre reinforcements.

- Axial strength of filled-tube columns was found to increase with concrete compressive strength and cross-sectional area. However, strength enhancement was most prominent in LWC, followed by CRC and NC. LWC-filled steel tube axial strength enhancement reached up to $48 \%$ more than that of NC filled columns. UHSC and ECC, neither of which contained coarse aggregates, showed the least strength enhancement. UHSC filled column strength enhancement was only $54 \%$ to $65 \%$ that of NC filled columns. Thus, the use of CFST columns was most efficient with LWC, CRC, and NC.

- Analytical models which did not assume direct proportionality between concrete compressive strength and confinement performed better in estimating confined strength and CFST axial capacity. Overall, existing analytical models for predicting confined concrete strength and ultimate load of CFST columns tended to perform better for circular sections, and in columns filled with concretes with coarse aggregate components. As estimations for axial strength of circular columns in-filled with these concretes ranged from $74 \%$ to $123 \%$ of experimental values. This is because analytical models were developed based on 
experiments on cylindrical-shaped $\mathrm{NC}$, and concretes containing coarse aggregates behave more similarly to NC. Calculated results were closest to experimental values when slenderness ratio was less than 6 , since theoretical models were not developed to account for global instability failures in longer columns.

- Comparing code-based design procedures with experimental results showed that equations were capable of estimating strength of circular CFST columns with or without bar reinforcements. Code-based equations which did not provide any factors accounting for cross-sectional shape overestimated axial strength of square and rectangular CFST by up to 47\% more than the experimental values. Code procedures which incorporated a factor to account for cross-sectional shape rather than converting square and rectangular sections to an equivalent circle had better performance, and were therefore considered safer. The maximum CFST axial strength over-prediction from those equations was $12 \%$ more than experimental axial strength for shorter columns.

\subsection{Recommendations for future research}

This research focused on the behaviour of concentrically loaded steel tube columns in-filled with various high-performance concretes. Load was applied across both concrete and steel simultaneously (Type A loading) on circular, square, and rectangular columns. Specimens ranged in slenderness ratios from 3 to 20 and breadth-to-thickness or diameter-to-thickness ratios from 24 to 32 .

- There is still room to widen the range of CFST column slenderness and breadth-to-thickness or diameter-to-thickness ratios in future research. This will expand the use of filled steel tube columns in-filled with high-performance concretes in structural applications. 
- Aspect ratios (breadth-to-depth ratio) of rectangular and square CFST columns tested in this research were limited to values of 1 and 2. A broader range of steel tube aspect ratios can be studied in the future. This will allow for better understanding of the effects of aspect ratio on behaviour of filled steel tube columns in-filled with high-performance concretes.

- Besides Type A loading, situations may arise in practical applications where load is applied on the concrete core only (Type B loading). Thus, additional research is necessary to understand the behaviour of steel tube columns in-filled with modern high-performance concretes under Type B loading.

- In addition to concentric loading, future research on the behaviour of tube columns filled with high-performance concretes under eccentric and cyclic loading will enlarge the potential applications of these composite structural elements.

- Fire resistance of CFSTs is a common concern, and must be carefully studied before applying these columns in-filled with various high-performance concretes in practice. Future research is necessary to determine the effects of UHSC, ECC, LWC, and CRC on behaviour of CFST columns under elevated temperatures. 


\section{REFERENCES}

Abdelrahman, M. A., \& Carpenter, S. H. (1999). Mechanism of interaction of asphalt cement with crumb rubber modifier. Transportation Research Record: Journal of the Transportation Research Board, 1661(1), 106-113.

Airey, G. D., Singleton, T. M., \& Collop, A. C. (2002). Properties of polymer modified bitumen after rubber-bitumen interaction. Journal of Materials in Civil Engineering, 14(4), 344354.

AISC (2005). Manual of steel construction: Load and resistance factor design (LRFD). American Institute of Steel Construction. Chicago, Illinois.

Allen, H. G. (1971). Stiffness and strength of two glass-fiber reinforced cement laminates. Journal of Composite Materials, 5(2), 194-207.

Aveston, J., Cooper, G. A., \& Kelly, A. (1971). Single and multiple fracture. Paper presented at The Properties of Fiber Composites Conference, Guildford, U.K., (pp. 15-24). IPC Science and Technology Press.

Bahia, H. U., \& Davies, R. (1994). Effect of crumb rubber modifiers (CRM) on performance related properties of asphalt binders. Asphalt Paving Technology, 63(1), 414-449.

Benazzouk, A., \& Queneudec, M. (2002). Durability of cement-rubber composites under freeze thaw cycles. Paper presented at The International Conference: Sustainable Concrete Construction, University of Dundee, Scotland, UK, (pp. 356-362).

Bukovská, P., \& Karmazínová, M. (2012). Behaviour of the tubular columns filled by concrete subjected to buckling compression. Procedia Engineering, 40(1), 68-73. 
Cattaneo, S., Giussani, F., \& Mola, F. (2012). Flexural behaviour of reinforced, prestressed and composite self-consolidating concrete beams. Construction and Building Materials, 36(1), 826-837.

Chitawadagi, M. V., Narasimhan, M. C., \& Kulkarni, S. M. (2010). Axial strength of circular concrete-filled steel tube columns - DOE approach. Journal of Constructional Steel Research, 66(10), 1248-1260.

Chou, L. H., Lu, C. K., Chang, J. R., \& Lee, M. T. (2007). Use of waste rubber as concrete additive. Waste Management and Research, 25(1), 68-76.

CSA (2009). Limit states design of steel structures. CAN/CSA S16-09. Canadian Standards Association.

de Oliveira, W., De Nardin, S., de Cresce El Debs, A., \& El Debs, M. (2009). Influence of concrete strength and length/diameter on the axial capacity of CFT columns. Journal of Constructional Steel Research, 65(12), 2103-2110.

Dong, Q., Huang, B., \& Shu, X. (2013). Rubber modified concrete improved by chemically active coating and silane coupling agent. Construction and Building Materials, 48(1), 116-123.

Dundu, M. (2012). Compressive strength of circular concrete filled steel tube columns. ThinWalled Structures, 56(1), 62-70.

EFNARC. (2005). Specifications and guidelines for self-compacting concrete. The European Federation of Specialist Construction Chemicals and Concrete Systems.

Eldin, N. N., \& Senouci, A. B. (1993). Rubber-tire practices as concrete aggregate. Journal of Materials in Civil Engineering, 5(4), 478-496. 
El-Dieb, A. S. (2009). Mechanical, durability and microstructural characteristics of ultra-highstrength self-compacting concrete incorporating steel fibers. Material and Design, 30(10), 4286-4292.

El-Dieb, A. S., \& Reda-Taha, M. M. (2012). Flow characteristic and acceptance criteria of fiberreinforced self-compacted concrete (FR-SCC). Construction and Building Materials, 27(1), 585-596.

Eurocode 4. (2004). Design of composite steel and concrete structures: Part 1.1: General rules and rules for buildings. British Standards Institution, London.

Fam, A., Qie, F. S., \& Rizkalla, S. (2004). Concrete filled steel tubes subjected to axial compression and lateral cyclic loads. Journal of Structural Engineering, 130(4), 631-640.

Fava, C., Bergol, L., Fornasier, G., Giangrasso, F., \& Rocco, C. (2003). Fracture behaviour of self -compacting concrete. Paper presented at The 3rd International RILEM Symposium on Self-Compacting Concrete. (pp. 628-636.). Reykjavik: RILEM Publications S.A.R.L.

Fischer, G., Wang, S., \& Li, V. C. (2003). Design of engineered cementitious composites for processing and workability requirements. Paper presented at the $7^{\text {th }}$ International Symposium on Brittle Matrix Composites, Warsaw, Poland, 13-15 October (pp. 29-35).

Gardner, N., \& Jacobson, E. (1967). Structural behavior of concrete-filled steel tubes. ACI Journal, 64(7), 404-412.

Giakoumelis, G., \& Lam, D. (2004). Axial capacity ofcircular concrete-filled tube columns. Journal of Constructional Steel Research, 60(7), 1049-1068.

Gupta, P., Sarda, S. M., \& Kumar, M. S. (2007). Experimental and computational study of concrete filled steel tubular columns under axial loads. Journal of Constructional Steel Research, 63(2), 182-193. 
Han, L. H. (2002). Tests on stub columns of concrete-filled RHS sections. Journal of Constructional Steel Research, 58(3), 353-372.

Han, L. H, \& Yang, Y. (2001). Influence of concrete compaction on the behaviour of concrete filled steel tubes with rectangular sections. Advanced Structural Engineering, 4(1), 93108.

Han, L. H., \& Yao, G. H. (2003). Influence of concrete compaction on the strength of concrete filled steel RHS columns. Journal of Constructional Steel Research, 59(6), 751-767.

Han, L. H., \& Yao, G. H. (2004). Experimental behaviour of thin-walled hollow structural steel (HSS) columns filled with self-consolidating concrete (SCC). Thin-Walled Structures, 42(9), 1357-1377.

Han, L. H., Yao, G. H., \& Zhao, X. L. (2005). Tests and calculations of hollow structural steel (HSS) stub columns filled with self-consolidating concrete (SCC). Journal of Constructional Steel Research, 61(9), 1241-1269.

Han, L. H., Zhao, X. L., \& Tao, Z. (2001). Tests and mechanics model of concrete-filled SHS stub columns, columns and beam-columns. Steel \& Composite Structures, An International Journal, 1(1), 51-74.

Han, L. H., Zhao, X. L., \& Tao, Z. (2003). Concrete-filled thin-walled steel SHS and RHS beamcolumns subjected to cyclic loading. Thin-walled Structures, 41(9), 801-833.

Heitzman, M. (1992). Design and construction of asphalt paving materials with crumb rubber modifier. Transportation Research Record, 1339(1), 1-8.

Hossain, K. M. A. (1998). Behaviour of thin walled composite sections as structural elements. Paper presented at the Australasian Structural Engineering Conference, Auckland, September 30-October 2. 
Hossain, K. M. A. (1999). Performance of volcanic pumice concrete with especial reference to high-rise composite construction. In R. K. Dhir \& M. R. Jones (Eds.), Innovation in concrete structures: design and construction (pp. 365-74). London, UK: Thomas Telford Publishing.

Hossain, K. M. A. (2003a). Behaviour of volcanic pumice based thin walled composite filled columns under eccentric loading. Structural Engineering and Mechanics- International Journal, 16(1), 63-82.

Hossain, K. M. A. (2003b). Behaviour of thin walled composite columns under axial loading. Composites Part B: Engineering, 34(8), 715-725.

Hossain, K.M.A. (2004). Properties of volcanic pumice based cement and lightweight concrete. Cement and Concrete Research, 34(2). 283-291.

Hossain, K. M. A., Ahmed, S., \& Lachemi, M. (2011). Lightweight concrete incorporating pumice based blended cement and aggregate: Mechanical and durability characteristics. Construction and Building Materials, 25(3), 1186-1195.

Hossain, K. M. A., Mak, C., \& Ametrano, D. (2012). GFRP reinforced UHPC composites for sustainable bridge construction. Canadian Civil Engineer, 29(1), 12-15.

Huang, B., Li, G., Pang, S-S., \& Eggers, J. (2004). Investigation into waste tire rubber-filled concrete. Journal of Materials in Civil Engineering, 16(3), 187-194.

Huang, B., Shu, X., \& Cao, J. (2013). A two-staged surface treatment to improve properties of rubber modified cement composites. Construction and Building Materials, 40(3), 270274.

Hunaiti, Y. M. (1996). Composite action of foamed and lightweight aggregate concrete. Journal of Materials in Civil Engineering. ASCE, 8(3), 111-113. 
Hunaiti, Y., Falah, N., \& Assi, I. (2002). Evaluation of the concrete contribution factor for composite sections with lightweight concrete under axial compression. Pakistan Journal of Applied Sciences, 2(10), 990-999.

Ichinose, L. H., Watanabe, E., \& Nakai, H. (2001). An experimental study on creep of concrete filled steel pipes. Journal of Constructional Steel Research, 57(4), 453-466.

Johansson, M. (2002). The efficiency of passive confinement in CFT columns. Steel and Composite Structures, 2(5), 379-396.

Khaloo, A., Raisi, E. M., Hosseini, P., \& Tahsin, H. (2014). Mechanical performance of selfcompacting concrete reinforced with steel fibers. Construction and Building Materials, 5l(1), 179-186.

Khatib, Z. K., \& Bayomy, F. M. (1999). Rubberized Portland cement concrete. Journal of Materials in Civil Engineering, 11(3), 206-213.

Krenchel, H., \& Stang, H. (1989). Stable microcracking in cementitious materials. In A. M. Brandt, \& J. H. Marshall (Eds.), Brittle Matrix Composites 2, (pp. 20-33). Elsevier, Amsterdam.

Lachemi, M., Hossain, K. M., \& Lambros, V. (2006a). Axial load behavior of self-consolidating concrete filled steel tube columns in construction and service stages. American Concrete Institute Structural Journal, 103(1), 38-47.

Lachemi, M., Hossain, K. M., \& Lambros, V. (2006b). Self-consolidating concrete filled steel tube columns - design equations for confinement and axial strength. Structural Engineering and Mechanics, 22(5), 541-562. 
Lankard, D. R. (1986). Preparation, properties and applications of cement based composites containing 5-20 percent steel fiber reinforcement. In S. P. Shah, \& A. Skarendahl (Eds.), Steel Fiber Concrete. Elsevier, Amsterdam.

Lee, E. T., Yun, B. H., Shim, H. J., Chang, K. H., \& Lee, G. C. (2009). Torsional behavior of concrete-filled circular steel tube columns. Journal of Structural Engineering, 35(10), $1250-1258$.

Lepech, M., \& Li, V. C. (2007). Large scale processing of engineered cementitious composites. Concrete Institute Materials Journal, 105(4), 358-366.

Li, G., Stubblefield, M. A., Garrick, G., Eggers, J., Abadie, C., \& Huang, B. (2004). Development of waste tire modified concrete. Cement and Concrete Research, 34(12), 2283-2289.

Li, V. C. (1993). From micromechanics to structural engineering: the design of cementitious composites for civil engineering applications. JSCE Journal of Structural and Mechanical Earthquake Engineering, 10(2), 37-48.

Li, V. C. (2011). High-ductility concrete for resilient infrastructures. Journal of Advanced and High-Performance Materials, 1(1),16-21.

Liu, F., Chen, G., Li, L., Guo, Y. (2012). Study of impact performance of rubber reinforced concrete. Construction and Building Material, 36(1), 604-616.

Mander, J. B., Priestly, M. J. N., \& Park, R. (1988). Theoretical stress-strain model for confined concrete. Journal of Structural Engineering, 114(8), 1804-1826.

McAteer, P., Bonacci, J. F., \& Lachemi, M. (2004). Composite response of high strength concrete confined by circular steel tube. American Concrete Institute Structural Journal, 101(4), 466-474. 
Miyazato, S., \& Hiraishi, Y. (2005). Transport properties and steel corrosion in ductile fiber reinforced cement composites. Paper presented at the $11^{\text {th }}$ International Conference on Fracture, Turin, Italy, 20-25 March.

Mohammed, B. S., Hossain, K. M. A., Swee, J. T. E., Wong, G., \& Abdullahi, M. (2012). Properties of crumb rubber hollow concrete block. Journal of Cleaner Production, 23(1), $57-67$.

Moliner, V., Espinos, A., Romero, M. L., \& Hospitaler, A. (2013). Fire behavior of eccentrically loaded slender high strength concrete-filled tubular columns. Journal of Constructional Steel Research, 83(1), 137-146.

Naaman, A. E. (1992). SIFCON: tailored properties for structural performance. In H. W. Reinhardt, \& A. E. Naaman (Eds.), High-performance fiber-reinforced cement composites, (pp. 18-38). E \& FN Spon, London.

Nakai, H., Kurita, A., \& Ichinose, L. H. (1991). An experimental study on creep of concrete filled steel pipes. Paper presented at the 3rd International Conference on Steel-Concrete Composite Structures, Fukuoka, Japan, (pp. 55-60).

Nawy, E. G. (2008). Concrete construction engineering handbook. CRC Press, Boca Raton, FL.

O'Shea, M. D., \& Bridge, R. Q. (2000). Design of circular thin-walled concrete filled steel tubes. Journal of Structural Engineering, 126(11), 1295-1303

Özbay, E., Karahan, O., Lachemi, M., Hossain, K. M. A., \& Atis, C. D. (2013). Dual effectiveness of freezing-thawing and sulfate attack on high-volume slag-incorporated ECC. Composites Part B: Engineering, 45(1), 1384-1390. 
Pires, T. A. C., Rodrigues, J. P. C., \& Silva, J. J. R. (2012). Fire resistance of concrete filled circular hollow columns with restrained thermal elongation. Journal of Constructional Steel Research, 77(1), 82-94.

Ranade, R., Zhang, J., Lynch, J. P., \& Li, V. C. (2014). Influence of micro-cracking on the composite resistivity of engineered cementitious composites. Cement and Concrete Research, 58(1), 1-12.

Richart, F. E., Brandtzaeg, A., \& Brown, R. L. (1928). A study of the failure of concrete under combined compressive stresses. Bulleting \#185. University of Illinois, Engineering Experimental station, Urbana, Ill.

Rodríguez-Alloza, A. M., Gallego, J., Pérez, I., Bonati, A., \& Giuliani, F. (2014). High and low temperature properties of crumb rubber modified binders containing warm mix asphalt additives. Construction and Building Materials, 53(1), 460-466.

Roeder, C., Cameron, B., \& Brown, C. (1999). Composite action in concrete filled tubes. Journal of Structural Engineering, 125(5), 477-484.

Şahmaran, M., Lachemi, M., Hossain, K. M. A., Ranade, R., \& Li, V. C. (2009). Influence of aggregate type and size on ductility and mechanical properties of engineered cementitious. ACI Materials Journal, 106(3), 308-316.

Şahmaran, M., \& Li, V. C. (2009). Influence of microcracking on water absorption and sorptivity of ECC. RILEM Journal of Materials and Structures, 42(5), 593-603.

Sakino, K., Nakahara, H., Morino, S., \& Nishiyama, I. (2004). Behavior of centrally loaded concrete-filled steel-tube short columns. Journal of Structural Engineering, ASCE, 130(2), 180-188. 
Schneider, S. (1998). Axially loaded concrete filled steel tubes. Journal of Structural Engineering, 124(10), 1125-1138.

Shakir-Khalil, H., \& Zeghiche, J. (1989). Experimental behavior of concrete filled rolled rectangular hollow section columns. Journal of Structural Engineering, ASCE, 67(19), 346-353.

Shams, M., \& Saadeghvaziri, M. A. (1997). State of the art of concrete-filled steel tubular columns. ACI Structural Journal, 94(5), 55871.

Shu, X., \& Huang, B. (in press). Recycling of waste tire rubber in asphalt and portland cement concrete: An overview. Construction and Building Materials. doi:10.1016/j.conbuildmat.2013.11.027

Terrey, P. J., Bradford, M. A., \& Gilbert, R. I. (1994). Creep and shrinkage in concrete filled steel tubes. Paper presented at the 6th International Symposium on Tubular Structures, Melbourne, Australia, (pp. 293-298).

Topcu, J. B. (1995). The properties of rubberized concretes. Cement and Concrete Research, 25(2), 304-310.

Toshiaki, F., Akiyoshi, M., Isao, N., \& Kenji, S. (2004). Behavior of eccentrically loaded concrete-filled steel tubular columns. Journal of Structural Engineering, 130(2), 20312.

Uy, B. (1998). Ductility, strength and stability of concrete-filled fabricated steel box columns for tall buildings. The Structural Design of Tall Buildings, 7(2), 113-133.

Uy, B. (2008). Stability and ductility of high performance steel sections with concrete infill. Journal of Constructional Steel Research, 64(7-8), 748-754.

Vrcelj, Z., \& Uy, B. (2002). Strength of slender concrete-filled steel box columns incorporating local buckling. Journal of Constructional Steel Research. 58(2), 275-300. 
Wang, S., \& Li, V. C. (2007). Engineered cementitious composites with high-volume fly ash. ACI Materials Journal, 104(3), 233-241.

Weimann, M. B., \& Li, V. C. (2003). Drying shrinkage and crack width of ECC. Paper presented at The $7^{\text {th }}$ International Conference: Brittle Matrix Composites, Warsaw, Poland, (pp. 3746).

Yang, Y., Han, L., \& Wu, X. (2008). Concrete shrinkage and creep in recycled aggregate concrete-filled steel tubes. Advanced Structural Engineering, 11(4), 383-396.

Yu, Q., Tao, Z., \& Wu, Y. (2008). Experimental behaviour of high performance concrete-filled steel tubular columns. Thin-Walled Structures, 46(4), 362-370.

Yun, H. D., \& Rokugo, K. (2012). Freeze-thaw influence on the flexural properties of ductile fiber reinforced cementitious composites. Cold Regions Science and Technology, 78(1), $82-88$.

Zeghiche, J., \& Chaoui, K. (2005). An experimental behaviour of concrete-filled steel tubular columns. Journal of Constructional Steel Research, 61(1), 53-66.

Zhang, J., \& Bing, L. (2008). Transition from multiple macro-cracking to multiple microcracking in cementitious composites. Tsinghua Science \& Technology, 13(5), 669-673.

Zhong, T., Han, L-H., \& Wang, D-Y. (2008). Strength and ductility of stiffened thin-walled hollow steel structural stub columns filled with concrete. Thin-Walled Structures, 46(10), 1113-1128. 